Aus dem Institut für Neurophysiologie und Zelluläre Biophysik

(Prof. Dr. rer. nat. Dr. med. D. Schild)

im Zentrum Physiologie und Pathophysiologie

der Medizinischen Fakultät der Universität Göttingen

\title{
Imaging-Analyse dopaminerger Wirkungen am olfaktorischen Nerven von Xenopus-laevis-Larven
}

\author{
INAUGURAL-DISSERTATION \\ zur Erlangung des Doktorgrades \\ der Medizinischen Fakultät \\ der Georg-August-Universität zu Göttingen
}

\author{
vorgelegt von \\ Eiko Baßfeld \\ aus Bad Kissingen
}

Göttingen 2013 
Dekan: Prof. Dr. rer. nat. H. K. Kroemer

I. Berichterstatter: Prof. Dr. rer. nat. Dr. med. D. Schild II. Berichterstatter/in: Prof. Dr. med. T. Gollisch III. Berichterstatter/in: Prof. Dr. rer. nat. P. Virsik-Köpp Tag der mündlichen Prüfung: 07.11.2013 


\section{Inhaltsverzeichnis}

1 Einleitung 10

1.1 Organisation des olfaktorischen Systems bei Vertebraten . . . . . . 12

1.1.1 Olfaktorische Mukosa . . . . . . . . . . . . . . 12

1.1.2 Der olfaktorische Nerv . . . . . . . . . . . . . 15

1.1.3 Olfaktorischer Bulb . . . . . . . . . . . . . . . . 15

1.2 Das dopaminerge System . . . . . . . . . . . . . . . . . . 15

1.2.1 Der Botenstoff Dopamin . . . . . . . . . . . 15

1.2 .2 Dopamin-Rezeptoren . . . . . . . . . . . . . 18

1.2.3 Dopaminerge Wirkungen im olfaktorischen System . . . . . 18

1.3 Zielsetzung . . . . . . . . . . . . . . . . . . 19

2 Material und Methoden 21

2.1 Das Versuchstier Xenopus laevis . . . . . . . . . . . . . . . . . . . . 21

2.1.1 Das olfaktorische System von Xenopus-laevis-Larven . . . . 22

2.1.2 Zucht von Xenopus-laevis-Larven . . . . . . . . . . . 24

2.2 Mikroskopie und Farbstoffe . . . . . . . . . . . . . . . . . . . . 25

2.2.1 Grundlagen der Fluoreszenz . . . . . . . . . . . . . . 25

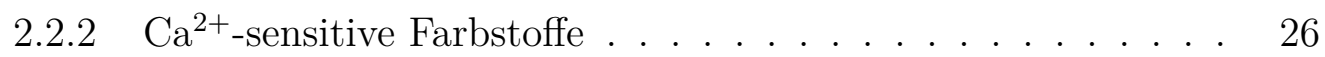

2.2.3 Konfokale Laserrastermikroskopie . . . . . . . . . . . . . . 27

2.3 Versuchsvorbereitung . . . . . . . . . . . . . . . . . . . . 30

2.3.1 Präparation von Gewebeschnitten . . . . . . . . . . . 32

2.3.2 Reizgeber am LIM . . . . . . . . . . . . . . . . . 33

2.4 Versuchsdurchführung . . . . . . . . . . . . . . . . . 34

2.4.1 Applikationssystem . . . . . . . . . . . . . . 34 
2.4.2 Darstellung eines duftstoffinduzierten $\mathrm{I}_{\mathrm{Ca}^{2+}}$ im olfaktorischen Nerven . . . . . . . . . . . . . . . . . . . . 35

2.4.3 Dopaminerge Modulation eines $\mathrm{I}_{\mathrm{Ca}^{2+}}$ im olfaktorischen Nerven 36

2.4.4 Messung der Nervenleitgeschwindigkeit . . . . . . . . . . . 37

2.5 Versuchsauswertung . . . . . . . . . . . . . . . . . . 39

2.6 Immunhistochemische Färbungen . . . . . . . . . . . . . . . . . 40

2.6 .1 Gefrierschnitte . . . . . . . . . . . . 40

2.6.2 Agaroseschnitte . . . . . . . . . . . . . . . . 40

2.6.3 Durchführung der Färbung . . . . . . . . . . . . . . . 41

2.6.4 Biocytin-Backfill-Verfahren . . . . . . . . . . . . . 42

2.7 Chemikalien . . . . . . . . . . . . . . . . . . . . . . . 43

2.7 .1 Badlösung . . . . . . . . . . . . . . . . . . 43

2.7.2 Aminosäure-Mixtur . . . . . . . . . . . . . . . 44

3 Ergebnisse 45

3.1 Darstellung eines $\mathrm{I}_{\mathrm{Ca}^{2+}}$ im olfaktorischen Nerven infolge einer Aminosäurereizung . . . . . . . . . . . . . . . . . . 45

3.1.1 Einfluss des $\mathrm{Na}^{+}$-Kanal-Blockers TTX . . . . . . . . . 48

3.1.2 Einfluss des L-Typ-Ca ${ }^{2+}$-Kanal-Blockers Nifedipin . . . . . . 48

3.2 Dopaminerge Modulation des nervalen $\mathrm{I}_{\mathrm{Ca}^{2+}} \ldots \ldots$. . . . . . . . 51

3.2.1 Modulation mittels $\mathrm{D}_{2}$-Rezeptoragonist Quinpirol . . . . . . 53

3.2.2 Modulation mittels $\mathrm{D}_{2}$-Rezeptorantagonist Sulpirid . . . . . 53

3.3 Änderungen der Nervenleitgeschwindigkeit unter Dopaminapplikation 53

3.4 Ergebnisse der immunhistochemischen Färbungen . . . . . . . . . 56

3.4.1 $\mathrm{D}_{2}$-Rezeptor-Färbung . . . . . . . . . . . . 56

3.5 Tyrosinhydroxylase-Färbung . . . . . . . . . . . . . . . . . . 58

4 Diskussion $\quad 60$

4.1 Darstellung eines $\mathrm{I}_{\mathrm{Ca}^{2+}}$ im Nervus olfactorius . . . . . . . . . . . . . 61

4.1.1 Schnelle $\mathrm{Na}^{+}$-Kanäle sind Voraussetzung einer $\mathrm{I}_{\mathrm{Ca}^{2+}}$ im olfaktorischen Nerven . . . . . . . . . . . . . . 62

4.1.2 Ein $\mathrm{I}_{\mathrm{Ca}^{2+}}$ tritt auch unter Blockade von L-Typ-Ca ${ }^{2+}$-Kanälen

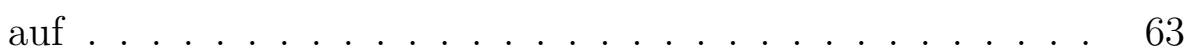

4.1.3 Bedeutung eines $\mathrm{I}_{\mathrm{Ca}^{2+}}$ in olfaktorischen Axonen . . . . . . . 63 
4.2 Dopaminerge Modulation eines $\mathrm{I}_{\mathrm{Ca}^{2+}}$ im olfaktorischen System . . . 65

4.3 Dopamin erhöht die Nervenleitgeschwindigkeit . . . . . . . . . . . . 67

$4.4 \quad \mathrm{D}_{2}$-Rezeptoren liegen im olfaktorischen Nerven vor . . . . . . . . . . 68

4.5 Tyrosinhydroxylase liegt in den Gliazellen des olfaktorischen Nerven vor ............................. 68

$\begin{array}{lll}5 & \text { Zusammenfassung } & 70\end{array}$

$\begin{array}{ll}\text { Literaturverzeichnis } & 72\end{array}$ 


\section{Abbildungsverzeichnis}

1.1 Schemazeichnung und immunhistochemische Aufarbeitung der Mukosa der Xenopus-laevis-Larve. . . . . . . . . . . . . . . . . . 13

1.2 Auszug aus dem Dopaminstoffwechsel . . . . . . . . . . . . . . . . . 17

1.3 Schematische Darstellung eines G-Protein-gekoppelten Rezeptors . . 18

2.1 Versuchstier Xenopus-laevis-Larve (Stadium 51-53) in Skizzen und als Fotografie . . . . . . . . . . . . . . . . 23

2.2 Schematische Aufarbeitung der Clusterlage im ventralen olfaktorischen Bulb der Xenopus-laevis-Larve . . . . . . . . . . . . . 25

2.3 Strukturformel von fluo-4-AM . . . . . . . . . . . . . . . . . 27

2.4 Schematische Darstellung des Strahlengangs des LSM 510 . . . . . . 29

2.5 Darstellung des Präparationsgebiets der Xenopus-laevis-Larve . . . 34

2.6 Schematische Darstellung des Trichterapplikationssystems . . . . . 35

3.1 Darstellung einer Übersichtsaufnahme während der LSM-Messung und Zeitserie zur Veranschaulichung des Fluoreszenzverhalten . . . 46

3.2 Darstellung der Antwortkurven für die drei verwendeten Konzentrationen $(100 \mu \mathrm{M}, 200 \mu \mathrm{M}, 500 \mu \mathrm{M})$ des Aminosäure-Mix (AA) . . . . . 47

3.3 Effekt von 250-nM- und 500-nM-TTX-Lösung sowie von 10- $\mu \mathrm{M}$ - und

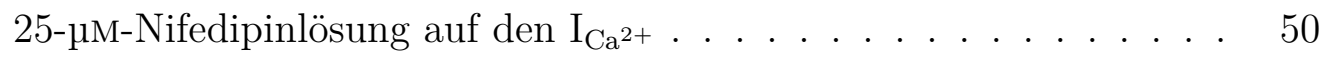

3.4 Darstellung der Dopamin-Modulationsexperimente . . . . . . . . . . 52

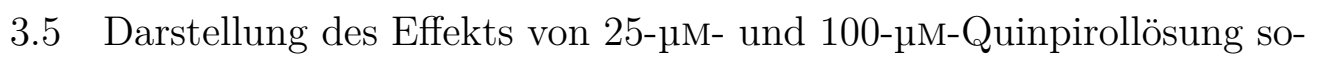

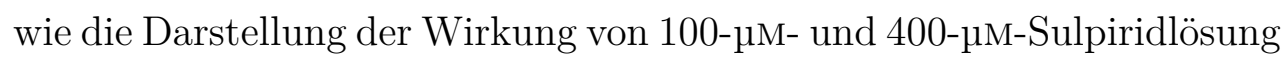
auf den $\mathrm{I}_{\mathrm{Ca}^{2+}} \ldots \ldots \ldots \ldots \ldots$. . . . . . . . . . . . . . 54

3.6 Boxplot der Messungen der Nervenleitgeschwindigkeit (NLG) . . . . 55 
$3.7 \quad \mathrm{D}_{2}$-Rezeptor-Antikörperfärbung . . . . . . . . . . . . 57

3.8 Übersicht über die Tyrosinhydroxylasefärbungen . . . . . . . . . . . 59 


\section{Tabellenverzeichnis}

2.1 Übersicht über die Versuchsteile „Darstellung eines duftstoffinduzierten $\mathrm{I}_{\mathrm{Ca}^{2+}}$ “, „dopaminerge Modulation eines $\mathrm{I}_{\mathrm{Ca}^{2+}}$ “ und „Messung der Nervenleitgeschwindigkeit". . . . . . . . . . . . . . . . . 31

2.2 Tabellarische Übersicht über die verwendeten Testsubstanzen und deren Konzentrationen . . . . . . . . . . . . . . . . . . 38

2.3 Übersicht über die Antikörperfärbungen . . . . . . . . . . . . . . . 41

2.4 Zusammensetzung der für die Versuche verwendeten Badlösung. . . 43

2.5 Zusammensetzung der Aminosäure-Mixtur . . . . . . . . . . . . . . 44

3.1 Mittelwerte und Standardabweichung der Maxima der Fluoreszenzänderung sowie der zeitlichen Lage der Maxima . . . . . . . . . . 48

3.2 Darstellung der verwendeten Kanalblocker, Konzentrationen und de-

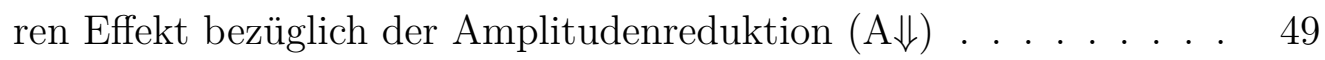

3.3 Darstellung verwendeter Dopamin- und Quinpirolkonzentrationen, Stichprobengröße, mittlerer Effekt auf Amplitude, Standardabweichung und Wash-Out-Verhalten . . . . . . . . . . . . 51

3.4 Tabelle der gemessenen Nervenleitgeschwindigkeiten (NLG) bzw. deren Mittelwerte $(\bar{x})$, Standardabweichungen $(\sigma)$ und Mediane (MD). 55 


\section{Abkürzungsverzeichnis}

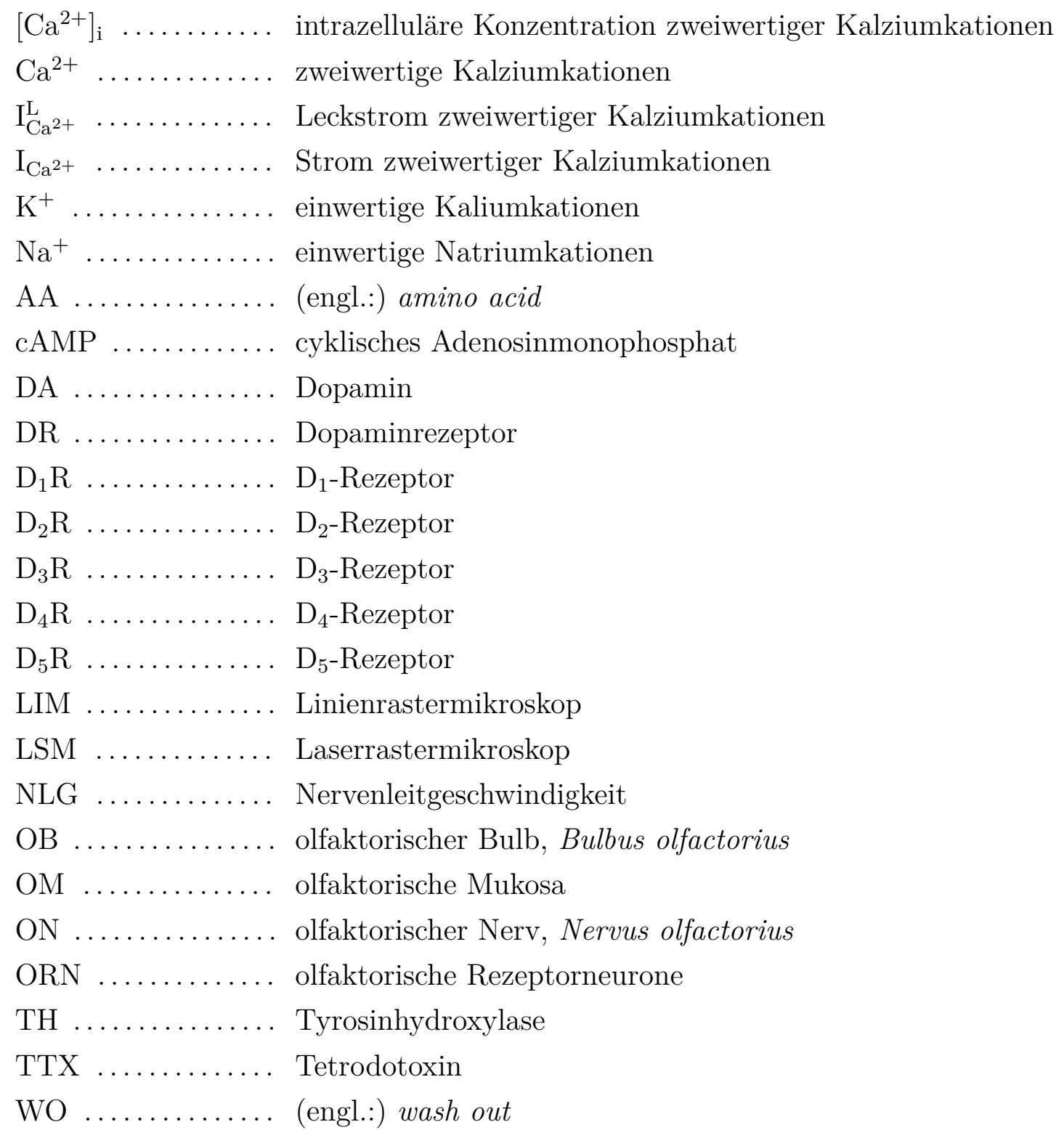


„Langsam naht sich der Duft auf irrender Bahn, und vorher oft / Schwindet er allzu leicht, in das Luftreich mählich zerfließend / Erstlich, löst sich nur schwer der Geruch aus dem Inneren der Stoffe."

Von der Natur, Lukrez, ca. $97-55$ v. Chr.

(vgl. Lukrez 1991, S. 209/Lukrez 50 v.Chr.)

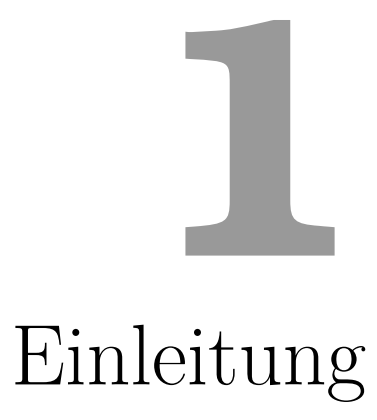

Mit der Installation $S M E L L Y O U » S M E L L M E^{1}$ veranschaulicht die Künstlerin Jenny Marketou die Bedeutung des Geruchssinns und der Gerüche. Inspiriert vom Reality-TV des ausgehenden 20. und beginnenden 21. Jahrhunderts, besteht diese Installation aus einer Reihe von Interviews, die dem Betrachter über Fernseher präsentiert werden. In den gezeigten Interviews setzen sich die Befragten mit dem Thema Geruch und Riechen auseinander. Es offenbart sich, dass diese Sinneserfahrung für die persönliche Entwicklung, die kulturelle Identität, persönliche Vorlieben und Abneigungen maßgeblich zu sein scheint (Szeemann et al. 2004). Die Auseinandersetzung mit diesem Werk zeigt nicht nur die fundamentale Bedeutung, sondern auch die unbewusste, dennoch ständige Wahrnehmung dieses Sinneseindrucks im Alltag. Wegriechen scheint nicht möglich.

Mit einer Einordnung des Geruchssinns taten sich nicht nur die Befragten schwer, sondern schon Platon. So schrieb er, dass die Gerüche „insgesamt Dunst oder Ne-

\footnotetext{
${ }^{1}$ erstmals ausgestellt in: Blut \& Honig. Die Zukunft liegt am Balkan; Szeemann H (Kurator); Essl-Sammlung, Wien 2003. Verwiesen sei an dieser Stelle auch auf Szeemann et al. 2004, S.16-35.
} 
bel“ und dabei „feiner als Wasser, aber dichter als Luft" seien (Platon 1841, S. 76 77/Platon 360 v.Chr.). Gerüche und deren Wahrnehmung offenbaren sich demzufolge als schwer greifbar. Dies schlägt sich in den Begrifflichkeiten nieder, die wir verwenden, um Gerüche zu beschreiben. Gerüche werden indirekt beschrieben: Es riecht nach etwas. Dies setzt bestehende Erinnerungen voraus, die lange im Gedächtnis gespeichert werden (Geschwind 1998). Arthur Schopenhauer bezeichnet in diesem Zusammenhang „den Geruch [als] den Sinn des Gedächtnisses“ (Schopenhauer 1972, S. 122/Schopenhauer 1819).

Diese unbegreifliche Erscheinung des Riechens scheint jedoch keinesfalls abschreckend zu sein. Dem Genuss eines Glases Rotwein, dessen geschmackliche Nuancen sich nicht auf der Zunge, sondern in der Nase entwickeln, scheint dies ebenso wenig abträglich zu sein, wie dem Erfolg von Patrick Süskinds Roman Das Parfüm (Süskind 1985). In diesem offenbart sich die schon in Marketous Installation anklingende Wichtigkeit des Geruchssinns für die Persönlichkeitsfindung. Die Hauptfigur Jean-Baptiste Grenouille, gesegnet mit der Gabe selbst entfernteste Gerüche genaustens aufschlüsseln zu können, zeigt sich als Wesen auf der Suche nach seiner Bestimmung. Gleichzeitig verknüpft Süßkind seine Figur mit dem Auftritt eines amoralischen Wesens, das Geruch mit Gewalt und Sexualität in Verbindung bringt.

Doch ist Riechen nicht durchaus auch mit Vernunft assoziiert? So kennt der Volksmund den Ausdruck Naseweis und Nietzsche behauptete sogar, die Nase „vermag noch Minimaldifferenzen der Bewegung zu constatieren, die selbst das Spektroskop nicht constatiert"(Nietzsche 1988, S. 75-76/Nietzsche 1889).

Der Geruchssinn steht also, ohne überhaupt einen Blick auf aktuelle wissenschaftliche Diskussionen werfen zu müssen, in einem interessanten Spannungsfeld der Gegensätze: Vernunft und Trieb, vage Impressionen und zugleich feste Verknüpfungen von Erfahrungen. Er scheint Gegensätze zu vereinen.

Auch wissenschaftlich hat er eine außergewöhnliche Rolle inne. So imponieren die olfaktorischen Rezeptorneurone mit ständiger, lebenslanger Regeneration und das Geruchssystem zeigt, dass auch Stützzellen Anteil an der Signalverarbeitung haben können (Hassenklöver et al. 2008). Ein einzigartiges, neuronales Netzwerk, dessen Erforschung vielleicht auch dazu führen wird, bisher gegensätzliche Erkenntnisse miteinander zu vereinen.

Die folgende Einleitung soll die anatomischen und physiologischen Gegebenheiten des olfaktorischen Systems verdeutlichen. 


\subsection{Organisation des olfaktorischen Systems bei Vertebraten}

Olfaktorische Mukosa (OM), olfaktorischer Nerv (ON) und olfaktorischer Bulb (OB) bilden das olfaktorische System. Assoziiert mit diesen sind höhere olfaktorische Zentren und eine Vielzahl kortikaler Bahnen, die die Vernetzung der Olfaktorik mit anderen Sinnessystemen ermöglichen. Diese Verknüpfungen lassen aus einem olfaktorischen Detektionssystem ein Sinnessystem entstehen.

Neben dem olfaktorischen System existiert das Vomeronasalorgan (VNO), welches erstmals vom dänischen Anatom Jacobson beschrieben wurde (Jacobson 1813). Dessen Funktion als Pheromon-Detektor ist insbesondere beim Menschen umstritten (Witt et al. 2002, Witt und Hummel 2006, Mast und Samuelsen 2009). Nervenbahnen dieses Organs laufen dabei im olfaktorischen Nerven und projizieren in einen akzessorischen Bulb im Bulbus olfactorius, dessen Existenz beim Menschen nicht eindeutig gezeigt werden konnte bzw. angenommen wird, dass dieser bis zur Geburt degeneriert (Müller und O'Rahilly 2004, Salazar und Quinteiro 2009).

\subsubsection{Olfaktorische Mukosa}

Die olfaktorische Mukosa ist der Ort der Duftstoffdetektion, die über olfaktorische Rezeptorneurone (ORN) abläuft. In einer laminären Gliederung der Mukosa haben die beteiligten Zellgruppen ihren spezifischen Platz: Basal findet man die Vorläuferzeller, die sogenannten Basalzellen, in der mittleren Schicht liegen die Somata der olfaktorischen Rezeptorneurone und apikal die Stützzellen (s. Abb.1.1). Die Mukosa wird von einem Schleim überzogen, dem man sowohl eine schützende Funktion (Débat et al. 2007) als auch eine Beteiligung an der Duftstoffdetektion über bestimmte Proteine zuschreibt (Hajjar et al. 2006).

\section{Olfaktorische Rezeptorneurone}

Olfaktorische Rezeptorneurone sind primäre Sinneszellen, die Duftstoffe detektieren. Ihre Axone ziehen als Nervus olfactorius durch die Lamina cribrosa direkt ins Gehirn. Es handelt sich also um eine direkte neuronale Verbindung zwischen Außenwelt und Gehirn. 


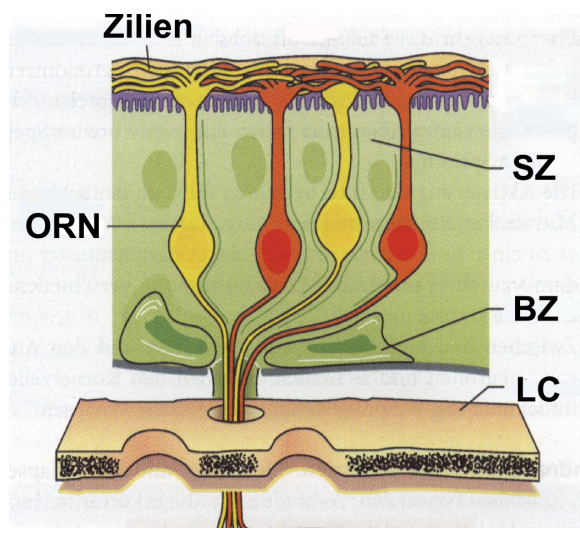

(a) Schema

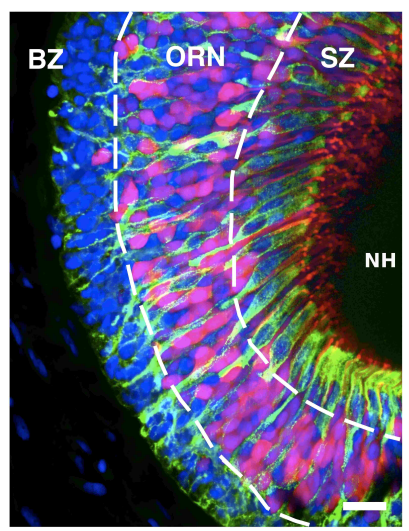

(b) Präparat

\section{Abbildung 1.1:}

Schemazeichnung (a; modifiziert n. Hatt 2010, S. 394) und immunhistochemische Aufarbeitung der Mukosa der Xenopus-laevis-Larve (b; verändert nach Hassenklöver et al. 2009, S. 2024). In der Basalzellschicht (BZ) erkennt man im Präparat lediglich die Zellkerne, die blau erscheinen. Die Schicht der olfaktorischen Rezeptorneurone (ORN) erscheint rot-pink, wo hingegen die Stützzellen (SZ) grün gefärbt sind. ORN und SZ reichen bis in die Nasenhöhle (NH). Maßstab in (b) entspricht einer Länge von $20 \mu \mathrm{m}$.

ORN sind morphologisch streng bipolar organisiert. An ihren apikalen Dendriten finden sich Zilien, die aus einem Knob hervorsprießen und - in Mucus eingebettet in die Nasenhöhle hineinreichen. Basal bündeln sich die Axone der einzelnen ORN, durchbrechen die Basalmembran und ziehen als olfaktorischer Nerv zum Bulb.

Hier liegt eine Vielzahl von Rezeptoren. Ausgehend von 1000 Rezeptorgenen exprimiert der Mensch lediglich 300-350 unterschiedliche Rezeptoren (Sharo et al. 1999, Fuchs et al. 2001). Hierbei handelt es sich um einen Sieben-TransmembranRezeptoren, der intrazellulär an ein G-Protein gekoppelt ist. Bindet ein Duftstoffmolekül bzw. eine einzelne Moleküldomäne, kommt es zur Konformationsänderung und damit verbunden zu einer Aktivierung des G-Proteins. Je nach Art des GProteins werden verschiedene Signalkaskaden aktiviert. Bekannte Signalkaskaden wie cAMP-(Pace et al. 1985, Belluscio et al. 1998, Wong et al. 2000) und IP3Signalweg (Schild und Restrepo 1998) sind hierbei gut erforscht. cAMP, welches zuvor aus ATP gebildet wurde, diffundiert an CNG-Ionenkanäle und öffnet diese. Der Öffnung folgt die Steigerung der intrazellulären Kalziumionenkonzentration $\left(\left[\mathrm{Ca}^{2+}\right]_{i}\right.$; Dhallan et al. 1990). Dieser Prozess wird durch den Ausstrom von 
Chloridionen über $\mathrm{Ca}^{2+}$-aktivierte Chloridkanäle unterstützt (Schild und Restrepo 1998). IP3 hingegen verursacht eine Entleerung von $\mathrm{Ca}^{2+}$-Speichern des endoplasmatischen Retikulums und führt nachgeschaltet zu einer Aktivierung von $\mathrm{Ca}^{2+}$-sensitiven Kationenkanälen. Aus beiden Wegen resultiert bei überschwelliger Stimulation eine Depolarisation (Transformation) und damit die Generierung eines Aktionspotentials. Über die Frequenz und das glomeruläre Aktivierungsmuster der zum olfaktorischen Bulb weitergeleiteten Aktionspotentiale erfolgt dann eine Informationskodierung (Hatt 2004, Rawson und Yee 2006).

Anzumerken ist an dieser Stelle, dass neben den o. g. Signalwegen auch hiervon unabhängige Signalwege (Schild und Restrepo 1998) existieren. Gegenstand der Diskussion sind dabei direkte Kanalöffnungen über Botenstoffe (Labarca und Bacigalupo 1988) sowie auch Wirkungen membrangängiger Gase wie Kohlenmonoxid und Stickstoffmonoxid (Broillet und Firestein 1996, Morales und Bacigalupo 1996, Schild und Restrepo 1998).

\section{Olfaktorische Stützzellen}

Olfaktorische Stützzellen sind so angeordnet, dass sie ORN voneinander trennen und sie so chemisch und physikalisch isolieren. Sie erfüllen die Aufgaben von Gliazellen, sorgen also für eine Regulation der extrazellulären Ionenkonzentration, sind beteiligt an der Phagozytose und produzieren Schleim (Getchell und Getchell 1991, Hansen et al. 1998). Neuere Forschungen zeigen sogar eine Beteiligung der Stützzellen an der Signalverarbeitung (Hassenklöver et al. 2008).

\section{Basalzellen}

Einzigartig am olfaktorischen System gegenüber anderen Sinnessystemen ist seine lebenslange Fähigkeit zur Regeneration. Durch seine exponierte Lage ist es starken Noxen ausgeliefert. Auch die ständige Auseinandersetzung mit Krankheitserregern stellt eine immense Belastung für dieses System dar. Behält man im Auge, dass die durchschnittliche Lebenszeit eines olfaktorischen Rezeptorneurons 30-60 Tage beträgt (Buck 2000), muss es eine grundlegende Eigenschaft dieses Systems sein, sich regenerieren zu können, um sein Fortbestehen zu sichern. Diese Aufgabe fällt den Basalzellen zu (Ronnett und Moon 2002). Diese rundlichen Zellen liegen an der 
Basalmembran und sind Vorläufer der ORN wie auch der Stützzellen (s. Abb. 1.1).

\subsubsection{Der olfaktorische Nerv}

Der olfaktorische Nerv aller Vertebraten besteht aus dünnen, unmyelinisierten Nervenfasern, die den olfaktorischen Rezeptorzellen der Nasenhöhle entspringen. Bündel von zehn bis hunderten Axonen werden dabei von Fortsätzen der Gliazellen (engl.: ensheathing glial cells) umgeben (Gross und Kreutzberg 1978, Doucette 1984). Als Filae olfactoriae ziehen sie durch die Lamina cribrosa in den rostralen Pol des Telenzephalons, den olfaktorischen Bulb. Nach Verschaltung im OB zieht der $N$. olfactorius dann als Tractus olfactorius zur primären Riechrinde. Beim Homo sapiens sapiens ist er der kürzeste der 12 Hirnnerven.

Die Geschwindigkeit der Nervenleitung variiert zwischen poikilothermen und homoiothermen Vertebraten. Nerven poikilothermer Tiere leiten dabei mit einer Geschwindigkeit von $0,14 \mathrm{~m} \mathrm{~s}^{-1}$ (Ottoson 1960), während Nerven homoiothermer Tiere drei bis viermal schnellere Leitungsgeschwindigkeiten aufweisen (Maus: 0,47 $\mathrm{m} \mathrm{s}^{-1}$, Griff et al. 2000).

\subsubsection{Olfaktorischer Bulb}

Die Axone des Nervus olfactorius innervieren den olfaktorischen Bulb und konvergieren dabei in verschiedene Glomerula. Sie interagieren hier mit den Dendriten von Mitralzellen und periglomerulären Zellen. Mitralzellen projizieren dabei ins ipsi- und kontralaterale Vorderhirn, wohingegen periglomeruläre Zellen als lokale Interneurone dienen. Granulazellen, eine zweite Gruppe von Interneuronen, die tiefer im Bulbus olfactorius liegen, bilden reziproke Synapsen mit den Mitralzellen (Eisthen 1997). Der olfaktorische Bulb repräsentiert mit diesem Aufbau den ersten Konvergenz- und Verschaltungspunkt des olfaktorischen Systems.

\subsection{Das dopaminerge System}

\subsubsection{Der Botenstoff Dopamin}

Dopamin (DA) ist ein biogenes Amin (s. Abb. 1.2). Es wird zusammen mit Adrenalin und Noradrenalin der Klasse der Katecholamine zugeordnet. Während Adrenalin 
und Noradrenalin weitgehend als systemisch wirksame Sympathomimetika bekannt sind, stehen beim Transmittermolekül Dopamin häufiger die zentralnervösen Wirkungen im Vordergrund.

Dopaminerge Bahnen im Gehirn beteiligen sich an vielfältigen neuronalen Regelkreisen. Sie sind beteiligt an der Bewegungsregulation, sind wichtiger Bestandteil eines endogenen Belohnungssystems, steuern Motivation und Bewegungsantrieb und beteiligen sich über die Steuerung von Prolaktin an der Regulation des Wachstums und der Milchsekretion der weiblichen Brustdrüse.

Störungen dieser mannigfaltigen Einbindung Dopamins in funktionelle Prozesse des Organismus führen so zwangsläufig zu vielfältigen Krankheitsbildern. So ist heute bekannt, dass ein Untergang DA-produzierender Neurone in den Basalganglien zur Parkinson-Erkankung führt (Fearnley und Lees 1991, Braak und Braak 2000), dessen Auslöser wohl in der Mutation einzelner Gene (Farrer et al. 1999, Gasser 2001), aber auch multifaktoriell bedingt sein kann (Maraganore et al. 2005, Bender A et al. 2006). Des Weiteren wurde ein gestörtes Dopamin-Gleichgewicht in Zusammenhang mit bspw. dem Restless-legs-Syndrom (Trenkwalder et al. 1996, Monaca 2010) und der Narkolepsie (Burgess et al. 2010) beobachtet, was darauf hindeutet, dass Dopamin auch eine wichtige Rolle bei der Schlafregulation inne hat. Starke Beteiligung schreibt man Dopamin auch bei der Entstehung von Suchterkrankungen zu. Hier scheinen die überlagernden Wirkungen von Glückshormon und die gleichzeitige Einbindung in das Lernverhalten zur Entstehung und Aufrechterhaltung der Suchterkrankung maßgeblich zu sein. Bleibt man im Formenkreis der psychiatrischen Erkrankungsbilder, so wird auch bei der Schizophrenie ein Ungleichgewicht des Dopaminhaushaltes diskutiert - die sog. Dopamin-Hypothese (Lee und Seeman 1980, Snyder 2006, Lipina et al. 2010).

Fernab von den zentralnervösen Mechanismen ist Dopamin ein wichtiger Agitator des vegetativen Nervensystems. In niedriger Dosierung bewirkt Dopamin eine Vasodilatation über Dopaminrezeptoren im Splanchnikusgebiet, was die Nierendurchblutung steigert. Hochdosiert stimuliert Dopamin zudem $\beta_{1}$-Rezeptoren, was eine Steigerung der Herzkraft (positive Inotropie) zur Folge hat (Plumb 2005).

Aus der Zusammenschau dieser Erkenntnisse lässt sich schlussfolgern, dass eine Reduktion Dopamins auf seinen zentralnervösen Einfluss der Wirkungsvielfalt im Organismus nicht gerecht wird. In seiner mannigfaltigen Einbindung ist Dopamin einer der wichtigsten Transmittermoleküle des Lebens. 


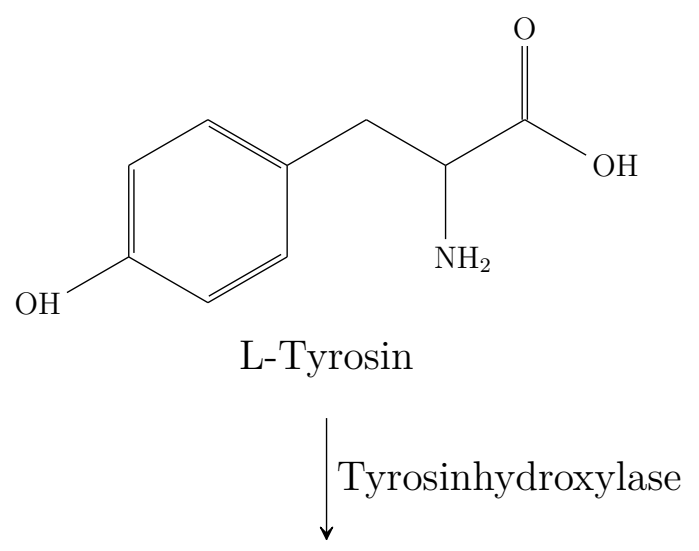<smiles>NC(Cc1ccc(O)c(O)c1)C(=O)O</smiles>

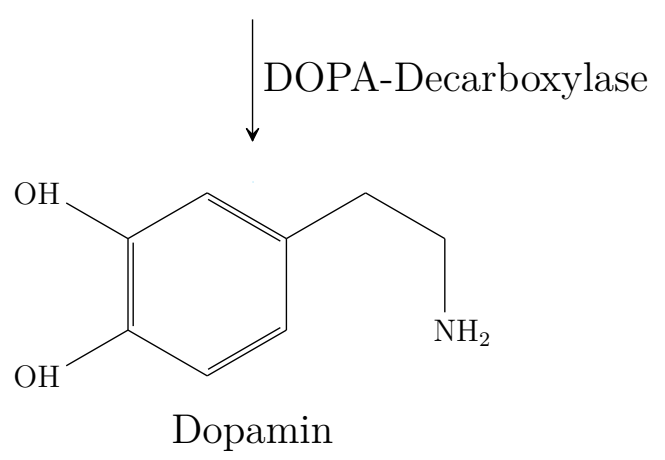

\section{Abbildung 1.2:}

Auszug aus dem Dopaminstoffwechsel. L-Tyrosin wird über die Tyrosinhydroxylase zu L-Dihydroxyphenylalanin (L-DOPA) umgewandelt. Die nachgeschaltete Decarboxylierung ergibt das biogene Amin Dopamin. Dopamin ist eigentlich ein Zwischenprodukt der Adrenalinbiosynthese. In weiteren enzymatischen Reaktionen kann Dopamin deswegen zu Adrenalin verstoffwechselt werden (nicht dargestellt). 


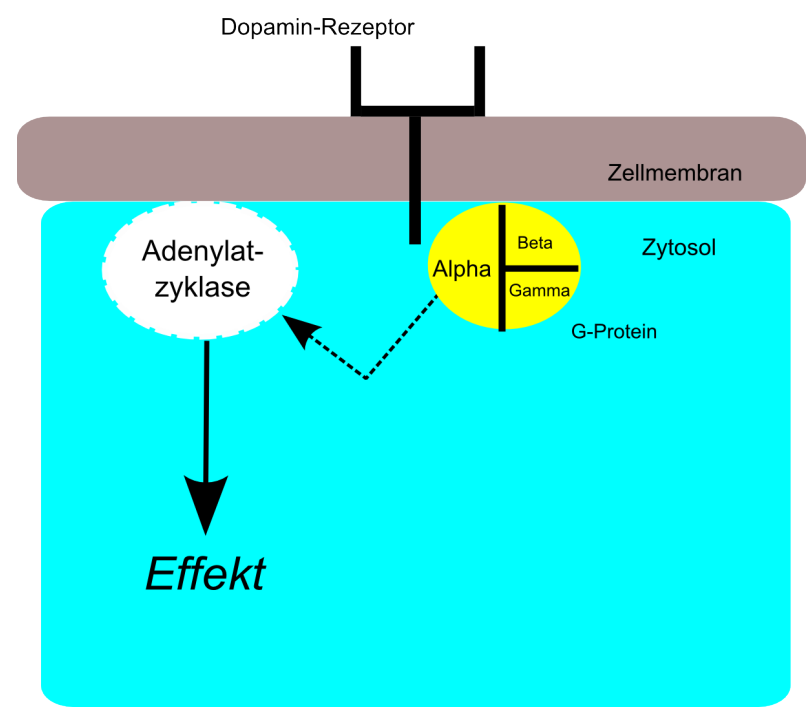

\section{Abbildung 1.3:}

Schematische Darstellung eines G-Protein-gekoppelten Rezeptors, wie er auch bei den Dopaminrezptorklassen vorliegt. Je nach Konfiguration der alphaUntereinheit werden unterschiedliche Effekt intrazellulär vermittelt.

\subsubsection{Dopamin-Rezeptoren}

Die oben beschriebenen Wirkungen des Neurotransmitters Dopamin werden nach intrazellulär durch Dopaminrezeptoren, sogenannte D-Rezeptoren, vermittelt. Zwar ist Dopamin auch in der Lage, an adrenerge $\alpha$ - und $\beta$-Rezeptoren zu binden, es ist aber davon auszugehen, dass der D-Rezeptor die Hauptwirkungen Dopamins vermittelt. Man unterteilt grundsätzlich fünf Untergruppen des D-Rezeptors. $\mathrm{D}_{1^{-}}$ Rezeptor $\left(D_{1} R\right)$ und $D_{5}$-Rezeptor $\left(D_{5} R\right)$ haben exzitatorische Effekte $\left(D_{1}\right.$-Familie), der $D_{2}$-Rezeptor $\left(D_{2} R\right)$, der $D_{3}$-Rezeptor $\left(D_{3} R\right)$ und der $D_{4}$-Rezeptor $\left(D_{4} R\right)$ wirken inhibitorisch ( $\mathrm{D}_{2}$-Familie; Gingrich und Caron 1993).

Allen Klassen ist gemein, dass sie G-Protein-gekoppelt agieren, also ein intrazelluläres Protein über eine Second-Messenger-Kaskade aktivieren, welches dann die Aktivität der Adenylatzyklase hemmt oder steigert (s.Abb. 1.3).

\subsubsection{Dopaminerge Wirkungen im olfaktorischen System}

Die Wirkung von Dopamin auf das olfaktorische System ist indes noch nahezu ungeklärt. Die Existenz dopaminerger Neurone im olfaktorischen Bulb wurde von Cave und Baker für die Maus gezeigt (Cave und Baker 2009). Im Vorderhirn des 
Vertebraten scheint dies das einzige dopaminerge Zentrum zu sein. Dopaminerge periglomeruläre Zellen, die sich postnatal schnell zu entwickeln scheinen, bilden hier Synapsen mit den axo-dendritischen Synapsen von ORN und Mitralzellen. Durch Ausschüttung von Dopamin und Bindung an $\mathrm{D}_{2}$-Rezeptoren auf der Membran der ORN und Mitralzellen haben sie einen inhibitorischen Effekt auf diese Zellen. Sie scheinen also eine Schlüsselrolle in der Signalverarbeitung auf Ebene des olfaktorischen Bulb inne zu haben (Cave und Baker 2009). Dopamin reduziert hier das postsynaptische Potential bei ORN-Reizung (Berkowicz und Trombley 2000). Nicht nur die inhibitorischen Effekte in der Geruchsstoffverarbeitung, sondern auch das Geruchsstoff-Lernen fußt wohl auf einer Beteiligung Dopamins. So konnte gezeigt werden, dass sich die Dopaminkonzentration im Bulbus olfactorius, während Odoranzien erlernt werden, erhöht (Coopersmith et al. 1991).

Abgesehen von diesen Wirkungen im Bulbus olfactorius wird Dopamin aber auch eine Wirkung in der Mukosa zugeschrieben. So wurden $\mathrm{D}_{2}$-Rezeptoren auf den ORN der Maus gezeigt und nachgewiesen, dass deren Stimulation zu einer reduzierten Geruchsstoffantwort des ORN führt (Hegg und Lucero 2004). Auf der Ebene der ORN scheint aber nicht nur eine inhibitorische Wirkung zu existieren. Es werden weiterhin modulatorische Effekte bezüglich Zelldifferenzierung und -apoptose diskutiert (Féron et al. 1999).

\subsection{Zielsetzung}

Kalzium-Imaging gehört zu den grundlegenden Methoden in der Erforschung des olfaktorischen Systems von Xenopus laevis. Hierbei wurden die olfaktorische Mukosa und die glomerulären Projektionsfelder im Bulbus olfactorius ausführlich untersucht. Kalzium-Imaging-Untersuchungen im olfaktorischen Nerven von Xenopuslaevis-Larven wurden bisher nicht durchgeführt. Deswegen ist primäres Ziel dieser Arbeit:

- Entwicklung einer Methode zur Untersuchung von $\mathrm{I}_{\mathrm{Ca}^{2+}}$ im olfaktorischen Nerven.

Dopamin als Neurotransmitter hat vielfältige Wirkungen auf das zentralnervöse System. In Xenopus-laevis-Larven wurden hierzu bereits bei Zellkörpern der ORN 
modulatorische Effekte mittels Kalzium-Imaging nachgewiesen (Schriever 2012). Inwieweit es sich hierbei um einen rein lokalen Effekt auf Ebene der Mukosa handelt oder ob dieser Effekt auch auf im Nervus olfactorius nachzuweisen ist, soll deswegen folgende Frage klären:

- Beeinflusst Dopamin einen duftstoffinduzierten $\mathrm{I}_{\mathrm{Ca}^{2+}}$ im olfaktorischen Nerven von Xenopus-laevis-Larven?

Axone haben die Funktion, Nervenimpulse zu leiten. Zentraler Punkt dieser Nervenleitung ist deren Geschwindigkeit, welche zunächst von morphologischen Determinanten des Axons abhängt. So verändert sich beispielsweise bei der Multiplen Sklerose durch strukturelle Degeneration der Myelinscheiden die Nervenleitgeschwindigkeit. Der Nachweis einer kurzfristigen pharmakologischer Beeinflussung der Nervenleitgeschwindigkeit am isolierten Präparat wurde hingegen nur selten erbracht. Deswegen ist folgende Untersuchung ein weiteres Ziel dieser Arbeit:

- Beeinflusst Dopamin die Nervenleitgeschwindigkeit des olfaktorischen Nerven von Xenopus-laevis-Larven?

Weiterhin sollen Beweise für die Existenz molekularer Strukturen erbracht werden, die einen Rückschluss über Synthese- und Wirkungsort von Dopamin im olfaktorischen Nerven zulassen. Da zuvor genannte Arbeiten bereits $\mathrm{D}_{2}$-Rezeptoren im olfaktorischen System der Maus nachweisen konnten (Cave und Baker 2009), ergibt sich im Hinblick auf diese Struktur die Frage:

- Existieren $\mathrm{D}_{2}$-Rezeptoren im olfaktorischen Nerven der Xenopus-laevis-Larve?

Bei der weiteren Untersuchung des Stoffwechsels von Dopamin hat es sich etabliert, Tyrosinhydroxylase als Markerenzym für die Synthese nachzuweisen (Ratte: Baker et al. 1983, Armstrong et al. 1982, Pickel et al. 1981; Maus: Kanda et al. 2004, Baker et al. 1983; Drosophilamelanogaster: Friggi-Grelin et al. 2003). Gerade der Syntheseort Dopamins könnte wegweisende Belege zum Verständnis erbringen. Es ergibt sich also abschließend die Frage:

- Ist Tyrosinhydroxylase im olfaktorischen Nerven von Xenopus-laevis-Larven nachweisbar?

Der folgende Teil Material und Methoden beschreibt die Herangehensweisen an diese Fragestellungen. 
„Die eigene Zeit des Riechens ist keine abstrakte, messbare Zeit, sondern fällt mit dem vitalen Rhythmus unseres Atmens zusammen."

Tasten, Riechen, Schmecken. Eine Ästhetik der anästhesierten Sinne. Mǎdǎlina Diaconu (*1970)

(vgl. Diaconu 2005, S. 207)

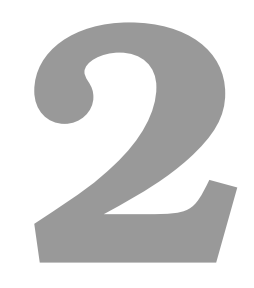

\section{Material und Methoden}

\subsection{Das Versuchstier Xenopus laevis}

Als Versuchstier für die Experimente wurden Xenopus-laevis-Larven verwendet, die sich im Entwicklungsstadium 51-53 befanden (s. Abb. 2.1, Nieuwkoop und Faber 1994). Xenopus laevis ist eine der 18 Arten umfassenden Xenopus-Gattung. Diese gehört zur Familie Pipidae (zungenlose Frösche) innerhalb der Ordnung Anura (Froschlurche), die zur Klasse der Amphibien (Lurche), Unterklasse Lissamphibia, gezählt wird. Der natürliche Lebensraum beschränkt sich auf Afrika südlich der Sahara. Die Verbreitung ist aber schon weit über den natürlichen Lebensraum hinausgewachsen. In ihrem ursprünglichen Lebensraum lebt die Xenopus-laevisLarve meist in verschlammten Gräben und Wasseransammlungen, wobei sie sich meistens nah am Grund oder in Ruhestellung an der Wasseroberfläche aufhalten. Xenopus-laevis-Larven sind vollaquatil und durchbricht meist nur zum Atmen die Wasseroberfläche. Krallenfrösche ernähren sich vorwiegend von Insektenlarven und Würmern, sind aber generell Allesfresser (Omnivoren). Sie durchwühlen den Gewässergrund mit ihren Vorderarmen und schlucken die aufgewirbelten Beutetiere 
mittels einer Saugschnapp-Bewegung. Insbesondere in Gefangenschaft ist Kannibalismus beobachtet worden.

Die leichte Zugänglichkeit zu Embryonen, starke Resistenz gegenüber äußeren Einflüssen, leichte Aufzucht und hohe Nachkommenschaft machen Xenopus-laevisLarven $\mathrm{zu}$ einem verbreiteten Versuchstier. Insbesondere für entwicklungsphysiologische Fragestellungen ist die Xenopus-laevis-Larve ein weithin bekannter Modellorganismus. Bis in die 1960er Jahre wurde sie als Schwangerschaftsindikator eingesetzt (Hobsen-Test). Hierzu wurde Morgenurin der zu untersuchenden Frau in den dorsalen Lymphsack injiziert und abgewartet, ob der weibliche Krallenfrosch Laich produziert. Bei einer Laichproduktion innerhalb von $24 \mathrm{~h}$, die auf das Vorhandensein von humanem Choriongonadotropin (hCG) im Urin der Schwangeren zurückzuführen ist, galt der Test als positiv (Hobson 1952, Hobson 1958). Eine Injektion von hCG wird auch bei den hier verwendeten Versuchstieren eingesetzt, um während der Aufzucht Laich zu produzieren (s. u.).

Für die Arbeit am olfaktorischen System bieten Xenopus-laevis-Larven viele Vorteile. Die fehlende Verknöcherung der Larven macht das olfaktorische System vollständig zugänglich und eine Präparation einfach. Gehirn und Epithel werden (noch) nicht durch einen knöcherne Lamina cribrosa getrennt. Weiterhin ist die Xenopus-laevis-Larve poikilotherm. Die Experimente können folglich bei Raumtemperatur durchgeführt werden, was dazu führt, dass Gewebeschnitte nicht, wie für Warmblüter üblich, einer Thermoregulation zugeführt werden müssen.

\subsubsection{Das olfaktorische System von Xenopus-laevis-Larven}

In Xenopus-laevis-Larven treffen wasser- und luftgebundene Olfaktorik sowie das Vomeronasalorgan (VNO) aufeinander. Die Entwicklung des olfaktorischen Systems der Xenopus-laevis-Larve muss daher einen komplexen Entwicklungsprozess durchlaufen. Zugrunde liegt für die weiteren Beschreibungen, die von Nieuwkoop und Faber erstellte Entwicklungstafel (Nieuwkoop und Faber 1994).

\section{Entwicklung des olfaktorischen Epithels}

Der Entwicklung des olfaktorischen Epithels liegt die Bildung der olfaktorischen Plakode zugrunde. Diese formiert sich im Stadium 23. Sieben Stadien später erreichen die ersten olfaktorischen Axone den olfaktorischen Bulb. Mezler et al. konnten 


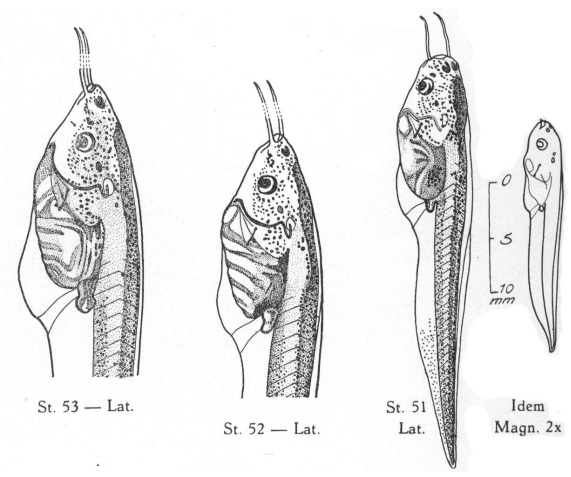

(a) Skizzen

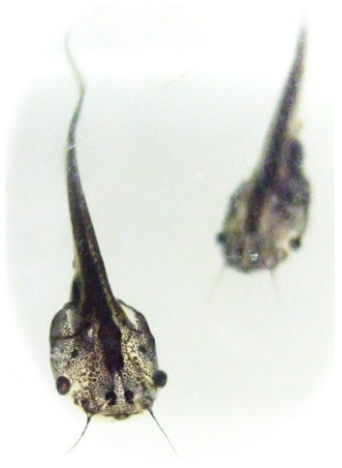

(b) in vivo

\section{Abbildung 2.1: \\ Versuchstier Xenopus-laevis-Larve (Stadium 51 - 53) in Skizzen (a; Nieuwkoop und Faber 1994, Anhang) und als Fotografie (b).}

zeigen, dass nahezu zeitgleich die ersten aquatischen Rezeptoren nachweisbar sind (Mezler et al. 1999). Im Stadium 40 entsteht aus der Plakode die Haupthöhle und das VNO. Im Stadium 47 existiert ein voll entwickeltes olfaktorisches System, in dem, neben dem VNO, das aquatische Riechepithel erscheint (Gaudin und Gascuel 2005). Wenig später beginnt die Entwicklung hin zum adulten olfaktorischen System: Im Stadium 49 startet die Umorganisation des olfaktorischen Systems, deren Ziel es ist, neben dem aquatischen, ein volatiles System entstehen zu lassen. Verwirklicht wird dies im Stadium 52, wo es zu einer Teilung der Haupthöhle kommt und eine laterale und eine mediale Höhle sichtbar wird (Mezler et al. 1999). Diese geteilte Konfiguration erlangt ihre vollständige Reife im Stadium 58 (Weiss 1986). Die laterale Höhle steht im Dienst der aquatischen Geruchserkennung, in der medialen Höhle liegen die Strukturen der luftgebundenen Geruchsstoffdetektion.

\section{Der olfaktorische Nerv}

Der Nervus olfactorius von Xenopus-laevis-Larven besteht aus unmyelinisierten Fasern. Im Stadium 30 erreichen die ersten Axone den olfaktorischen Bulb, nachdem sie aus der olfaktorischen Plakode, dem späteren olfaktorischen Epithel, entsprangen. Mit fortschreitender Entwicklung erreichen weitere Axonen den rostralen Pol des Telenzephalons. Vom Stadium 48 bis zum Stadium 58 erfolgt eine Längenzunahme des Nerven, die im Einklang mit der Zunahme von Gewicht, Kör- 
perlänge und Kopfbreite steht. Im Stadium 58 erreicht der Nerv mit einer Länge von 1,61 mm sein Maximum, ausgehend von einer Länge von 0,57 $\mathrm{mm}$ im Stadium 48.

Anders verhält es sich mit der Anzahl der Axone. Deren Anzahl steigt kontinuierlich [Stadium 48:ca. 10.000; Stadium 50: 45.000, Stadium 56:110.000, Stadium 60:170.000 (Burd 1991)]. Bemerkenswert ist auch, dass die Axonenzahl zwischen rostralen und kaudalen Nervenabschnitten divergiert. Es finden sich Differenzen zwischen 4\% (Stadium 48) und 26\% (Stadium 58). Zwischen rechten und linken Nerven treten hingegen keine statistisch relevanten Abweichungen auf (Burd 1991).

\section{Der olfaktorische Bulb}

Zur morphologischen Klassifikation des olfaktorischen Bulb von Xenopus-laevisLarven sind zur Zeit zwei verschiedene Einteilungen von Belang: Zum Einen die Einteilung von Manzini und Schild, die sich auf Biocytin-Färbungen, präsynaptische Proteinverteilung und unterschiedliches Aminosäureantwortverhalten stützt (Manzini und Schild 2009), und zum Anderen eine detaillierte Einteilung nach Gaudin und Gascuel (Gaudin und Gascuel 2005). Letztere schafft einen umfassenden Blick über die morphologischen Änderungen in der Entwicklung der Larve mittels Carbocyanin-Farbstoffen und Lectin-Färbungen. Da in der vorliegenden Arbeit das Aminosäureantwortverhalten von grundlegender Bedeutung ist, stützt sich diese Arbeit auf die Erkenntnisse von Manzini und Schild (Manzini und Schild 2009). Nach dieser existieren vier glomeruläre Zonen im Bulbus olfactorius principalis. Ventral gelegen unterscheidet man den lateralen, den intermediären und den medialen Cluster. Zusätzlich existiert ein weiterer kleiner Cluster. In der Eintrittsebene des Nerven sind jedoch nur die drei Hauptcluster erkennbar. Intermediärer und medialer Cluster verschmelzen in dorsaler Richtung (s. Abb. 2.2).

\subsubsection{Zucht von Xenopus-laevis-Larven}

Die für die Experimente verwendeten Zuchttiere wurden nach Richtlinien des Ethikkomitees der Universität Göttingen gehalten und behandelt. Die Larven stammen aus eigener Aufzucht im Labor. Sie wurden in 30-l-Süßwasseraquarien bei $20^{\circ} \mathrm{C}$ gehalten und mit Algenpulver (TetrA, Melle, Deutschland) gefüttert. Für die Zucht erhielten die zwei Tage zuvor isolierten Tiere subkutane Injektionen von hCG in 


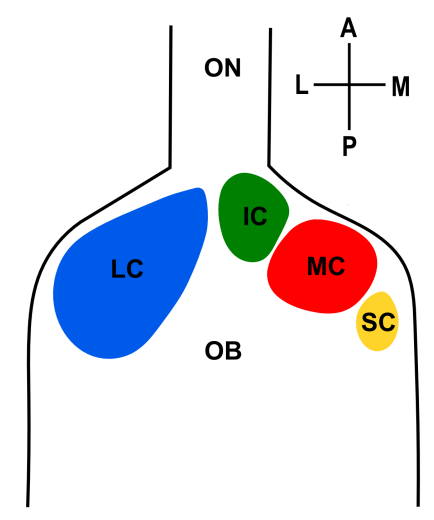

\section{Abbildung 2.2:}

Schematische Aufarbeitung der Clusterlage im ventralen olfaktorischen Bulb der Xenopus-laevis-Larve beruhend auf Manzini und Schild 2009.

Abk.: $\mathrm{ON}=$ olfaktorischer Nerv, $\mathrm{LC}=\cdot$ lateraler Cluster, $\mathrm{IC}=$ intermediärer Cluster, $\mathrm{MC}=$ medialer Cluster, $\mathrm{SC}=$ kleiner Cluster, $\mathrm{A}=$ anterior, $\mathrm{M}=$ medial, $\mathrm{P}=$ posterior, $\mathrm{L}=$ lateral

den Oberschenkel. 1000 i. E. erhielt dabei das Weibchen, 600 i.E. das Männchen. Anschließend wurden die Tiere über Nacht zusammengesetzt. Die adulten Tiere wurden danach aus dem Becken entfernt. Bei erfolgreicher Fortpflanzung gediehen so in einem 30-l-Aquarium ca. 200 Xenopus-laevis-Larven. Bei geeignetem Entwicklungsstadium wurden die Tiere entnommen.

\subsection{Mikroskopie und Farbstoffe}

\subsubsection{Grundlagen der Fluoreszenz}

Kalzium-Imaging ist eine hauptsächlich in der Wissenschaft verwendete Methode, die einen $\mathrm{I}_{\mathrm{Ca}^{2}}$ in Zellen sichtbar macht. Es kann dabei die zeitliche wie auch die räumliche Änderung der $\left[\mathrm{Ca}^{2+}\right]_{\mathrm{i}}$ aufgezeigt werden. Durch räumliche und zeitliche Veränderungen der $\left[\mathrm{Ca}^{2+}\right]_{i}$, die sich in Abhängigkeit vom Erregungszustand der Zelle ändert, können Rückschlüsse auf die Aktivität der einzelnen Zelle oder des Zellverbandes gezogen werden.

Um diese $\mathrm{I}_{\mathrm{Ca}^{2+}} \mathrm{zu}$ beobachten, benötigt man $\mathrm{Ca}^{2+}$-sensitive Farbstoffe, die in Abhängigkeit von der $\left[\mathrm{Ca}^{2+}\right]_{\mathrm{i}}$ ihre Fluoreszenz ändern. Fluoreszenz bedeutet, dass 
Licht von Molekülen absorbiert wird und ein Teil der dadurch aufgenommenen Energie mit kurzer Verzögerung wieder als Photon abgegeben wird. Dabei trifft zunächst Licht geeigneter Wellenlänge auf das Farbstoffmolekül, wobei die Energie des Photons absorbiert wird. Dies hat zur Folge, dass ein Elektron von einem bestimmten Energieniveau auf ein höheres Niveau angehoben wird und das Molekül von seinem Grundzustand in einen angeregten Zustand übergeht. Zeitlich betrachtet dauert dieser Vorgang wenige Femtosekunden. Grundzustand und angeregter Zustand sind dabei kein wohldefiniertes Energieniveau, sondern ganze Energiebänder. Damit Fluoreszenzstrahlung entsteht, fällt im Energieband des angeregten Zustandes ein Elektron auf das tiefste Niveau des angeregten Zustandes (Relaxation) ohne dabei Photonen freizusetzen. Hier verweilt es einige Nanosekunden, um dann spontan in den Grundzustand zurückzufallen und dabei ein Photon auszusenden - die eigentliche Fluoreszenzstrahlung. Absorptions- und Fluoreszenzenergie sind dabei durch die Relaxationsvorgänge niemals gleich groß, was bedeutet das Anregungs- $\left(\lambda_{e x}\right)$ und Fluoreszenzwellenlänge $\left(\lambda_{e m}\right)$ niemals identisch sind. Fluoreszenzlicht ist immer langwelliger und energieärmer als Anregungslicht. Anzumerken ist auch, dass Absorption und Fluoreszenz nicht bei einer einzigen Wellenlänge auftreten, sondern vielmehr ein ganzes Spektrum von absorbiertem Licht und Fluoreszenzlicht zu beobachten ist (Deitmer und Schild 2000).

\subsection{2 $\mathrm{Ca}^{2+}$-sensitive Farbstoffe}

Es existieren Stoffe, die ihre spektralen Eigenschaften in Abhängigkeit von der Bindung an $\mathrm{Ca}^{2+}$-Ionen ändern. Diese Stoffe bezeichnet man als $\mathrm{Ca}^{2+}$-sensitiv. Sie senden Licht bestimmter Wellenlänge aus. Durch Kenntnis dieser Wellenlängen lassen sich diese dann durch die Wahl bestimmter Filter und dichroischer Spiegel darstellen. Bekannte $\mathrm{Ca}^{2+}$-sensitive Farbstoffe sind fluo-3, fluo-4, fura-2 oder Calcium-Green-1 (Invitrogen, Leiden, Niederlande). Für die Experimente dieser Arbeit wurde fluo-4 $\left(\lambda_{e x}=494 \mathrm{~nm}, \lambda_{e m}=516 \mathrm{~nm}\right)$ als Farbstoff verwendet. Fluo-4 hat eine niedrige Grundfluoreszenz und zeichnet sich durch eine hohe Steigerung der Fluoreszenzintensität bei $\mathrm{Ca}^{2+}$-Bindung aus (Gee et al. 2000). Er eignet sich somit zur Visualisierung kurzer $\mathrm{I}_{\mathrm{Ca}^{2+}}$, die bei einer Stimulation im Neuron stattfinden. Für die Versuche wurde fluo-4 gekoppelt an ein $10 \mathrm{kDa}$ Dextran eingesetzt. Dextrane sind hydrophile Polysaccharide und biologisch nahezu inert, die vielfach für 
<smiles>CC(=O)COc1cc2oc3cc(=O)c(F)cc-3c(-c3ccc(NCCOC(=O)COC(C)=O)c(OCC(C)=O)c3)c2cc1F</smiles>

\section{Abbildung 2.3:}

Strukturformel von fluo-4-AM (Invitrogen 2012). Das reine fluo-4 Molekül ist hydrophil und kann deswegen Zellen nicht penetrieren, deswegen nutzt man den Ester fluo-4-AM, der intrazellulär gespalten wird und so den Farbstoff freigibt. Mit steigender intrazellulärer $\mathrm{Ca}^{2+}$-Konzentration erhöht sich die Intensität des Emissionslichtes. Der $K_{d}\left(\mathrm{Ca}^{2+}\right)$ für fluo-4 beträgt $345 \mathrm{~nm}$. In den hier durchgeführten Experimenten wurde fluo-4 gekoppelt an ein Dextran verwendet.

die Beladung von zellulären Strukturen eingesetzt werden (Falk et al. 2007, Boutin et al. 2008). Sie verhindern durch ihre Größe eine Ausschleusung des gekoppelten Farbstoffs (Kreitzer et al. 2000) und werden durch anterograden Transport entlang des Axons im gesamten Neuron bis hin zu den Axonterminalen im olfaktorischen Bulb verteilt (Bonnot et al. 2005, Nagayama et al. 2007).

\subsubsection{Konfokale Laserrastermikroskopie}

Im Rahmen dieser Dissertation sollten Messungen in Gewebeschnitten durchgeführt werden, weswegen eine konfokale Optik von Nöten war, um gezielt einzelne Schnittebenen des Gewebes betrachten zu können. Weiterhin stützten sich die Messungen auf den Gebrauch von Fluoreszenzindikatoren (s. o.), weswegen ein Fluoreszenzmikroskop gebraucht wurde. Diese Grundvoraussetzungen erfüllten die eingesetzten konfokalen Laserscan-Mikroskope LSM 510 (ZEISS, Jena, Deutschland) und LIM (Linienrastermikroskop, Eigenbau der Abt. Neurophysiologie und zelluläre Biophysik). Zelluläre Strukturen können hiermit qualitativ hochwertig und eindeutig dar- 
gestellt werden.

\section{Strahlengang LSM}

Im Gegensatz zu einem gewöhnlichen Lichtmikroskop wird bei der Laserscan-Mikroskopie das Präparat punktweise bestrahlt und punktweise gemessen (s. Abb. 2.4). Dabei bewegt sich der genutzte Laser punktweise über das gesamte Objekt, man spricht aufgrunddessen auch von einem Punktscanner. Als Anregungsquelle wird - wie erwähnt - ein Laser gewählt, der paralleles, monochromatisches Licht $(\lambda=$ $488 \mathrm{~nm}$ ) erzeugt. Dies trifft auf einen dichroischen Spiegel, der das Anregungslicht zum Präparat lenkt. Durch die Verwendung von Scanspiegeln kann jeder Punkt in $x y$-Richtung erreicht werden, ein Objektiv fokussiert das Licht in der Probe. Das ausgerichtete und fokussierte Licht trifft so auf das Detektionsvolumen und regt dort Fluorophore an. Folglich kommt es zur Aussendung von Photonen, die durch eine längere Wellenlänge als das Anregungslicht charakterisiert sind. Das Objektiv sammelt einen Teil der ausgesendeten Photonen ein. Diese treffen auf den zu Beginn erwähnten dichroischen Spiegel, den sie aufgrund der größeren Wellenlänge aber passieren können. Eine nachgeschaltete Lochblende (Pinhole) ist so arrangiert, dass nur Licht aus der Fokusebene auf den nachgeschalteten Detektor trifft. Ausserfokuslicht wird ausgeblendet. Durch die variable Öffnungsfläche der Lochblende wird so die optische Schichtdicke bestimmt. Der erwähnte Detektor ist ein Photomultiplier, der es erlaubt das Signal zu verstärken. Detektiert wird das Licht dabei unterhalb des Präparates, weswegen man in diesem Fall von einem inversen Strahlengang spricht.

\section{Strahlengang LIM}

Als zweites Mikroskop wurde in dieser Arbeit ein konfokales Linienrastermikroskop (LIM) eingesetzt, welches ein besseres zeitliches Auflösungsvermögen hat. Aufgrunddessen wurde es zur Messung der dopaminergen Modulation der NLG eingesetzt (s. Kap. 2.4.4).

Grundsätzlich handelt es sich bei dem LIM um eine Abwandlung des LSM, bei der der Rasterpunkt durch eine Zylinderlinse in eine Linie aufgespalten wird. Das verwendete Pinhole des LSM wird analog durch eine $14 \mu \mathrm{m}$ breite CCD-Linie ersetzt. So wird entlang der $x$-Achse eine Linie mit einer Länge von 512 px abgebildet. 


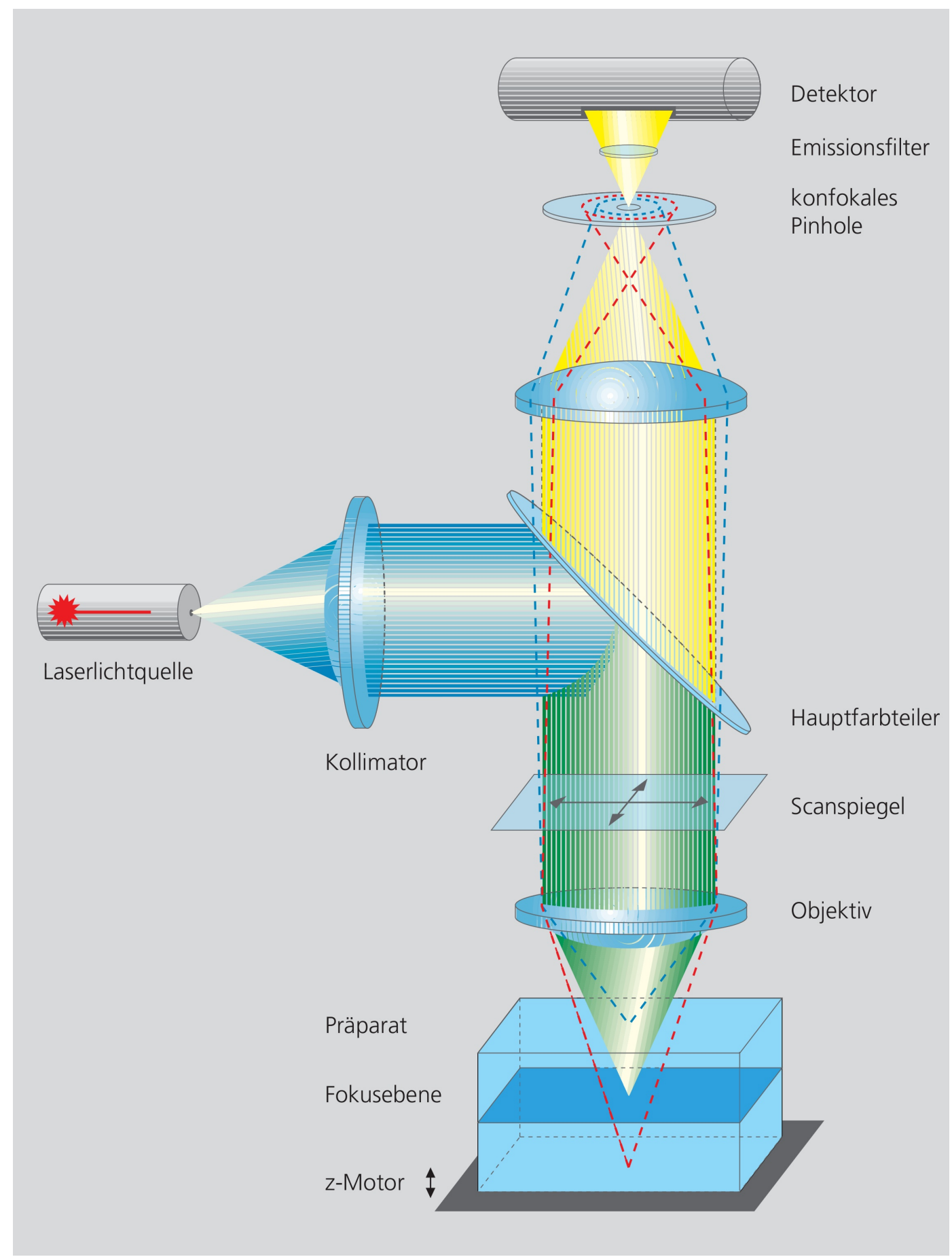

\section{Abbildung 2.4:}

Schematische Darstellung des Strahlengangs des LSM 510 (Zeiss-Broschüre 2003, S. 1). Das verwendete LSM 510 zeichnet sich jedoch durch einen inversen Strahlengang aus, d.h. das Fluoreszenzlicht wird unterhalb des Präparats gemessen, nicht - wie dargestellt - über dem Präparat. 
Bei vollständiger Abbildung des Bildbereichs (512x 512 px) wird eine Frequenz von $60 \mathrm{~Hz}$ erreicht. Durch Verkleinerungen des Bildausschnittes ist die Bildfrequenz steigerbar.

Die Laserlichtquelle ist ein Argon-Ionen-Laser (LAser Technologies, Kleinostheim, Deutschland). Dessen Licht wird durch eine Kollimationslinse parallelisiert und passiert einen Anregungsfilter und ein Filterrad mit wählbaren Neutralfiltern. Diese wurden so eingestellt, dass 100\% des Laserlichtes das Präparat erreichten. Ein dichroischer Spiegel reflektiert den Strahl zu einer Zylinderlinse. Diese fokussiert das Laserlicht in einer Dimension auf einen Scanspiegel, welcher es in der Fokusebene in y-Richtung lenkt. Durch Tubuslinse und Objektiv (hier: PlanApochromat 25x/0,8 W; ZEISs, Göttingen, Deutschland) wird eine verkleinerte Abbildung auf die Fokusebene des Objekts erreicht. Der in das Objekt eingebrachte Fluoreszenzfarbstoff wird so entlang der Linie angeregt und das emittierte Licht gelangt entlang des Anregungsstrahlengangs zum o.g. dichroischen Spiegel, den es aufgrund der größeren Wellenlänge im Vergleich zum Anregungslicht passieren kann. Ein nachgeschalteter Emissionslichtfilter wird passiert, bevor das Emissionslicht von der Kameralinse in $y$-Richtung parallelisiert und in $x$-Richtung auf eine CCD-Linie der Kamera abgebildet wird.

Die Aufnahmezeit für ein Bild $t$ setzt sich dabei aus folgender Formel zusammen:

$$
t=(\text { lines }+ \text { delaylines }) * \text { delaystacks } * \text { step } *\left(32 * 10^{-6}\right) \mathrm{s}
$$

mit lines $=$ Anzahl der gemessenen Linien (bis maximal 512 Linien für ein quadratisches Bild); delaylines = Anzahl der zusätzlichen Linien vor der eigentlichen Datenaufnahme; delaystacks = Bilder, die vor der eigentlichen Datenaufnahme als Vorlauf dienen; step $* 32 \mu \mathrm{s}=$ Belichtungszeit für eine Linie, in ganzzahligen Schritten (step) von $32 \mu \mathrm{s}$

\subsection{Versuchsvorbereitung}

Sowohl das beginnende Kapitel Versuchsvorbereitung als auch die folgenden Kapitel Versuchsdurchführung (s. Kap. 2.4) und -auswertung (s. Kap. 2.5) beziehen sich auf die Experimente am LSM sowie LIM. Diese haben das Ziel, einen $\mathrm{I}_{\mathrm{Ca}^{2+}}$ im 


\begin{tabular}{|c|c|c|c|}
\hline Mikroskop & Versuchsvorbereitung & Reizung & Versuchsteil \\
\hline LSM & $\begin{array}{l}\text { Elektroporation } \\
\qquad(1 \mathrm{x})\end{array}$ & $\mathrm{AA}$ & $\begin{array}{l}\text { duftstoffinduzierte Antwort } \\
\text {-Mod. mit TTX, Nifedipin } \\
\text {-Mod. mit DA } \\
\text {-Mod. mit D } \text { D }_{2} \text {-(Ant)Agonisten }\end{array}$ \\
\hline LIM & $\begin{array}{l}\text { Elektroporation } \\
(2 \mathrm{x})\end{array}$ & Reizgeber & NLG-Mod. mit DA \\
\hline
\end{tabular}

Tabelle 2.1:

Übersicht über die Versuchsteile „Darstellung eines duftstoffinduzierten $\mathrm{I}_{\mathrm{Ca}^{2+}}$ ", „dopaminerge Modulation eines $\mathrm{I}_{\mathrm{Ca}^{2+}}$ “ und „Messung der Nervenleitgeschwindigkeit".

olfaktorischen Nerven zu visualisieren und deren Eigenschaften und dopaminerge Modulation zu untersuchen. Der Großteil dieser Versuche wurde am LSM durchgeführt. Die dopaminerge Modulation der NLG, die hier auch aufgeführt werden soll, wurde hingegen am LIM untersucht. Für beide Versuchsabschnitte - wenn auch hier zusammen dargestellt - war es erforderlich, die Versuchsvorbereitungen und -durchführung anzupassen (s. Tab. 2.1).

Die immunhistochemischen Versuche wurden, der Übersicht halber, aus dieser Gliederung herausgenommen und in einem eigenen Kapitel dargestellt (s. Kap. 2.6).

\section{Elektroporation}

Um die nachfolgend beschriebenen Versuche durchführen zu können, war es nötig, Axone von ORN mit einem fluoreszierenden Farbstoff zu beladen, um sie anschließend unter dem Laserlicht der konfokalen Mikroskope untersuchen zu können (s. Kap. 2.2.1). Hierzu wurde das Verfahren der Elektroporation gewählt. Hierbei wird die Zellmembran durch Anlegen eines elektrischen Feldes kurzzeitig permeabel und somit für Makromoleküle durchlässig gemacht (Teruel und Meyer 1997, Haas et al. 2002, Nagayama et al. 2007). Ein breites Spektrum verschiedener Stoffklassen, u.a. Fluoreszenzfarbstoffe, konnten damit erfolgreich in Zellen transferiert werden (Falk et al. 2007, Boutin et al. 2008).

Die Methode zur Anfärbung des olfaktorischen Nervs der Xenopus-laevis-Larven wurde hierzu von Kludt entwickelt (Kludt 2010): Die Tiere wurden zunächst in einer 0,02\%-igen MS-222 Lösung (SIGMA-AldRICH, Steinheim, Deutschland)) an- 
ästhesiert und ihnen anschließend fluo-4-Dextran-Farbstoffkristalle (MOLECULAR Probes, Leiden, Niederlande) in die Nasenhöhle eingesetzt. Mittels zweier Platinelektroden (Durchmesser $200 \mu \mathrm{m}$ ), die ebenfalls in die Nasenhöhle eingeführt wurden, erfolgte dann die Stromapplikation. Der Abstand der Elektroden konnte individuell angepasst werden. Die Elektroden waren mit einem Pulsgenerator verbunden. Über diesen wurden anschließend zwölf 20-mV-Pulse mit einer Dauer von $20 \mathrm{~ms}$ appliziert. Es erfolgte eine manuelle Auslösung bei $1 \mathrm{~Hz}$. Nach Überführung in ein Gefäß wurden die Tiere bis zum Experiment mindestens einen Tag lang in dunkler Umgebung inkubiert, um die Diffusion des Farbstoffs entlang des gesamten Nervs zu ermöglichen. Nach Ablauf dieser Zeit wurden die Tiere innerhalb der nächsten zwei Tage für Versuche eingesetzt.

Anzumerken ist hier, dass für die Versuche am LIM die Tiere zweimal elektroporiert werden mussten. Das heißt, dass nach der ersten Elektroporation die Tiere $24 \mathrm{~h}$ in Dunkelheit aufbewahrt wurden und dann anschließend erneut elektroporiert wurden. Die Vorgehensweise war identisch zur oben beschriebenen.

\subsubsection{Präparation von Gewebeschnitten}

Zur Untersuchung der gefärbten Riechnerven mussten diese den Tieren entnommen und geschnitten werden, um sie anschließend am LSM betrachten zu können. Zur Herstellung dieser Gewebeschnitte wurden die Tiere zunächst in einem Eiswasserbad betäubt. Nach Fixierung auf einer Agarplatte wurden die Tiere mit einem Schnitt ins Stammhirn getötet. Mit Hilfe eines Skalpells wurde nun ein Block herausgeschnitten, welcher beide Riechepithelien, Nerven und Bulbi enthielt (s. Abb. 2.5). Mit Gewebekleber (Roti @-coll 1, CARL Roth, Karlsruhe) wurde dieser Gewebeblock auf der Grundplatte des Vibratoms (VT 1200 S, LEICA MicrosysTEMs, Wetzlar) fixiert. Beim Schneiden der Gewebeblöcke befand sich die Grundplatte samt Präparat in einer mit Badlösung gefüllten Wanne.

Dabei wurde zunächst ein Schnitt dorsal der Nerven gesetzt, um möglichst viel umliegendes Gewebe zu entfernen ohne dabei jedoch eine Durchtrennen der Nerven hervorzurufen. Da der Nerv von anterior nach posterior in einem leichten Bogen verläuft, musste die Schnitthöhe in Intervallen angepasst werden. Ein zweiter Schnitt wurde nun so gesetzt, dass die Nasenhöhlen minimal von ventral angeschnitten wurden, ohne jedoch zu viel olfaktorisches Epithel zu entfernen. Daraus 
ergaben sich Gewebeschnitte mit einer ungefähren Dicke von $250 \mu \mathrm{m}$. Nachfolgend wurden Falcon-3001-Petrischalen ( $\mathrm{d}=35 \mathrm{~mm}$, Becton Dickinson And CompaNY, Großbritannien) verwendet, aus deren Boden zunächst eine Rechteckfläche herausgefräst wurde. Anschließend wurde diese Öffnung mit einem Deckglas (170 $1 \mathrm{~m})$ verschlossen. Auf diese Weise wurde eine rechteckige Aussparung geschaffen, die sog. Perfusionskammer. Hier hinein wurde der Gewebeschnitt überführt. Eine örtliche Fixierung des Schnittes, um eine konstante Position zu gewährleisten, wurde mittels eines Netzes durchgeführt. Dieses bestand aus einem Platinrahmen, welcher passend zur rechteckigen Perfusionskammeraussparung gefertigt und anschließend mit Nylonfäden umspannt wurde. Das Netz wurde dabei so platziert, dass die gespannten Nylonfäden sich nicht im Bereich des untersuchten Gewebes befanden.

Auch hier waren Änderungen in der Vorgehensweise für Experimente am LIM nötig. Folgende Modifikationen wurden durchgeführt:

- Nach erfolgtem dorsalem Schnitt wurden die den Nerv umhüllenden Melanozyten mit Pinzetten entfernt, um eine Überlagerung im Bild zu verhindern.

- Der ventrale Schnitt erfolgte unter vollständiger Erhaltung der Mukosa. Dies erhöhte die Gewebedicke auf ca. $350 \mu \mathrm{m}$.

- Die Nylonfäden des Fixierungsnetzes waren nicht quer, sondern längs des Axons gespannt, damit sie sich nicht mit den Messpunkten überlagern.

\subsubsection{Reizgeber am LIM}

Zur Messung der NLG am LIM wurden die Rezeptorneurone elektrisch gereizt. Dazu wurden zunächst zwei mit Teflon isolierte Silberelektroden (ADVENT RESearch Materials Ltd., Oxford, Großbritannien) mit einem Durchmesser von 0,27 $\mathrm{mm}$ jeweils in der Mukosa als Kathode und in den anterioren Bereiches des olfaktorischen Nerven als Anode platziert. Sie sind verbunden mit dem eigentlichen Reizgeber Isolated Stimulator TYPE 2533 (Digitimer LTd., Hertfordshire, Großbritannien). Dieser erzeugte für die Dauer von 5 ms eine Spannung von 15 V. Durch die Kondensatoreigenschaften der Zellmembran wird dabei das Zellinnere zunächst negativ aufgeladen (hyperpolarisiert) und so eine maximale Anzahl von schnellen $N a^{+}$-Kanälen deaktiviert. Am Ende des Pulses hingegen springt die Spannung um 


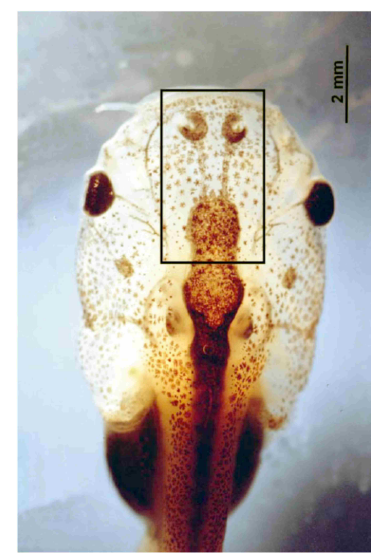

(a) Präp.-Gebiet

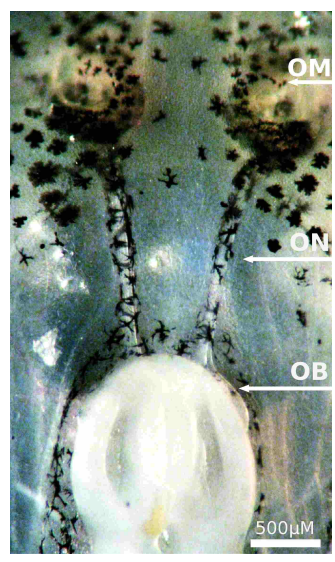

(b) n. Schnitt

\section{Abbildung 2.5:}

Darstellung des Präparationsgebiets der Xenopus-laevis-Larve (Junek 2008, S. 8). In (a) stellt der Rahmen den zu präparierenden Bereich heraus. In (b) ist eine Aufsicht auf das Präparat nach der Beendigung des oberen Schnittvorgangs knapp oberhalb des $\mathrm{ON}$ zu sehen. Er enthält olfaktorische Mukosa $(\mathrm{OM})$, den olfaktorischen Nerv (ON) und den olfaktorischen Bulb (OB) beiderseits. Das OM wurde nicht angeschnitten.

und eine maximale Anzahl von schnellen $\mathrm{Na}^{+}$-Kanälen geht in den aktivierten Zustand über. Die Zelle depolarisiert. Aktionspotentiale ziehen durch den olfaktorischen Nerv und können unter dem LIM gemessen werden.

\subsection{Versuchsdurchführung}

Neben den schon erwähnten unterschiedlichen Mikroskopen zur Versuchsdurchführung (s. Tab. 2.1), waren auch innerhalb der Versuchsreihen unterschiedliche Schritte nötig, um die Wirkungen aufschlüsseln zu können. Zur Aufrechterhaltung eines kontinuierlichen Zustroms von Badlösung wurde zudem ein spezielles Applikationssystem (s. u.) benötigt.

\subsubsection{Applikationssystem}

Bei sämtlichen Kalzium-Imagingversuchen wurden vitale Gewebe untersucht. Um diese Vitalität zu gewährleisten, wurde ein Verfahren verwendet, bei dem die Ge- 


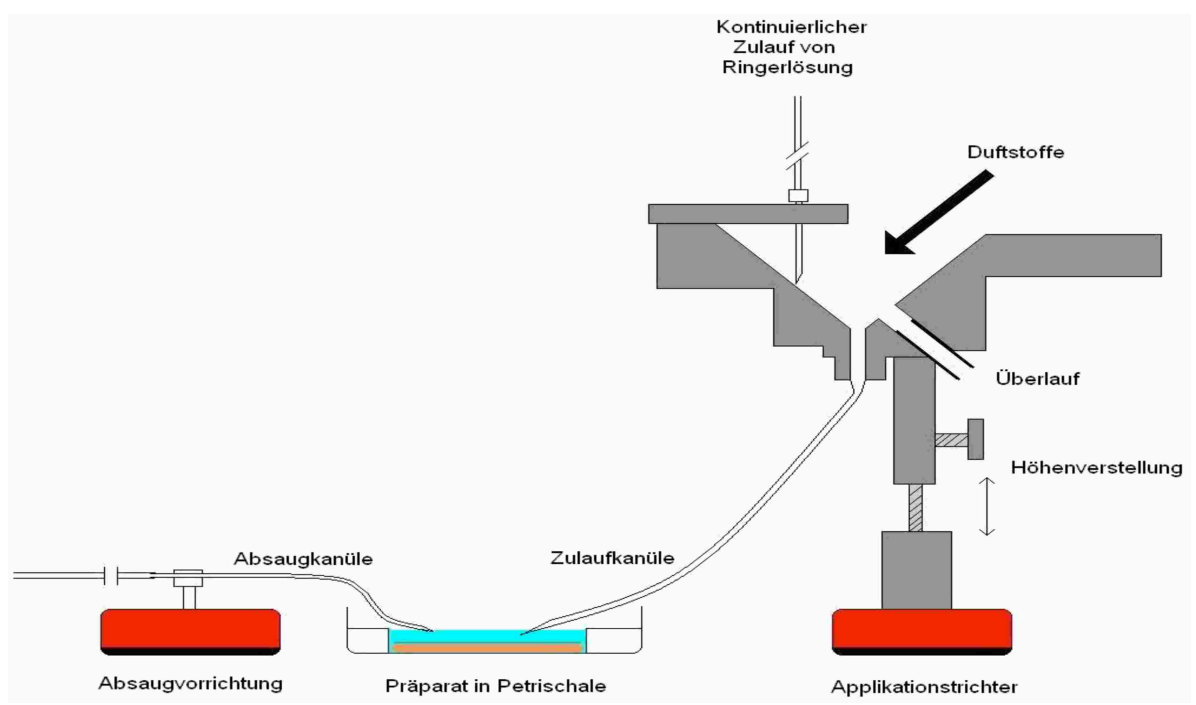

Abbildung 2.6:

Schematische Darstellung des Trichterapplikationssystems nach Schild (Schild 1985, S. 73)

webeblöcke mittels einer Badlösung ständig umspült wurden und so vital blieben (s. Abb. 2.6, Schild 1985). Die Applikation der Badlösung erfolgt bei diesem Verfahren über einen Trichter, der mit einer gebogenen Kanüle als Auslauf bestückt ist. Mit einem Mikromanipulator kann die Kanülenspitze über der Mukosa plaziert werden und so der Gewebeschnitt nicht nur kontinuierlich umspült, sondern es können auch Testsubstanzen herangeführt werden. Zum Trichter hin besteht ein ständiger Zufluss der Badlösung, der entlang der Trichterwand hinabrinnt. Testsubstanzen können zusätzlich hineinpipettiert werden. Eine Absaugvorrichtung gewährleistet den Flüssigkeitsabfluss (Schild 1985).

\subsubsection{Darstellung eines duftstoffinduzierten $\mathrm{I}_{\mathrm{Ca}^{2+}}$ im olfaktorischen Nerven}

Durch das oben beschriebene Trichtersystem wurde, zusätzlich zur Badlösung, eine Aminosäurelösung (s. Kap. 2.7.2) als Stimulus appliziert und anschließend die Fluoreszenz im ON beobachtet. In den weiteren Versuchen wurden - neben diesem grundsätzlichen Vorgehen - verschiedene Substanzen in die Badlösung hinzugefügt und ebenfalls Änderungen der Fluoreszenz gemessen. Diese Testsubstanzen waren Nifedipin, Tetrodotoxin (s. u.) sowie dopaminerge Substanzen (s. Kap. 2.4.3). 
Während des Versuchs wurden alle 3 min Messungen für die Dauer von ca. $30 \mathrm{~s}$ durchgeführt. Die Messung erfolgt bei ca. $2 \mathrm{~Hz}$ bei einer Auflösung von $256 * 256$ Bildpunkten am LSM.

\section{Modulation mittels Nifedipin}

Die Testsubstanz Nifedipin (Sigma-Aldrich, Steinheim, Deutschland) ist ein Kalzium-Kanal-Blocker. Dieser wurde zur Badlösung für die Dauer von 12 min hinzugefügt, nachdem zuvor dreimal unter den o. g. Bedingungen ein Stimulus dargestellt werden konnte. Die verwendeten Konzentrationen des Blockers sind in Tab. 2.2 ersichtlich. Anschließend wurden die Gewebeschnitte mit reiner Badlösung für die Dauer von 30 min umspült. Während des Versuchs wurden alle 3 min Messungen für die Dauer von ca. 30s durchgeführt. Die Messung erfolgte bei ca. $2 \mathrm{~Hz}$ bei einer Auflösung von $256 * 256$ Bildpunkten am LSM.

\section{Modulation mittels TTX}

Als weitere Testsubstanz wurde Tetrodotoxin (TTX, Alomone Labs, Jerusalem, Israel) eingesetzt. Hierbei handelt es sich um einen Blocker schneller $\mathrm{Na}^{+}$-Kanäle. Auch hier wurde zunächst dreimal ein Stimulus bei Fluss der Badlösung dargestellt und dann für die Dauer von sechs Minuten TTX zur Spüllösung hinzugefügt (Konzentrationen s. Tab. 2.2). Anschließend wurden die Gewebeschnitte mit reiner Badlösung für die Dauer von 30 min umspült. Während des Versuchs wurden alle 3 min Messungen für die Dauer von ca. 30s durchgeführt. Die Messung erfolgt bei ca. $2 \mathrm{~Hz}$ bei einer Auflösung von $256 * 256$ Bildpunkten am LSM.

\subsubsection{Dopaminerge Modulation eines $\mathrm{I}_{\mathrm{Ca}^{2+}}$ im olfaktorischen Nerven}

Zur Untersuchung der dopaminergen Modulation eines $\mathrm{I}_{\mathrm{Ca}^{2+}}$ in Folge einer Duftstoffreizung wurden in den Experimenten neben Dopamin auch Dopaminagonisten und -antagonisten (s.u.) untersucht.

Auch hier wurde zunächst eine dreimalige Duftstoffantwort mittels Aminosäurereizung unter Fluss der Badlösung dargestellt. Dann erfolgte die Zugabe Dopamin zur Badlösung und es wurde das Antwortverhalten des Nervs untersucht. Dopamin 
(Sigma-Aldrich, Steinheim, Deutschland) wurde in diesem Versuchsteil für die Dauer von $30 \mathrm{~min}$ und in den Konzentrationen $15 \mu \mathrm{M}, 25 \mu \mathrm{M}$ and $50 \mu \mathrm{M}$ verwendet (s. Tab. 2.2). Nach Abschluss erfolgte ein 15-minütiges Auswaschen mit Badlösung. Während des Versuchs wurden alle 3 min Messungen für die Dauer von ca. $30 \mathrm{~s}$ durchgeführt. Die Messung erfolgte bei ca. $2 \mathrm{~Hz}$ bei einer Auflösung von $256 * 256$ Bildpunkten am LSM.

\section{Dopaminagonist}

Zur Spezifizierung der dopaminergen Modulation wurde der $\mathrm{D}_{2}$-Agonist Quinpirol (Sigma-Aldrich, Steinheim, Deutschland) eingesetzt. Die verwendeten Konzentrationen können Tabelle 2.2 entnommen werden. Analog zu der DopaminVersuchsreihe (s. o.) wurde Quinpirol für 30 min zur Badlösung hinzugefügt. Nach Abschluss erfolgte ein 15-minütiges Auswaschen mit Badlösung.

\section{Dopaminantagonist}

Auch der $\mathrm{D}_{2}$-Antagonist Sulpirid (Sigma-Aldrich, Steinheim, Deutschland) fand in dieser Arbeit Verwendung. Hierbei wurde wieder zu Beginn eine dreimalige Duftstoffreizung durchgeführt. Dann wurden zunächst für 15 min $50 \mu \mathrm{M}$ Dopamin und anschließend in unterschiedlichen Konzentration Sulpirid eingewaschen (s. Tab. 2.2), wobei kein Dopamin mehr zugesetzt wurde. Hier erfolgte keine erneute Darstellung des $\mathrm{I}_{\mathrm{Ca}^{2}+}$ unter Badlösung.

\subsubsection{Messung der Nervenleitgeschwindigkeit}

Zur Messung der Nervenleitgeschwindigkeit wurden zunächst, nach Anfertigung eines Gewebeschnitts (s. Kap. 2.3.1), die Reizelektroden, welche mit dem Reizgeber (s. Kap. 2.3.2) verbunden waren, platziert. Es erfolgte dann die Kontrollmessung unter Fluss der Badlösung, die über das Trichtersystem zugefügt wurde. Fünf Minuten nach dieser erfolgte der Zusatz von Dopamin (SigmA-AldRich, Steinheim, Deutschland) zur Badlösung, sodass die Lösung eine Konzentration von $50 \mu \mathrm{M}$ hatte. Nun wurde alle 5 min eine Messung durchgeführt. Hierbei wurde entlang einer Linie des LIM beim Belichtungszeitfaktor 7 (step) gemessen. Dies entspricht einer Frequenz von etwa $4464 \mathrm{~Hz}$. Um eine gute Bildqualität zu erreichen, musste mit 


\begin{tabular}{|c|c|c|}
\hline \multicolumn{3}{|c|}{ Natriumkanal-Blocker } \\
\hline Testsubstanz & [Testsubstanz] & [Duftstoff] \\
\hline \multirow{2}{*}{ TTX } & $100 \mathrm{nM}$ & $500 \mu \mathrm{M}$ \\
\hline & $500 \mathrm{nM}$ & $500 \mu \mathrm{M}$ \\
\hline \multicolumn{3}{|c|}{ Kalziumkanal-Blocker } \\
\hline Testsubstanz & [Testsubstanz] & [Duftstoff] \\
\hline \multirow{2}{*}{ Nifedipin } & $10 \mu \mathrm{M}$ & 500 \\
\hline & $25 \mu \mathrm{M}$ & $500 \mu \mathrm{M}$ \\
\hline \multicolumn{3}{|c|}{ Dopaminrezeptor-Agonist } \\
\hline Testsubstanz & [Testsubstanz] & [Duftstoff] \\
\hline \multirow{3}{*}{ Dopamin } & $10 \mu \mathrm{M}$ & $500 \mu \mathrm{M}$ \\
\hline & $25 \mu \mathrm{M}$ & $500 \mu \mathrm{M}$ \\
\hline & $50 \mu \mathrm{M}$ & $500 \mu \mathrm{M}$ \\
\hline \multicolumn{3}{|c|}{ D-2-Rezeptor-Antagonist } \\
\hline Testsubstanz & [Testsubstanz] & [Duftstoff] \\
\hline \multirow{2}{*}{ Sulpirid } & $10 \mu \mathrm{M}$ & $500 \mu \mathrm{M}$ \\
\hline & $25 \mu \mathrm{M}$ & $500 \mu \mathrm{M}$ \\
\hline \multicolumn{3}{|c|}{ D-2-Rezeptor-Agonist } \\
\hline Testsubstanz & [Testsubstanz] & [Duftstoff] \\
\hline \multirow{2}{*}{ Quinpirol } & $10 \mu \mathrm{M}$ & $500 \mu \mathrm{M}$ \\
\hline & $25 \mu \mathrm{M}$ & $500 \mu \mathrm{M}$ \\
\hline
\end{tabular}

Tabelle 2.2:

Tabellarische Übersicht über die verwendeten Testsubstanzen und deren Konzentrationen. Als Duftstoff fand eine Aminosäuremixtur in allen Versuchen Verwendung. 
sehr hohen Laserintensitäten gemessen werden.

\subsection{Versuchsauswertung}

Zur Auswertung der Kalzium-Imaging-Experimente am LSM wie auch LIM wurde Matlab (The MathWorks, Natick, USA) herangezogen. Hierbei handelt es sich um eine Software, mit welcher primär nummerische Berechnungen mit Hilfe von Matrizen durchgeführt werden können. Eingebunden in diese Software erfolgte die explizite Auswertung der Experimente mit matVis, einem in Matlab eingebundenen Skript, welches von Junek (Abteilung für Neurophysiologie und Zelluläre Biophysik, Universität Göttingen) entwickelt wurde.

Zur exakten Auswertung der LIM-Messungen (s. Kap. 2.4.2-2.4.3) wurde dabei eine ROI (engl.: Region of Intrest) auf den reaktiven Teil des Nerven gelegt. Die Antwortkurven wurden mittels eines kurzen Skripts auf die durchschnittliche Fluoreszenz der ersten 10 Bilder geeicht und der Fluoreszenzanstieg als prozentuale Abweichung von dieser Grundfluoreszenz dargestellt $(\delta F / F[\%])$.

Auch die Auswertung der LIM-Experimente (Messung der NLG, s. Kap. 2.4.4) erfolgte computergestützt mit der bereits erwähnten Matlab-Software. Zusätzlich zum matVis-Skript von Junek wurde von Diedrichs (Diedrichs 2011) und Alvera ein Skript zur Auswertung von Geschwindigkeitsexperimenten entwickelt (beide Abteilung Neurophysiologie und Zelluläre Biophysik, Universität Göttingen). Wie erwähnt, erfolgte die Messung entlang einer Linie parallel zum Nerven. Wenn eine regelrechte Ausbreitung des AP entlang eines Axons von anterior nach posterior postuliert wird, erscheint es logisch zwei ROIs zu platzieren. Jeweils eine ROI anterior und eine weitere posterior. Dabei sollte zunächst ein Fluoreszenzanstieg in der anterioren ROI zu beobachten sein, gefolgt von einem weiteren posterioren Anstieg. Ermittelt man nun den Abstand von ROI-Mitte zu ROI-Mitte $\delta s$ und berechnet den zeitlichen Versatz des Anstiegs $\delta t$ (genauer: bei genau der Hälfte des maximalen, auf 1 normierten, gaußgeglätteten Fluoreszenzanstiegs), erhält man über die allgemeinhin bekannte Gleichung $v=\delta s / \delta t$ die Geschwindigkeit $v$. 


\subsection{Immunhistochemische Färbungen}

Um die Wirkung von Dopamin im olfaktorischen Nerv strukturell zu visualisieren, wurden immunhistochemische Färbungen durchgeführt. Mit Antikörpern gegen Dopamin-2-Rezeptoren und Tyrosinhydroxylase sollte also eine signalverarbeitende Struktur wie auch ein charakteristisches Enzym der Dopaminsynthese nachgewiesen werden. Außerdem wurden Antikörper gegen Tubulin, ein Zytosklettbaustein von Neuronen, angewendet, um die Ergebnisse besser strukturell einordnen zu können. Dabei wurden unterschiedliche Verfahren gewählt, um die Präparate zur Färbung zu gewinnen. Zum einen das Agaroseblockschnitt-Verfahren (s. Kap. 2.6.2), zum anderen wurden Gefrierschnitte mit Hilfe eines Kryostaten erstellt (s. Kap. 2.6.1).

Weiterhin wurde zur weiteren strukturellen Visualisierung das Biocytin-BackfillVerfahren angewendet (s. Kap. 2.6.4).

\subsubsection{Gefrierschnitte}

Aus den Kaulquappen, die in Eiswasser anästhesiert und anschließend getötet wurden, wurde zunächst ein Gewebeblock herausgeschnitten, der beide Riechepithelien, Nerven und Bulbi olfactorii enthielt. Nach einstündiger Fixierung in Formaldehyd (Roti (C-histofix, CARL Roth, Karlsruhe, Deutschland) wurden die Blöcke in 30\%iger Saccharoselösung (Verdünnungsmedium: 0,1 M PBS) mindestens $12 \mathrm{~h}$ inkubiert. Anschließend wurden die Gewebeblöcke bei $-23^{\circ} \mathrm{C}$ am Kryostaten (LEICA MicroSystems, Wetzlar, Deutschland) in $30 \mu \mathrm{m}$ dicke Schichten geschnitten, diese auf einen beschichteten Objektträger überführt und gefärbt (s. Kap. 2.6.3).

\subsubsection{Agaroseschnitte}

Zunächst wurde ein Gewebeblock aus den in Eiswasser anästhesierten und anschließend durch Rückenmarksdurchtrennung getöteten Kaulquappen herausgeschnitten, welcher beide Riechepithelien, Nerven und die Bulbi olfactorii enthielt. Nach einstündiger Fixierung in 4\% Formaldehyd wurden die Gewebeblöcke in 5\%-ige Agarose überführt. Nach dem Erkalten dieser zu festen Blöcken, wurden mit Hilfe eines Vibratoms (Leica Microsystems, Wetzlar) aus diesen $70 \mu \mathrm{m}$ dicke horizontale Schnitte erstellt. Beim Schneiden der Agaroseblöcke befanden sich diese in einer mit Badlösung gefüllten Wanne. 


\begin{tabular}{lccc}
\hline Primärer Antikörper & Spezies & Konzentration & NGS-Block \\
\hline Anti-Dopamin-2-Rez. & Rabbit & $1: 500$ & $5 \%$ \\
Anti-Dopamin-2-Rez. & Rabbit & $1: 1000$ & $5 \%$ \\
Anti-Tyrosinhydroxylase & Rabbit & $1: 500$ & $2 \%$ \\
Anti-Tyrosinhydroxylase & Rabbit & $1: 1000$ & $2 \%$ \\
Anti-Tubulin & Rabbit & $1: 1000$ & $2 \%$ \\
\hline
\end{tabular}

\section{Tabelle 2.3:}

Übersicht über die Antikörperfärbungen. Verwendete Antikörper von MiLLIPORE, Schwalbach, Deutschland

\subsubsection{Durchführung der Färbung}

Die Schnitte vom Kryostaten und Vibratom wurden zunächst mit PBS-T (engl.: Phosphate Buffered Saline-Triton X-100) gewaschen. Der Zusatz des Detergens Triton X-100 (Octoxinol 9) zur regulären PBS-Lösung erfolgte, um die Zellmembran permeabel zu machen. Es folgte die Inkubation mit dem ersten Antikörper. Dieser bindet an sein spezifisches Antigen. Nach fünf Waschvorgängen wurde vor der Inkubation mit dem zweiten Antikörper eine PBS-T und NGS Lösung zugegeben (Blocklösung). Neben der schon oben beschriebenen Verwendung von Triton X-100, kam hier auch NGS (engl.: Normal Goat Serum, GIBCO, Victoria, Neuseeland) zum Einsatz. Dies blockiert unspezifische Bindungsstellen.

Es erfolgte nun die Zugabe des zweiten Antikörpers. Es wurden Alexa-Fluor-488Antirabbit (grün) oder Alexa-Fluor-546-Antirabbit (rot) verwendet (MOLECULAR Probes, Leiden, Niederlande). Sie binden an den ersten Antikörper und können durch ihre Kopplung an einen Farbstoff zum Fluoreszieren angeregt werden. Zur Zellkernfärbung erfolgte eine Zugabe von Propidium-Iodid (Molekular Probes, Leiden, Niederlande). Dies interkaliert in die DNA und kann deshalb genutzt werden, um Zellkerne sichtbar zu machen.

Abschließend wurden die nun vollständig gefärbten Gewebeschnitte mit Dako Fluorescence Mounting Medium (DAKO, Glostrup, Dänemark) eingedeckt. Zur Aufbewahrung wurden die Schnitte bei $4{ }^{\circ} \mathrm{C}$ eingelagert. Tabelle 2.3 gibt Auskunft über die verwendeten Antikörper, deren Mischverhältnisse und NGS-Block. 


\subsubsection{Biocytin-Backfill-Verfahren}

Das Biocytin-Backfill-Verfahren macht sich die besonders starke Bindung zwischen Biocytin und Streptavidin zunutze. Biocytin diffundiert gut durch Zellen und kann somit strukturelle Gegebenheiten der Zellen, in die es eingegeben wurde, sichtbar machen. Streptavidin, konjugiert an einen Farbstoff, bindet außerordentlich stark an Biocytin, was die Zugabe weiterer Antikörper erlaubt, da es zu keinen Überlagerungen mit der Biocytin-Streptavidin-Bindung kommt. Aus dieser Erkenntnis heraus können mittels des Biocytin-Backfill-Verfahrens die o.g. Antikörperfärbungen strukturell-topografisch eingeordnet werden. Das Verfahren wurde dabei wie folgt verwendet:

Xenopus laevis Kaulquappen wurden in Eiswasser anaesthesiert und die olfaktorischen Nerven mit einem Skalpell posterior eröffnet. Biocytin-Kristalle (MoLECULAR Probes, Leiden, Niederlande) wurden in die entstandene Wunde eingesetzt und diese anschließend mit Histoacryl-Kleber (B.BRAun, Melsungen, Deutschland) verschlossen. Nun wurden die Tiere zurück in Wasser überführt und für $2 \mathrm{~h}$ in Dunkelheit aufbewahrt. Nach dieser Zeit wurden die Tiere erneut in Eiswasser anaesthesiert und durch Schnitt in die Medulla oblongata getötet. Es erfolgte die Präparation eines Gewebeblocks, welcher beide Riechnerven und die jeweilige Mukosa enthielt. Anschließend wurden die Gewebeblöcke für eine Stunde in 4\% Formaldehyd (Roti@histofix, CARL Roth, Karlsruhe, Deutschland) überführt, in PBS (SIGMA-ALDRICH, Steinheim, Deutschland) gewaschen und in flüssige 5\%ige Agaroseblöcke (Sigma-Aldrich, Steinheim, Deutschland) eingebettet. Nach Aushärten der Agarose wurden die Blöcke, umspült von Badlösung, am Vibratom (LEICA MicroSystems, Wetzlar, Deutschland) in $70 \mu \mathrm{m}$ dicke Gewebeschichten geschnitten. Diese wurden anschließend mit PBS-T dreimal alle 10 min gewaschen und mit NGS und PBS-T für $1 \mathrm{~h}$ inkubiert. Nun wurde ein primärer Antikörper hinzugegeben und über Nacht bei $4{ }^{\circ} \mathrm{C}$ erneut inkubiert. Nach Ablauf dieser Zeit wurden die ungebundenen primären Antikörper (s. Tab. 2.3) mit PBS ausgewaschen und Streptavidin konjugiert mit Alexa-546 (Molecular Probes, Leiden, Niederlande) für $6 \mathrm{~h}$ hinzugegeben. Die Konzentration betrug $5 \mathrm{mg} / \mathrm{ml}$ in PBS-T. Nach durchlaufener Inkubationszeit wurde erneut dreimal alle 10 min gewaschen und dann der sekundäre Antikörper Alex-488-konjugiert-Anti-Rabbit (Molecular ProBes, Leiden, Niederlande) hinzugefügt. Es erfolgte eine weitere 2-stündige Inkubation und 


\begin{tabular}{lc}
\hline \multicolumn{2}{c}{ Badlösung } \\
Substanz & $\mathrm{mm}$ \\
\hline $\mathrm{NaCl}$ & 98 \\
$\mathrm{KCl}$ & 2 \\
$\mathrm{CaCl}_{2}$ & 1 \\
$\mathrm{MgCl}_{2}$ & 2 \\
$\mathrm{Glucose}$ & 5 \\
PyruvatNa & 5 \\
HEPES & 10 \\
\hline
\end{tabular}

Tabelle 2.4:

Zusammensetzung der für die Versuche verwendeten Badlösung.

abschließendes Auswaschen mit PBS dreimal alle 10 min. Abschließend wurden die nun vollständig gefärbten Gewebeschnitte mit Dako Fluorescence Mounting Medium (DAKO, Glostrup, Dänemark) eingedeckt. Zur Aufbewahrung wurden die Schnitte bei $4{ }^{\circ} \mathrm{C}$ eingelagert.

\subsection{Chemikalien}

\subsubsection{Badlösung}

Für die Gewebepräparationen und Experimente wurde folgende Lösung als Badlösung eingesetzt. Sie besitzt einen pH-Wert von 7,8 und eine Osmolarität von 225 mOsm. Die Badlösung wurde mit destilliertem Wasser hergestellt. Tabelle 2.4 stellt die Inhaltsstoffe dar. 


\subsubsection{Aminosäure-Mixtur}

Als Duftstoff wurde eine Aminosäure-Mixtur aus 19 Aminosäuren verwendet (s. Tab. 2.5).

\begin{tabular}{|l|c|}
\hline \multicolumn{2}{|c|}{ Aminosäure-Mix } \\
\hline Aminosäure & $\mathrm{mg}(10 \mathrm{ml})^{-1}$ \\
\hline \hline \multicolumn{1}{|c|}{ Neutrale Aminosäuren } \\
\hline L-Glycin & 0,75 \\
\hline L-Alanin & 0,89 \\
\hline L-Serin & 1,05 \\
\hline L-Threonin & 1,19 \\
\hline L-Cystein & 1,21 \\
\hline L-Asparagin & 1,32 \\
\hline L-Glutamin & 1,46 \\
\hline L-Valin & 1,17 \\
\hline L-Leucin & 1,31 \\
\hline L-Isoleucin & 1,31 \\
\hline L-Methionin & 1,49 \\
\hline L-Prolin & 1,15 \\
\hline \hline \multicolumn{2}{|c|}{ Basische Aminosäuren } \\
\hline L-Arginin & 2,10 \\
\hline L-Lysin & 1,83 \\
\hline L-Histidin & 2,10 \\
\hline \hline \multicolumn{2}{|c|}{ Saure Aminosäuren } \\
\hline L-Glutamat & 1,47 \\
\hline L-Aspartat & 1,33 \\
\hline \hline Aromatische Aminosäuren \\
\hline L-Tryptophan & 2,04 \\
\hline L-Phenylalanin & 1,65 \\
\hline
\end{tabular}

Tabelle 2.5:

Zusammensetzung der Aminosäure-Mixtur (AA-Mix). $1 \mathrm{mg} / 10 \mathrm{ml}$ entspricht dabei einer 10-mM-Stammlösung 
„Deshalb wirst du sehen wie schwierig es ist, bei den Düften / Aufzufinden den Ort, wo der Ursprung ist des Geruchs."

Von der Natur, Lukrez, ca. 97 - 55 v. Chr.

(vgl. Lukrez 1991, S. 210/Lukrez 50 v.Chr.)

\section{3 \\ Ergebnisse}

\subsection{Darstellung eines $\mathrm{I}_{\mathrm{Ca}^{2+}}$ im olfaktorischen Nerven infolge einer Aminosäurereizung}

Die in Abschnitt 2.4.2 beschriebene Methode führte zu einer guten Darstellung eines einwärtsgerichteten $\mathrm{I}_{\mathrm{Ca}^{2+}}$ infolge einer Reizung mittels Aminosäurelösung bei

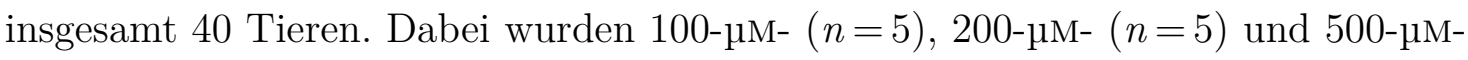
$(n=30)$ Aminosäurelösungen als Duftstoff verwendet (s. Abb. 3.2). Abbildung 3.1 veranschaulicht in einer Zeitserie, wie sich der Fluoreszenzanstieg unter dem Mikroskop darstellte.

Bei gelungener Erstzeizung waren die Reizungen reproduzierbar. Die minimalen Abweichungen in der Höhe der Maxima innerhalb der drei Testreihen waren nicht signifikant verschieden (s. Tab.3.1). Die beobachtet Zunahme der Maxima bei Erhöhung der Konzentration von $100 \mu \mathrm{M}$ auf $200 \mu \mathrm{M}$ war, wie die Zunahme auf $500 \mu \mathrm{M}$, statistisch nicht signifikant. Eine Erhöhung der Konzentration war also nicht mit einer größeren Amplitude verbunden. 


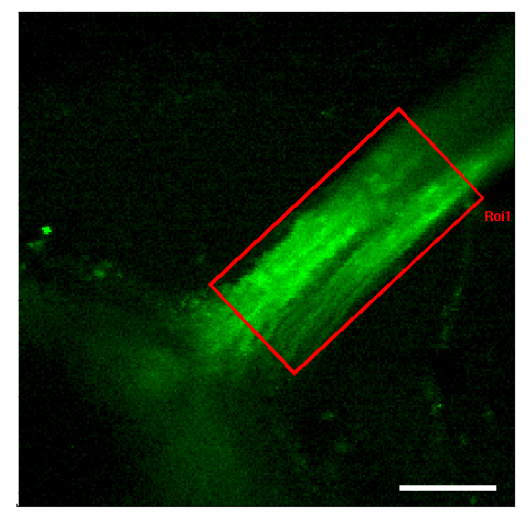

(a) Übersicht

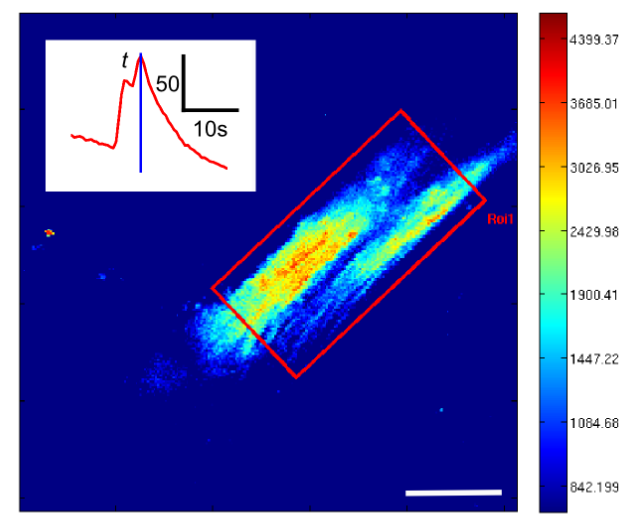

(c) $\mathrm{t}=13,5 \mathrm{~s}$

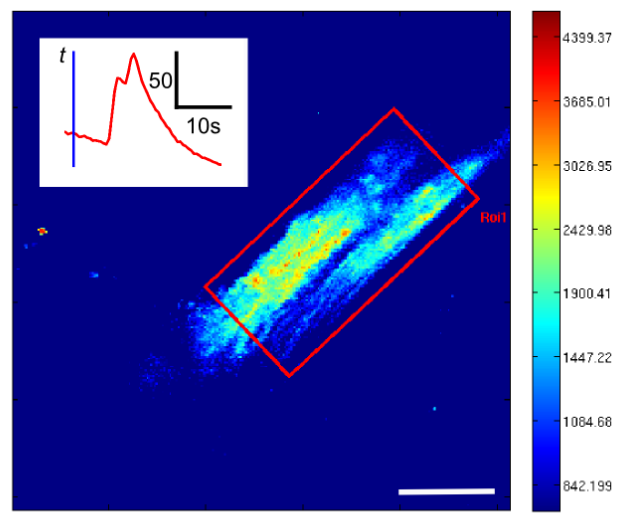

(b) $\mathrm{t}=2,5 \mathrm{~s}$

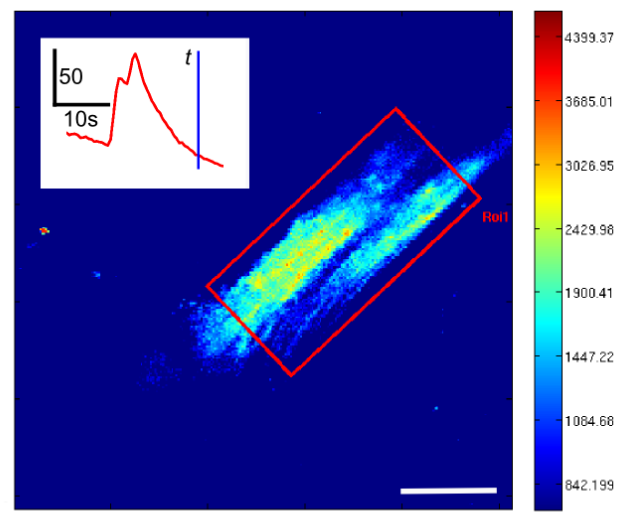

(d) $\mathrm{t}=25 \mathrm{~s}$

\section{Abbildung 3.1:}

Darstellung einer Übersichtsaufnahme, wie sie während der LSM-Messung zu sehen war (a), sowie eine Zeitserie zur Veranschaulichung des Fluoreszenzverhaltens (b,c,d). Es werden die Fluoreszenzen bei 2,5s (b), 13,5 s (c) und $25 \mathrm{~s}$ (d) gezeigt. Zur Orientierung ist oben links in (b) - (d) der relative Fluoreszenzanstieg dargestellt. Maßstabsleiste entspricht einer Länge von $70 \mu \mathrm{m}$. 


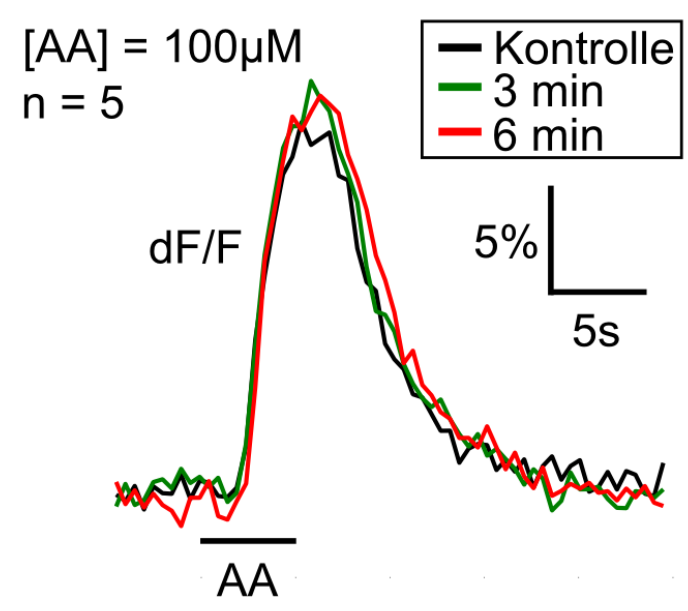

(a) $100 \mu \mathrm{M}$

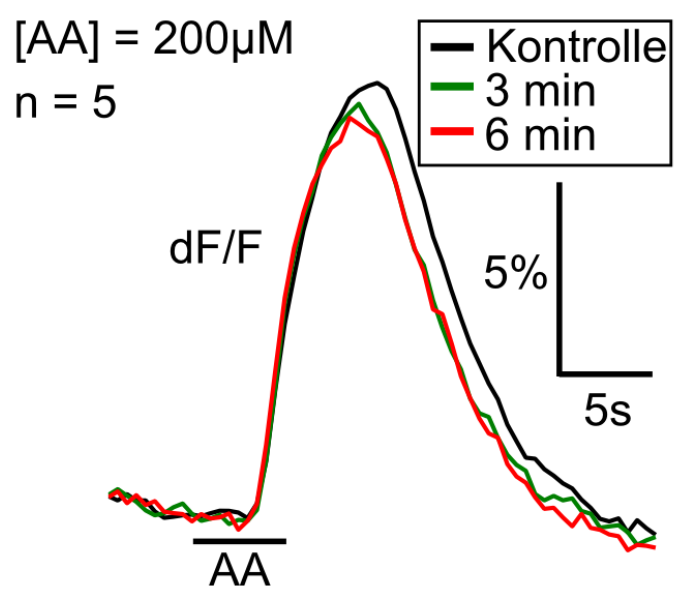

(b) $200 \mu \mathrm{M}$

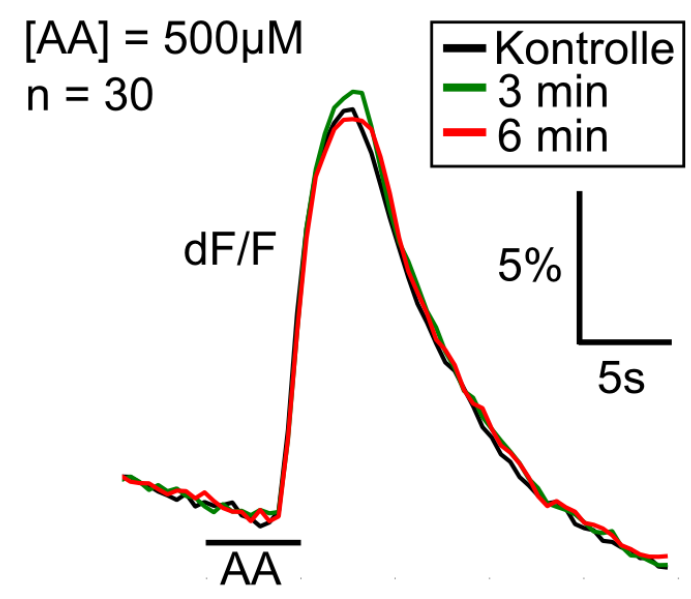

(c) $500 \mu \mathrm{M}$

\section{Abbildung 3.2:}

Darstellung der Antwortkurven für die drei verwendeten Konzentrationen

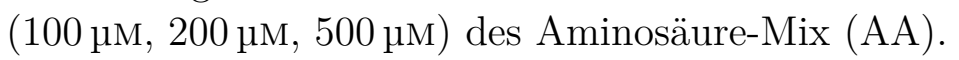




\begin{tabular}{l|ccc}
\hline AA-Konzentration & 100 & 200 & 500 \\
\hline \multirow{2}{*}{$\operatorname{Max}(K)[\%]$} & 5,80 & 6,35 & 8,21 \\
& $\pm 2,91$ & $\pm 3,06$ & $\pm 2,88$ \\
\hline \multirow{2}{*}{$\operatorname{Max}(3$ min $)[\%]$} & 5,68 & 6,23 & 8,037 \\
& $\pm 2,91$ & $\pm 3,04$ & $\pm 4,05$ \\
\hline \multirow{2}{*}{$\operatorname{Max}(6$ min $)[\%]$} & 5,65 & 6,56 & 8,94 \\
& $\pm 2,68$ & $\pm 2,32$ & $\pm 3,86$ \\
\hline \multirow{2}{*}{$t_{\operatorname{Max}(K)}[\mathrm{s}]$} & 11,43 & 11,65 & 13.95 \\
& $\pm 1,81$ & $\pm 0,54$ & $\pm 2,95$ \\
\hline \multirow{2}{*}{$t_{\operatorname{Max}(3 \min )}[\mathrm{s}]$} & 11,60 & 11,21 & 12.76 \\
\hline \multirow{2}{*}{$t_{\operatorname{Max}(6 \min )}[\mathrm{s}]$} & $\pm 1,61$ & $\pm 1,64$ & $\pm 3,71$ \\
\hline & 11,30 & 11,24 & 13,66 \\
& $\pm 1,58$ & $\pm 3,06$ & $\pm 3,06$ \\
\hline
\end{tabular}

Tabelle 3.1:

Mittelwerte und Standardabweichung der Maxima der Fluoreszenzänderung $(\operatorname{Max})$ sowie der zeitlichen Lage der Maxima $\left(t_{M A X}\right)$.

\subsubsection{Einfluss des $\mathrm{Na}^{+}$-Kanal-Blockers TTX}

Zur weiteren Charakterisierung des $\mathrm{I}_{\mathrm{Ca}^{2+}}$ wurde dessen Verhalten bei unterschiedlichen Konzentrationen von Tetrodotoxin (TTX) bei sechs Tieren untersucht (s. Tab. 3.2). Hierbei kam es bei der Verwendung geringer Konzentrationen von $250 \mathrm{~nm}$ $(n=3)$ zur Reduktion des $\mathrm{I}_{\mathrm{Ca}^{2+}}$ hin zu einer Bleichkurve. Dieses Ergebnis konnte für 500-nM-TTX-Lösungen $(n=3)$ wiederholt werden. Es wurde eine Reduktion der Amplitude um $\bar{x}$ 101, $65 \pm 7,67 \%$ für 250-nM- und um $\bar{x} 108,36 \pm 5,11 \%$ für 500-nM-TTX-Lösungen beobachtet. Es zeigten sich keine Veränderungen bezüglich Latenz, Anstieg, Plateau-Dauer und Rückbildungsform (s. Abb. 3.3 (a)-(b)).

Weiterhin konnte die Reversibilität der TTX-Bindung für die beiden verwendeten Konzentrationsstufen belegt werden. In $100 \%$ der Fälle konnte eine Wash-OutKurve gezeigt werden, welche sich durch eine mindestens $50 \%$ ige Steigerung zur vorherigen Messung unter Drogeneinfluss auszeichnete (s. Tab. 3.2).

\subsubsection{Einfluss des L-Typ-Ca ${ }^{2+}-$ Kanal-Blockers Nifedipin}

Hinsichtlich der Beteiligung von $\mathrm{Ca}^{2+}$-Kanälen an einem $\mathrm{I}_{\mathrm{Ca}^{2+}}$ wurden Experimente unter Verwendung von Nifedipin bei sechs Tieren durchgeführt $(n=6)$. Es wur- 


\begin{tabular}{lcccc}
\hline & \multicolumn{2}{c}{$\mathrm{Na}^{+}$-K-Blocker } & \multicolumn{2}{c}{$\mathrm{Ca}^{2+}$-K-Blocker } \\
Droge & \multicolumn{2}{c}{ TTX } & \multicolumn{2}{c}{ Nifedipin } \\
\hline Konz. $[\mu \mathrm{M}]$ & 0,25 & 0,5 & 15 & 25 \\
$n$ & 2 & 2 & 2 & 2 \\
$\bar{x}(\mathrm{~A} \Downarrow)[\%]$ & 101,65 & 108,36 & 86,87 & 26,04 \\
$\sigma(\mathrm{A} \Downarrow)[\%]$ & 7,67 & 5,11 & 4,17 & 10,01 \\
pos. WO $[\%$ d. F. $]$ & 100 & 100 & 100 & 0 \\
\hline
\end{tabular}

\section{Tabelle 3.2:}

Darstellung der verwendeten Kanalblocker, Konzentrationen und deren Effekt bezüglich der Amplitudenreduktion $(\mathrm{A} \Downarrow)$. Angegeben sind die Mittelwerte $\bar{x}$ und die Standardabweichung $\sigma$. Weiterhin ist dargestellt, in wie viel Prozent der Fälle (\% d. F.) ein positives Wash-Out-Verhalten (pos. WO) vorgelegen hat.

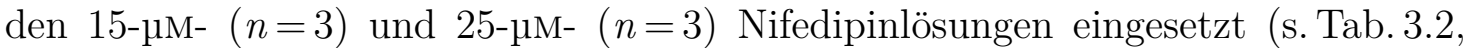

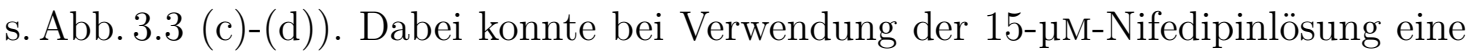
Amplitudenreduktion von $\bar{x} 86,87 \pm 4,17 \%$ nachgewiesen werden. Bei einer 25- $\mu \mathrm{M}-$ Lösung zeigte sich eine Amplitudenreduktion von $\bar{x}$ 26, $04 \pm 10,01 \%$. Unabhängig von der eingesetzten Konzentration erfolgte also keine vollständige Auslöschung des $\mathrm{I}_{\mathrm{Ca}^{2+}}$, d.h. ein Rest- oder auch Leckstrom $\left(\mathrm{I}_{\mathrm{Ca}^{2+}}^{\mathrm{L}}\right)$ verblieb. Es zeigten sich keine eindeutigen Veränderungen bezüglich Latenz, Anstieg, Plateau-Dauer und Rückbildungsform der Kalziumantwortkurven.

Wash-Out-Kurven wurden als positiv bewertet, sobald eine Steigerung der Amplitude nach Beendigung der Drogenapplikation um mindestens 50\% erfolgte. Unter Berücksichtigung dieser Vorschrift war die Applikation von 15- $\mu \mathrm{M}$-Nifedipinlösung

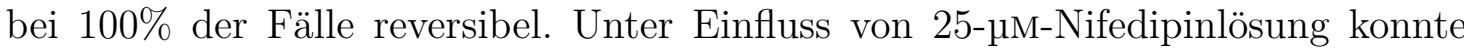
hingegen kein Versuch diese Vorschrift erfüllen. 


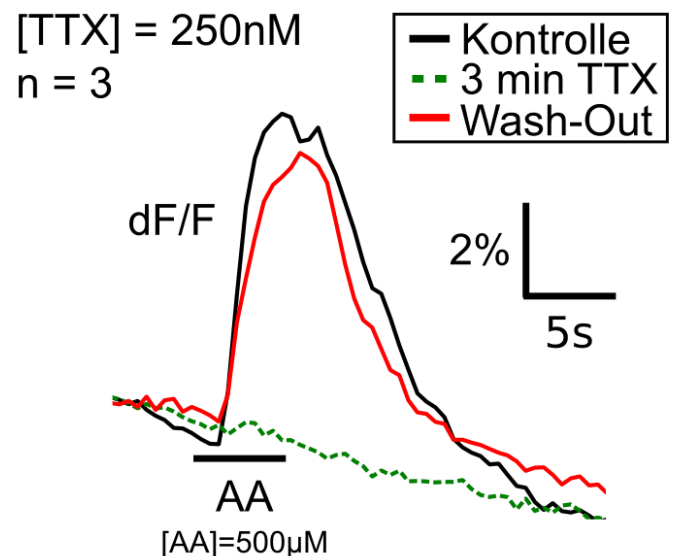

(a) $250 \mathrm{~nm}$ TTX

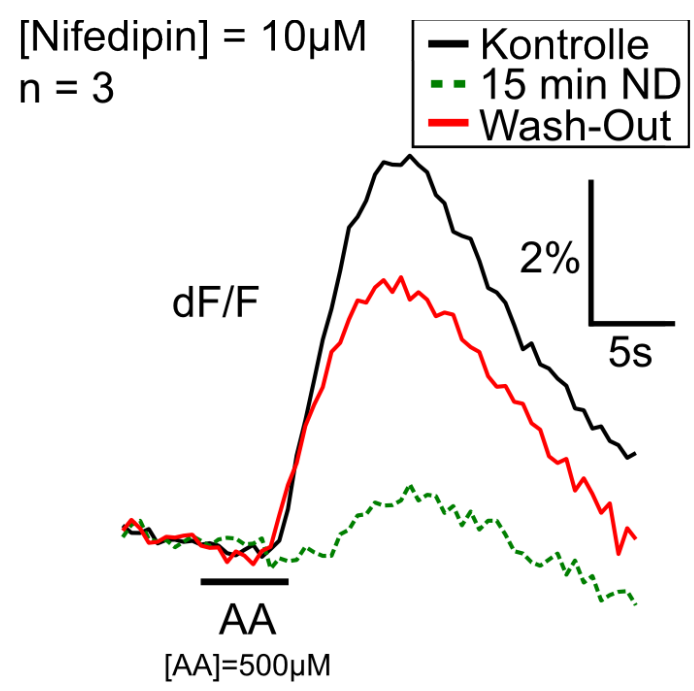

(c) $10 \mu \mathrm{M}$ Nifedipin

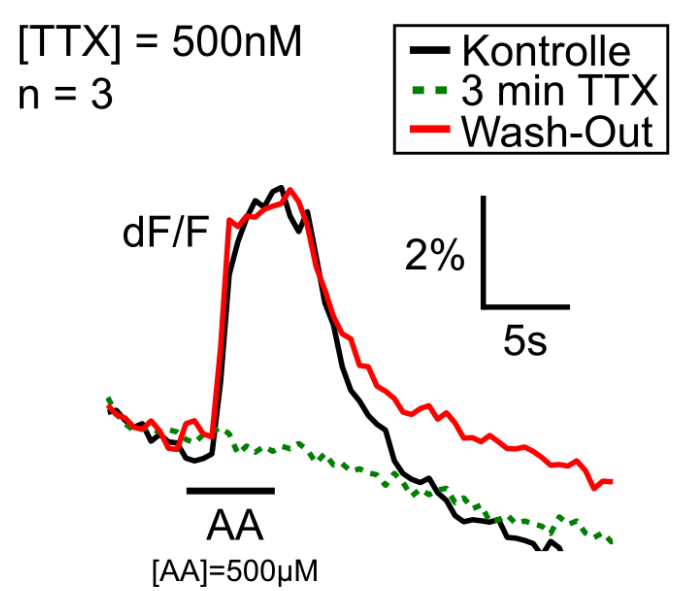

(b) $500 \mathrm{~nm}$ TTX
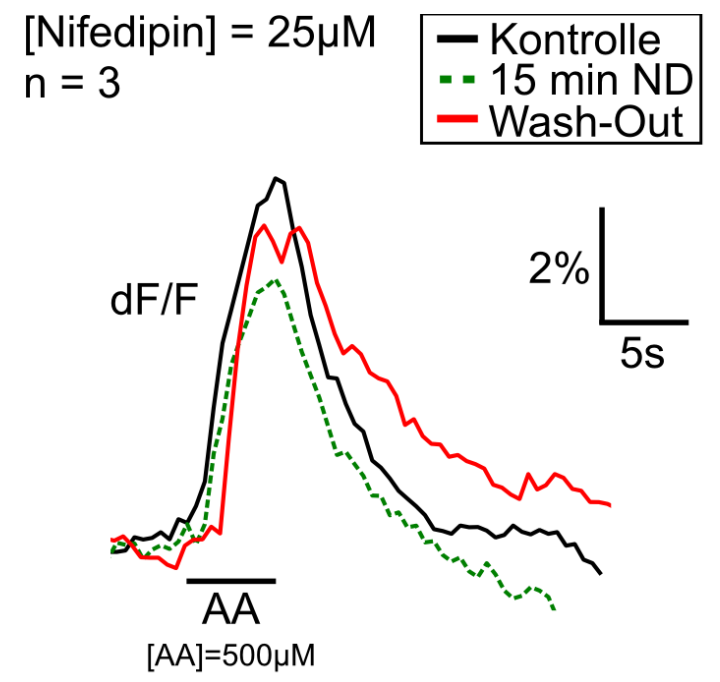

(d) $25 \mu \mathrm{M}$ Nifedipin

\section{Abbildung 3.3:}

Effekt von 250-nM- und 500-nM- Tetrodotoxinlösung [TTX; (a),(b)] sowie von

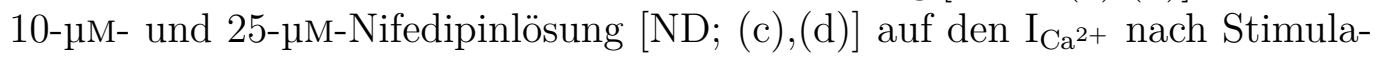
tion mittels Aminosäurelösung (AA). 
3 Ergebnisse

\begin{tabular}{lccccc}
\hline Droge & \multicolumn{3}{c}{ Dopamin } & \multicolumn{3}{c}{ Quinpirol } \\
Konz. $[\mu \mathrm{M}]$ & 15 & 25 & 50 & 25 & 100 \\
\hline$n$ & 5 & 5 & 5 & 2 & 2 \\
$\bar{x}(\mathrm{~A} \Downarrow)[\%]$ & 49,18 & 54,66 & 29,93 & 36,70 & 31,55 \\
$\sigma(\mathrm{A} \Downarrow)[\%]$ & 24,69 & 19,65 & 22,85 & 8,69 & 10,04 \\
pos. WO [\% d. F.] & 40 & 60 & 60 & 0 & 0 \\
\hline
\end{tabular}

\section{Tabelle 3.3:}

Dargestellt sind die verwendeten Dopamin- und Quinpirolkonzentrationen, die Stichprobengröße $(n)$, mittlerer Effekt auf die Amplitude $(\bar{x}(\mathrm{~A} \Downarrow))$ und die dazugehörige Standardabweichung $\sigma$. Zusätzlich ist ersichtlich, in wie viel Prozent der Fälle (\% d.F.) ein positives Wash-Out-Verhalten (WO pos.) vorgelegen hat.

\subsection{Dopaminerge Modulation des nervalen $\mathrm{I}_{\mathrm{Ca}^{2+}}$}

Unter den in Kapitel 2.4.3 beschriebenen Bedingungen wurde 15 Tiere untersucht, ob die Droge Dopamin einen Einfluss auf den $\mathrm{I}_{\mathrm{Ca}^{2+}}$ im olfaktorischen Nerven hat. Konzentrationen von $15 \mu \mathrm{M}(n=5), 25 \mu \mathrm{M}(n=5), 50 \mu \mathrm{M}(n=5)$ fanden Verwendung.

Unter allen verwendeten Konzentrationen ließ sich ein inhibitorischer Effekt auf den $\mathrm{I}_{\mathrm{Ca}^{2+}}$ beobachten (s. Abb.3.4). So konnte bei der niedrigsten Konzentration (15 $\mu \mathrm{M})$ eine Reduktion der Amplitude um $\bar{x}$ 49, $18 \pm 24,69 \%$ nachgewiesen werden (s. Tab.3.3). In $40 \%$ der Fälle gelang hier ein Wash-Out gemäß den schon zuvor definierten Regeln (s. Kap. 3.1.2).

Für die Konzentrationsstufen $25 \mu \mathrm{M}$ und $50 \mu \mathrm{M}$ lag ein positiver Wash-Out in $60 \%$ der Fälle vor. Auch hier gelang der Nachweis einer Amplitudenreduktion

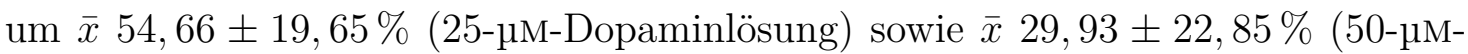
Dopaminlösung, s.Tab. 3.3).

Veränderungen der Latenz der Antwort, sowie Unterschiede in der $\mathrm{I}_{\mathrm{Ca}^{2+}-\mathrm{Kurve}}$ bezüglich Steilheit des Aufstiegs, Plateau-Dauer oder aber Form der Rückbildung traten nicht auf. Eine chronologische Korrelation des Effekts, wie Abbildung 3.4 (a) darstellt, ließ sich nicht in allen Fällen herstellen. 


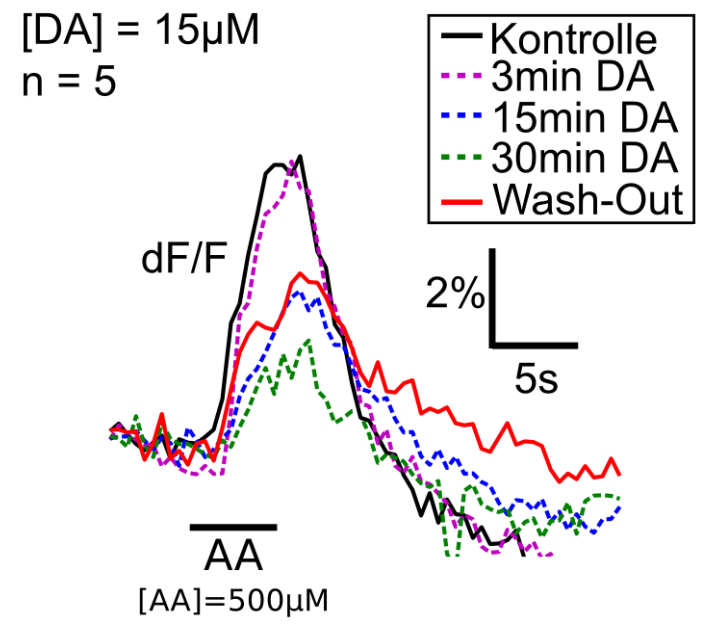

(a) Zeitverlauf

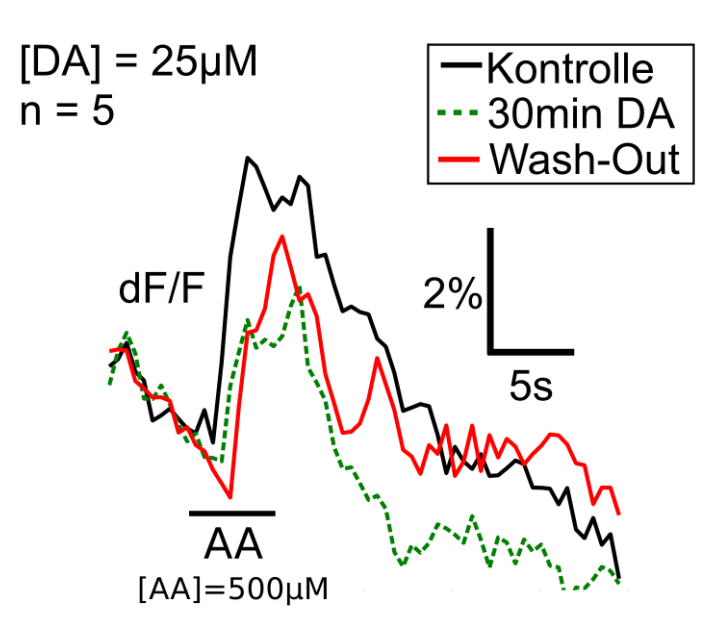

(c) $25 \mu \mathrm{M}$

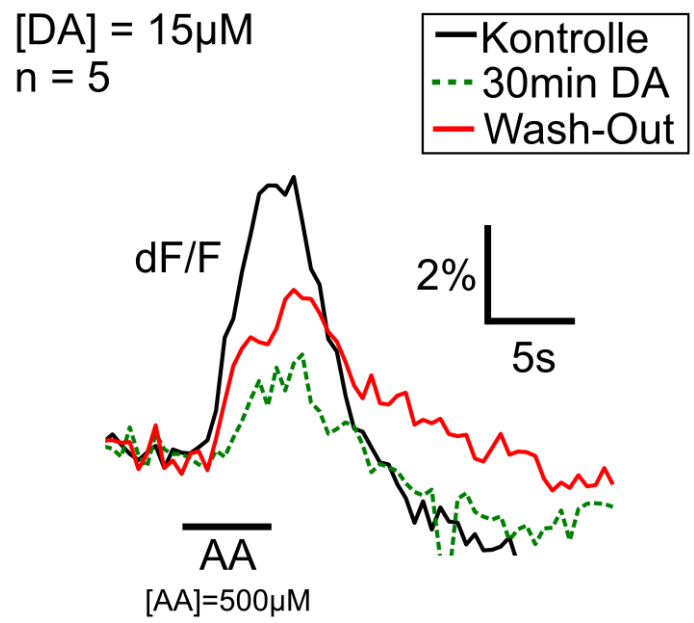

(b) $15 \mu \mathrm{M}$

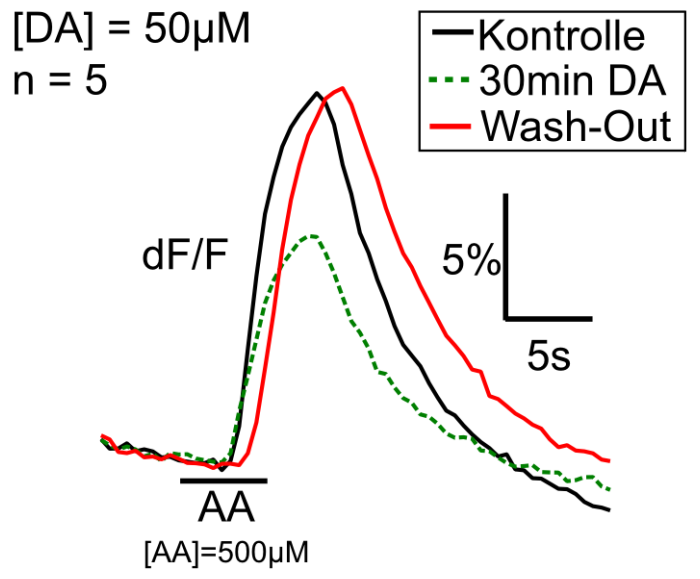

(d) $50 \mu \mathrm{M}$

\section{Abbildung 3.4:}

Darstellung der Dopamin(DA)-Modulationsexperimente. (a) zeigt den ausführlichen Zeitverlauf des inhibitorischen Effekts exemplarisch für eine 151M-Dopaminkonzentration. Die Kurven (b)-(c) stellen den Effekt jeweils nach

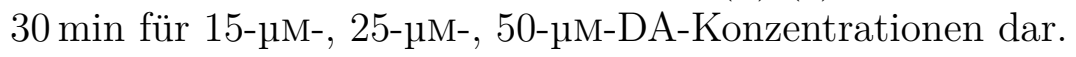




\subsubsection{Modulation mittels $\mathrm{D}_{2}$-Rezeptoragonist Quinpirol}

Quinpirol ist ein Agonist am $\mathrm{D}_{2}$-Rezeptor. In dieser Versuchsreihe wurde er an 4

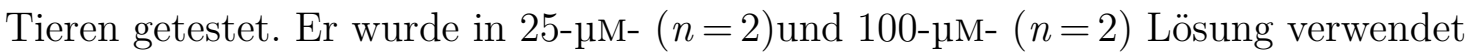
(s. Tab. 3.3). Er zeigte einen amplitudenreduzierenden Effekt (s. Abb. 3.5, a - b). So wurde eine Reduktion der Amplitude um $\bar{x} 36,70 \pm 8,69 \%$ bei Verwendung einer

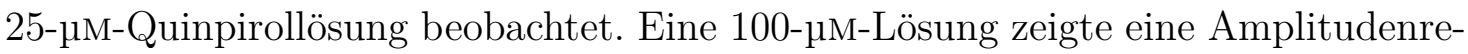
duktion um $\bar{x} 31,55 \pm 10,04 \%$. Anstiegsform und Latenzzeit blieben unverändert. Ein Wash-Out war nicht möglich.

\subsubsection{Modulation mittels $\mathrm{D}_{2}$-Rezeptorantagonist Sulpirid}

Sulpirid gilt als ein Antagonist am $\mathrm{D}_{2}$-Rezeptor. In dieser Versuchsreihe wurde er an vier Tieren getestet $(n=4)$. Er wurde wie in Kapitel 2.4.3 beschrieben nach 15-minütiger Dopaminapplikation $(50 \mu \mathrm{M})$ hinzugegeben. Es kamen dabei 100- $\mu \mathrm{M}-$ $(n=2)$ und 400- $\mu \mathrm{M}-(n=2)$ Sulpiridlösungen zum Einsatz. Die Dopaminlösung zeigte dabei eine Amplitudenreduktion von $\bar{x} 82,76 \pm 7,45 \%$. Unter anschließender Applikation von Sulpirid kam es zu einer Zunahme der Amplitude um $\bar{x}$ 215, $83 \pm$

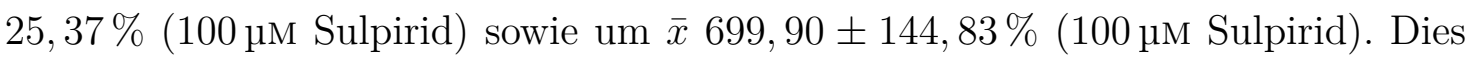

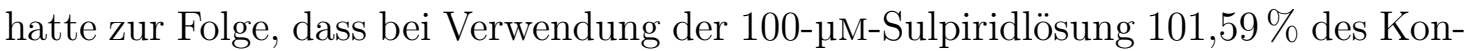
trollsignals und bei Versuchen mit der 400-pM-Sulpiridlösung 56,20\% wiederhergestellt wurden.

Veränderungen der Latenz der Antwort, sowie Unterschiede in der $\mathrm{I}_{\mathrm{Ca}^{2+}}$-Kurve bezüglich Steilheit des Aufstiegs, Plateau-Dauer oder aber Form der Rückbildung traten nicht auf (s. Abb. 3.5, c-d).

\section{3 Änderungen der Nervenleitgeschwindigkeit unter Dopaminapplikation}

Zur Bestimmung der Nervenleitgeschwindigkeit unter Einfluss von Dopamin erfüllten in dieser Versuchsreihe vier Tiere die im Kapitel 2.4.4 (S. 37) beschriebenen Bedingungen. Die Auswertung ergab den dargestellten Boxplot (s. Abb. 3.6). In diesem kann die Tendenz zur Zunahme der Nervenleitgeschwindigkeit beobachtet werden. Die kleine Stichprobengröße $(n=4)$ ließ hingegen keine abschließende Beurteilung 


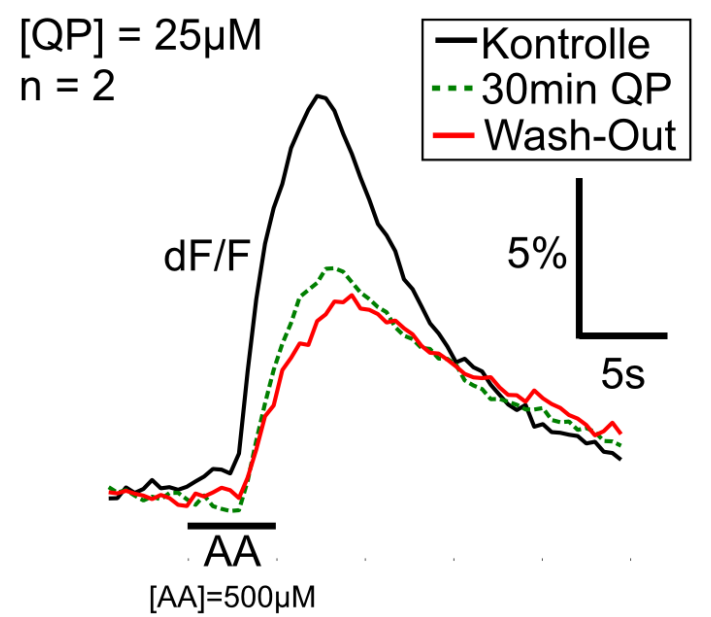

(a) Quinpirol, $25 \mu \mathrm{M}$

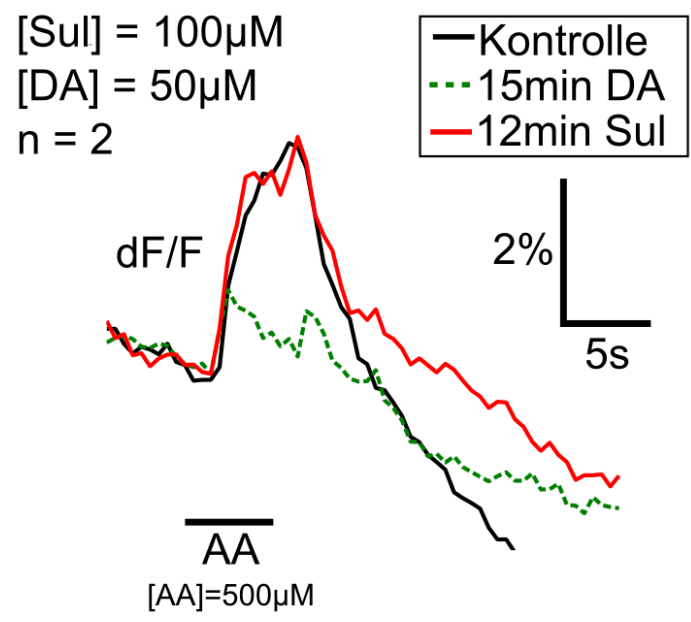

(c) Sulpirid, $100 \mu \mathrm{M}$

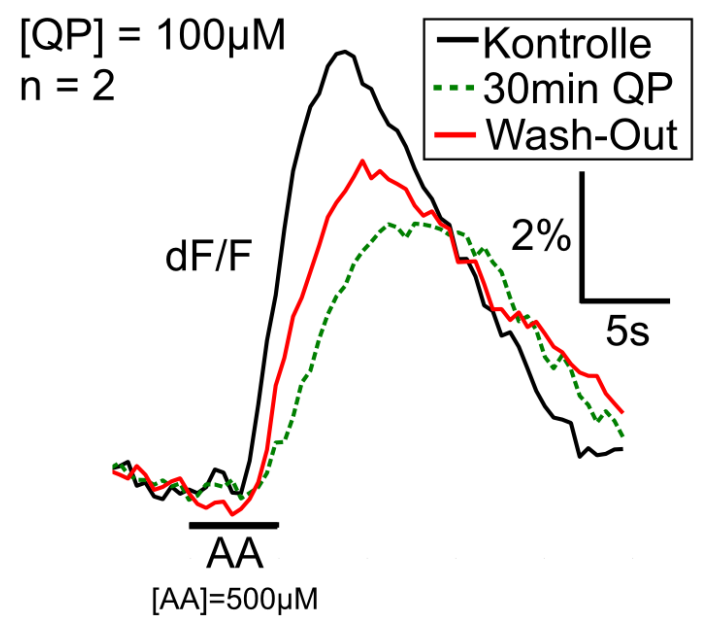

(b) Quinpirol, $100 \mu \mathrm{M}$

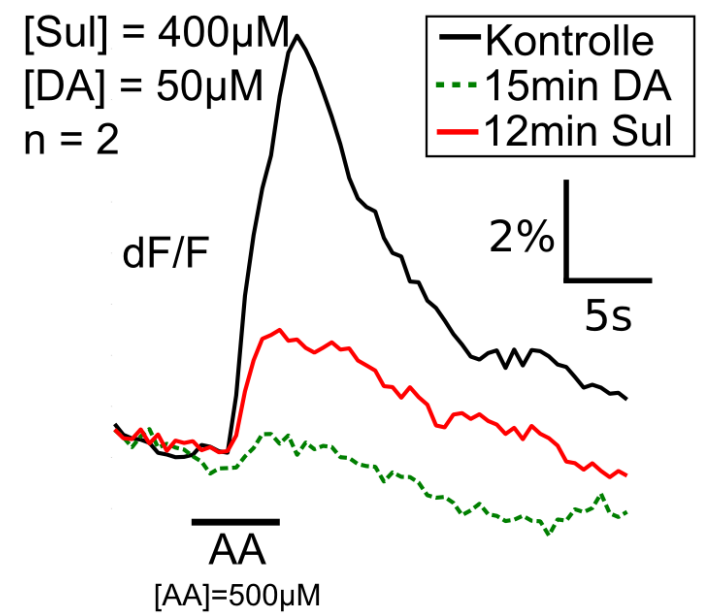

(d) Sulpirid, $400 \mu \mathrm{M}$

\section{Abbildung 3.5:}

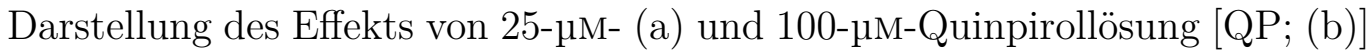

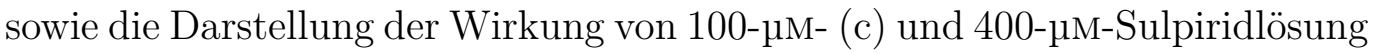
[Sul; (d)] auf den $\mathrm{I}_{\mathrm{Ca}^{2+}}$. 


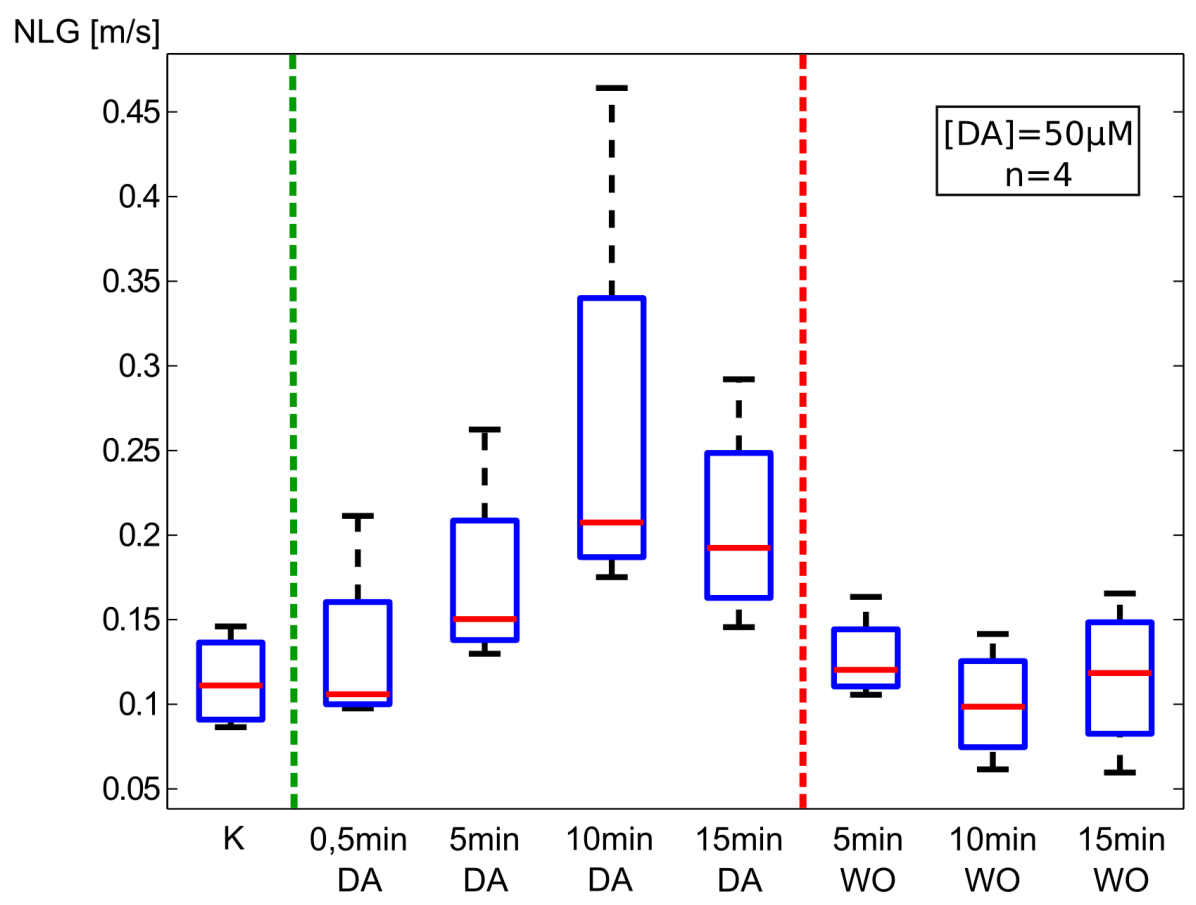

\section{Abbildung 3.6:}

Boxplot der Messungen der Nervenleitgeschwindigkeit (NLG).

Erläuterung: grün, gestrichelt $=$ Beginn DA-Applikation; rot, gestrichelt $=$ Beginn des Auswaschen mit Badlösung; $\mathrm{DA}=$ Dopamin; $\mathrm{K}=$ Kontrollmessung; $\mathrm{WO}=$ Wash-Out .

\begin{tabular}{ccccccccc}
\hline & $\mathrm{K}$ & \multicolumn{3}{c}{ DA-Wirkdauer } & \multicolumn{3}{c}{ Dauer Auswaschen } \\
& $0 \mathrm{~min}$ & $0,5 \mathrm{~min}$ & $5 \mathrm{~min}$ & $10 \mathrm{~min}$ & $15 \mathrm{~min}$ & $5 \mathrm{~min}$ & $10 \mathrm{~min}$ & $15 \mathrm{~min}$ \\
\hline $\operatorname{MD}[\mathrm{m} / \mathrm{s}]$ & 0,111 & 0,106 & 0,150 & 0,207 & 0,192 & 0,120 & 0,098 & 0,119 \\
$\bar{x}[\mathrm{~m} / \mathrm{s}]$ & 0,114 & 0,130 & 0,173 & 0,264 & 0,206 & 0,120 & 0,100 & 0,116 \\
$\sigma[\mathrm{m} / \mathrm{s}]$ & 0,028 & 0,054 & 0,060 & 0,135 & 0,062 & 0,025 & 0,034 & 0,045 \\
\hline
\end{tabular}

\section{Tabelle 3.4:}

Tabelle der gemessenen Nervenleitgeschwindigkeiten (NLG) bzw. deren Mittelwerte $(\bar{x})$, Standardabweichungen $(\sigma)$ und Mediane (MD). 
hinsichtlich der Signifikanz der Ergebnisse zu.

Die Kontrollmessungen ergaben einen Mittelwert von $\bar{x}$ 0, $11 \pm 0,03 \mathrm{~ms}$ (s. Tab. 3.4). Interessanterweise korrelierte der Effekt mit der Dauer der Einwaschzeit von Dopamin bis $10 \mathrm{~min}$. Bei $15 \mathrm{~min}$ indes, lag die gemessene Nervenleitgeschwindigkeit wieder auf dem Niveau der Messung zum Zeitpunkt 5 min.

Nach Auswertung des Wash-Out blieb festzustellen, dass der dopaminerge Effekt reversibel war. Die Kontrollmittelwerte wurden in den letzten Messungen - bei etwas größerer Standardabweichung - annähernd wieder erreicht.

\subsection{Ergebnisse der immunhistochemischen Färbungen}

Ziel der Durchführung von spezifischen Antikörperfärbungen war es, $\mathrm{D}_{2}$-Rezeptoren und ein spezifisches Enzym des Dopaminstoffwechsels, die Tyrosinhydroxylase (TH), nachzuweisen.

\subsection{1 $\mathrm{D}_{2}$-Rezeptor-Färbung}

In den Auswertungen der durchgeführten Färbungen stellten sich $\mathrm{D}_{2}$-Rezeptor im olfaktorischen Nerven von Xenopus-laevis-Larven dar. In Abbildung 3.7, in der die $\mathrm{D}_{2}$-Rezeptoren mittels Sekundärantikörper grün markiert worden sind, wird deutlich, dass eine exakte Zuordnung zu Gliazellen oder Neuronen nicht möglich war. Die $\mathrm{D}_{2}$-Rezeptoren präsentierten sich hier als im Nerven global verteilte Rezeptorklasse.

Eine durchgeführte Negativkontrolle, bei der $\mathrm{D}_{2}$-Rezeptor-Kontrollpeptid vor Zugabe der primären und sekundären Antikörper den Präparaten beigemengt wurde, zeigte keine Anfärbungen (s. Abb. 3.7, d). 


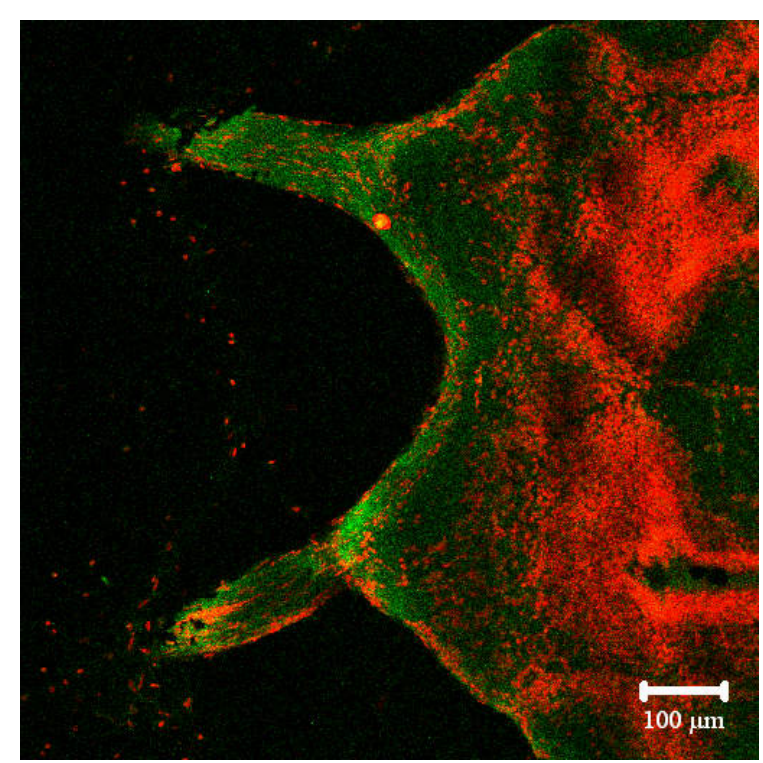

(a) Übersicht

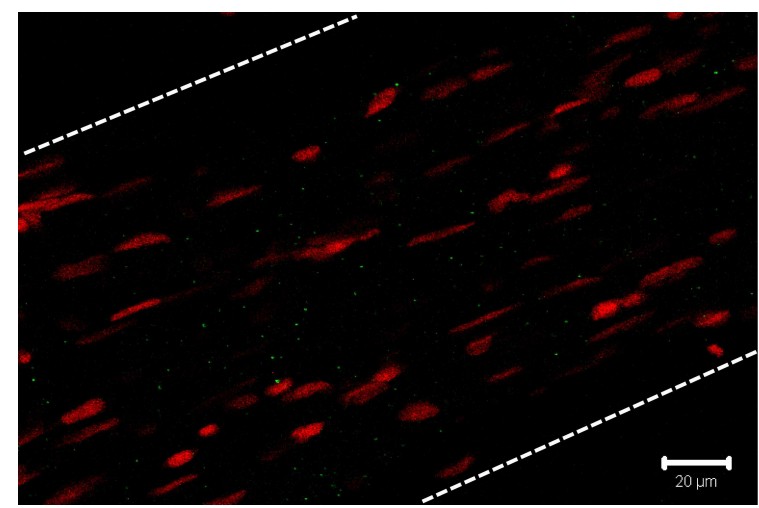

(c) $\mathrm{ON}$

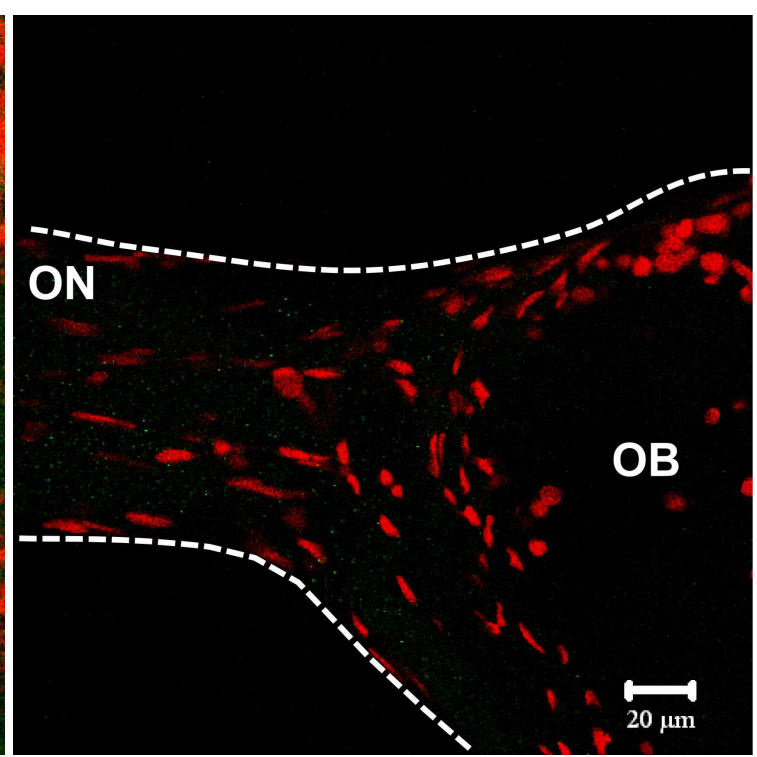

(b) ON, Übergang OB

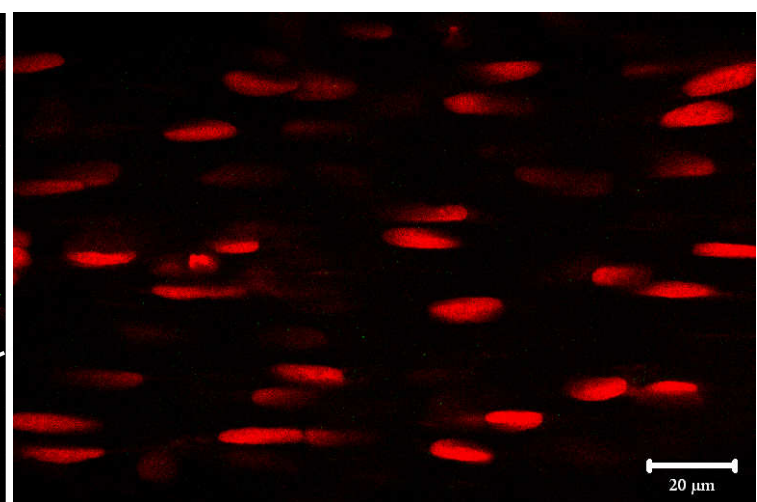

(d) Kontrolle

\section{Abbildung 3.7:}

$\mathrm{D}_{2}$-Rezeptor-Antikörperfärbung: $\quad \mathrm{D}_{2} \mathrm{R} \quad$ (grün), Zellkerne gefärbt mit Propidium-Iodid (rot). (a) zeigt eine Übersicht in der beide olfaktorischen Nerven $(\mathrm{ON})$ und deren Eintritt ins Gehirn sichtbar sind. (b) zeigt den Übergang des $\mathrm{ON}$ in den Bulbus olfactorius (OB). Eine detailliertere Aufnahme des $\mathrm{ON}$ (c) veranschaulicht ein deutliches Auftreten von $\mathrm{D}_{2} \mathrm{R}$. (d) zeigt die Kontrollmessung, der ein $\mathrm{D}_{2} \mathrm{R}$-Kontrollpeptid hinzugefügt wurde. Hier erfolgte keine Anfärbung. 


\subsection{Tyrosinhydroxylase-Färbung}

Auch die Tyrosinhydroxylase konnte im olfaktorischen Nerven immunhistochemisch nachgewiesen werden. Anders allerdings als der $\mathrm{D}_{2}$-Rezeptor, ist diese nicht global im olfaktorischen Nerv nachweisbar, sondern begrenzt auf die olfaktorische Glia.

Ein Biocytin-Backtrace bestätigte, dass Tyrosinhydroxylase nicht in Neuronen vorzufinden ist (s. Abb. 3.8, d-f). Hierbei wurden Neurone, mittels dieses Verfahrens, deutlich rot angefärbt. Es gab keine Überlagerung zur TH-Färbung (grün). Auch eine Doppelfärbung, in der, neben TH-Antikörpern, Antikörper gegen Tubulin eingesetzt wurden, ergab keine örtliche Überschneidung (s. Abb.3.8, g-i). Angemerkt sei, dass Tubulin ein Bestandteil von Neuronen ist. In Zusammenschau dieser beiden Methoden lässt sich also feststellen, dass die Tyrosinhydroxylase nicht in Neuronen vorliegt.

Zur genaueren Lokalisation wurden in einer weiteren Färbung Zellkerne im olfaktorischen Nerv, mittels Propidium-Iodid, rot gefärbt (s. Abb. 3.8, a-c). Diese Zellkerne gehören zur olfaktorischen Glia. Die Tyrosinhydroxylase wurde grün markiert. Auch hier gab es keine Überlagerung zur Zellkernfärbung. Allerdings zeigte sich die Tyrosinhydroxylase zellkernnah und scheint sich in Fortsätzen hiervon auszubreiten. Ein ähnliches Verteilungsmuster innerhalb des Nervens zeigte sich schon in den zuvor genannten Färbungen.

Somit lässt sich schlussfolgern, dass die Tyrosinhydroxylase in den olfaktorischen Gliazellen vorliegt und nicht in den Neuronen des olfaktorischen Nerven. 


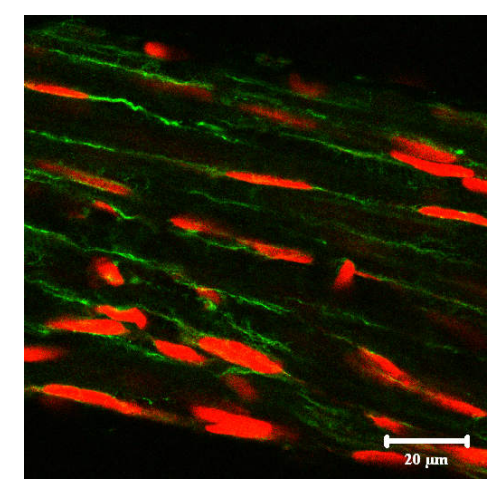

(a) $\mathrm{TH}+\mathrm{PI}$

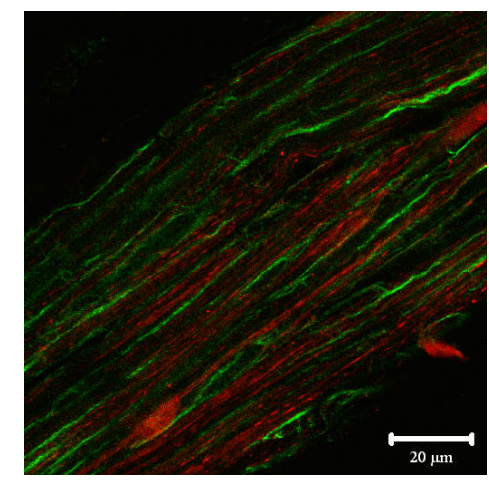

(d) $\mathrm{TH}+\mathrm{BT}$

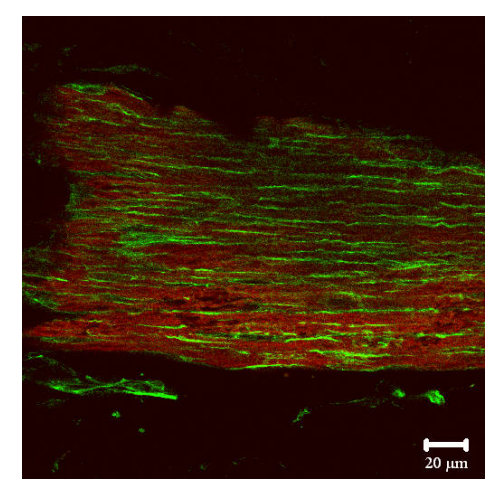

(g) $\mathrm{TH}+\mathrm{TUB}$

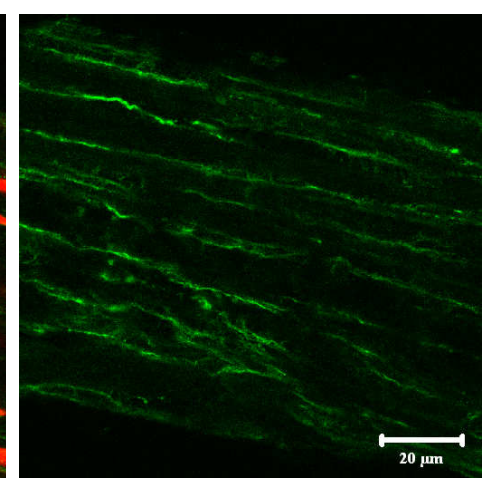

(b) $\mathrm{TH}$

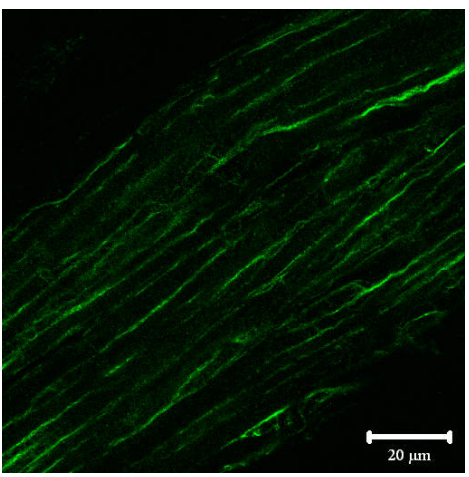

(e) $\mathrm{TH}$

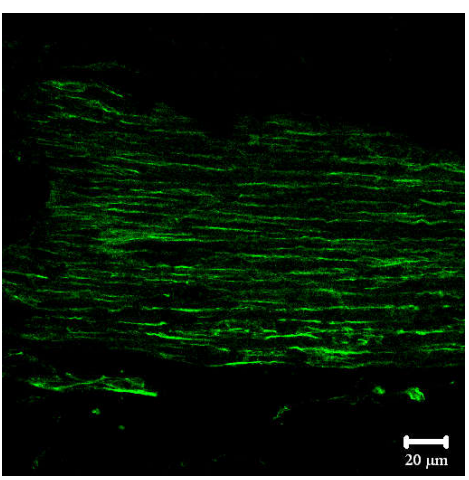

(h) $\mathrm{TH}$

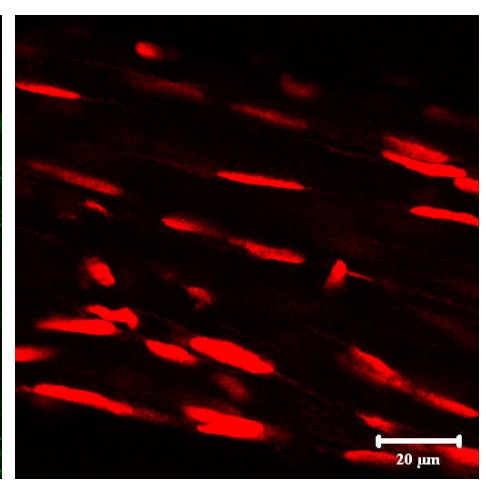

(c) PI

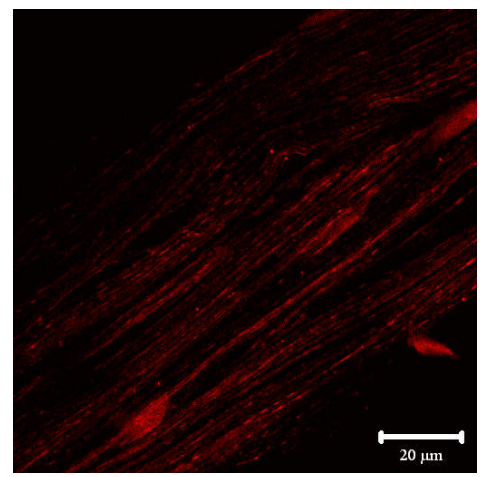

(f) BT

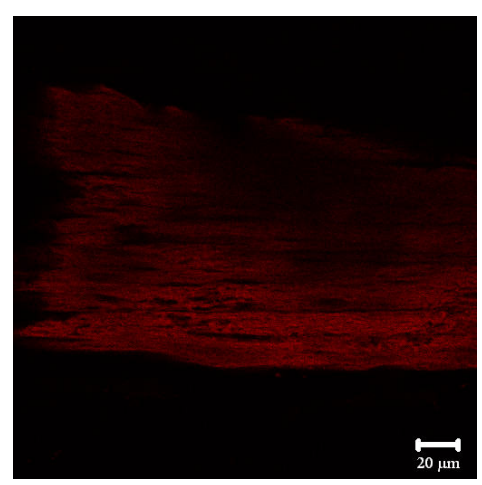

(i) TUB

\section{Abbildung 3.8:}

Übersicht über die Tyrosinhydroxylasefärbungen: In allen Färbungen erscheint die Tyrosinhydroxylase (TH) grün. In (a)-(c) wurde zusätzlich Propidium-Iodid (PI) verwendet, das spezifisch Zellkerne rot färbt. In (d) - (f) wurde zusätzlich zur TH-Färbung ein Biocytin-Backtrace (BT) durchgeführt, indem Neurone sich rot darstellen. In (g) - (i) wurde neben der TH-Färbung eine Antikörperfärbung gegen Tubulin (TUB, rot) durchgeführt, die ebenfalls spezifisch Neurone anfärbt. 
„Die durch den Geruch gewonnene Erkenntnis bleibt immer unabgeschlossen, gleichsam unterwegs [...]"

Tasten, Riechen, Schmecken. Eine Ästhetik der anästhesierten Sinne. Mădǎlina Dianconu, ${ }^{* 1970}$

(vgl. Diaconu 2005, S. 211)

\section{4 \\ Diskussion}

Ziel der vorliegenden Arbeit war es, einen $\mathrm{I}_{\mathrm{Ca}^{2+}}$ im olfaktorischen Nerven nachzuweisen und zu diskutieren, ob eine dopaminerge Modulation dieses Stroms nachweisbar ist. Neben der grundsätzlichen Aufzeichnung von $\mathrm{I}_{\mathrm{Ca}^{2+}}$ im olfaktorischen Nerven erfolgte eine Untersuchung des Stroms mit $\mathrm{Na}^{+}$- und L-Typ-Ca ${ }^{2+}-$ Kanalblockern. Eine dopaminerge Modulation wurde versucht mit Dopamin sowie $\mathrm{D}_{2} \mathrm{R}$-Agonisten und -Antagonisten zu spezifizieren. Immunhistochemische Untersuchungen hinsichtlich der Lokalisation von $\mathrm{D}_{2}$-Rezeptoren und der Tyrosinhydroxylase sollten helfen, die zuvor erbrachten Ergebnisse einzuordnen und zu erweitern.

Die nun folgende Diskussion versucht, die dabei erzielten Resultate mit den bisherigen wissenschaftlichen Erkenntnissen in Verbindung zu bringen und kritisch zu hinterfragen. 


\subsection{Darstellung eines $\mathrm{I}_{\mathrm{Ca}^{2+}}$ im Nervus olfactorius}

Im Rahmen dieser Arbeit wurde eine Methode entwickelt, mit der Veränderungen des $\mathrm{I}_{\mathrm{Ca}^{2+}}$, in Folge einer Aminosäurereizung, am olfaktorischen Nerven von Xenopuslaevis-Larven untersucht worden sind. Grundlage der Methode war es, nach lokaler Applikation von Duftstoffen, den $\mathrm{I}_{\mathrm{Ca}^{2+}}$ mittels Kalzium-Imaging im Nervus olfactorius sichtbar zu machen. Dies gelang, wobei der Strom nach Aminosäurereizung gut reproduzierbar war. Auch bei mehrmaliger Reizung zeigte sich keine signifikante Abweichung bezüglich des ausgelösten $\mathrm{I}_{\mathrm{Ca}^{2+}}$. Damit ist es in dieser Arbeit gelungen, den Fluss von $\mathrm{Ca}^{2+}$-Ionen im olfaktorischen Nerven, als Folge einer Reizung mit Duftstoffen, aufzuzeigen. Dies war Grundlage für die weiteren Versuche, die den Einfluss unterschiedlicher Drogen auf den dargestellten $\mathrm{I}_{\mathrm{Ca}^{2+}}$ zum Inhalt hatten.

Die gewählte Färbemethode, welche von Kludt für die Untersuchung bulbärer Strukturen von Xenopus laevis etabliert wurde (Kludt 2010), erwies sich als gutes Verfahren, die olfaktorischen Neurone mit Kalziumfarbstoff zu beladen. Bei sachkundiger Durchführung dieser Elektroporation hielt sich die elektrische wie auch die mechanische Schädigung des Gewebes in Grenzen. Einige Tiere reagierten später dennoch nicht auf einen Aminosäurereiz. Eine Schädigung der Mukosa während des Färbeverfahrens könnte hierbei ursächlich gewesen sein. Nicht auszuschließen sind aber auch Fehler, die bei der Herstellung der Gewebeschnitte auftraten. Durch Verletzung des Nerven, infolge des Durchtrennens einiger Faserbündel, ist es möglich gewesen, dass Axone, die zu den aminosäuresensitiven Neuronen gehören, letal geschädigt worden sind. Anzumerken ist auch, dass während der Präparation auch eine gewollte Schädigung mukosaler Strukturen stattfand, um eine ortsnahe Odoranzienapplikation zu ermöglichen. Eine exakte Aussage über das gewöhnliche Schädigungsausmaß lässt sich aber nicht treffen.

Eine Einschränkung dieses Versuchsaufbaus ist die Bestimmung des Wirkorts eingewaschener Pharmaka. Effekte können auf der beobachteten nervalen Ebene wie auch auf vorgeschalteten Ebenen stattfinden. Dennoch wurde versucht, durch eine optimale Präparation den Wirkort auf den Nervus olfactorius zu begrenzen und die Strukturen der Mukosa ausgespart. Die Überlegung, unterschiedliche Strömungen zu nutzen, die durch unterschiedliche Trichtersysteme erzeugt wurden, um damit abgetrennte Milieus zu schaffen, erwies sich als nicht praktikabel. Abhilfe 
würde die Entwicklung einer elektrischen Reizung schaffen, die entweder ein Abtrennen der Mukosa ermöglicht oder aber von solcher Effizienz ist, dass modulatorische Effekte in der Schleimhaut durch einen optimalen elektrischen Stimulus minimal wären. Ein solches Verfahren der elektrischen Stimulation wurde schon im Versuchsteil Messung der Nervenleitgeschwindigkeit (s. Kap. 2.4.4, S.37) genutzt. Es müssten jedoch noch weitere grundlegende Anpassungen an das hier vorliegenden Messsystem erbracht werden; insbesondere müsste eine Bewertung hinsichtlich des zeitlichen Auflösungsvermögens des LSM bei kurzen elektrischen Stimuli erfolgen. Kritisch muss dabei beachtet werden, dass durch die elektrische Stimulation der natürliche Stimulus durch einen künstlichen ersetzt werden würde. Eine Einschränkung der wissenschaftlichen Aussagekraft wäre die Folge.

Ausblickend bietet der Versuchsaufbau auf Ebene des Nerven die Möglichkeit, Effekte, die beispielsweise auf Mukosaebene nachgewiesen wurden, auf eine mögliche Veränderung der axonalen Gesamtaktivität hin zu untersuchen. Damit können kompensatorische Effekte ausgeschlossen werden. Dies war bisher nur auf Ebene des Bulbus olfactorius möglich. Das Verfahren schlägt damit eine Brücke zwischen den bisher etablierten Imaging-Methoden der mukosalen ORN-Zellkörper und der glomerulären Strukturen des Bulbus oflactorius.

\subsubsection{Schnelle $\mathrm{Na}^{+}$-Kanäle sind Voraussetzung einer $\mathrm{I}_{\mathrm{Ca}^{2+}}$ im olfaktorischen Nerven}

Unter dem Toxin Tetrodotoxin, das spezifisch schnelle $\mathrm{Na}^{+}$-Kanäle blockt, wurde ein vollständiges Ausbleiben der $\mathrm{Ca}^{2+}$-Antwortkurve bei Duftstoffreizung beobachtet. Dies bedeutet, dass keine $\mathrm{Ca}^{2+}$-Ionen mehr in die Axone einströmen, wie es ohne TTX zu beobachten war. Es liegt nahe, dass das hinzugegebene TTX die Ausbreitung des Aktionspotentials behindert und es folglich zu keinem Einstrom von $\mathrm{Ca}^{2+}$-Ionen kommt. Der beobachtete $\mathrm{I}_{\mathrm{Ca}^{2+}}$ steht in Abhängigkeit von der Ausbildung eines Aktionspotentials, welches sich über die Öffnung schneller $\mathrm{Na}^{+}$-Kanäle generiert und ausbreitet.

Zuvor konnte für die Xenopus-laevis-Larve mittels Patch-Clamp-Technik gezeigt werden, dass unter TTX die Spike-Rate des ORN ausgelöscht wird (Manzini 2002). Neuere Experimente stellten hierzu aber klar, dass diese Annahme nicht unbedingt das vollständige Ausbleiben eines $\mathrm{I}_{\mathrm{Ca}^{2+}}$ beinhaltet (Bao 2010). Unter TTX-Blockade 
wurde hierbei ein $\mathrm{I}_{\mathrm{Ca}^{2+}}$ beschrieben. Dieser Strom, der über $\mathrm{Ca}^{2+}$-Kanäle, die in $\mathrm{Mi}-$ krodomänen mit Kaliumkanälen veranlagt sind, stattfindet, konnte dabei am Soma aufgezeigt werden. Eine Existenz dieser Mikrodomänen in Axonen bzw. innerhalb des Nerven kann mit den hier vorliegenden Experimenten ausgeschlossen werden, da es zu keinem $\mathrm{I}_{\mathrm{Ca}^{2+}}$ unter TTX-Blockade kam. Ein $\mathrm{I}_{\mathrm{Ca}^{2+}}$ ist damit an die freie Funktion von schnellen $\mathrm{Na}^{+}$-Kanälen gebunden.

\subsubsection{Ein $\mathrm{I}_{\mathrm{Ca}^{2+}}$ tritt auch unter Blockade von L-Typ- $\mathrm{Ca}^{2+}$-Kanälen auf}

Nifedipin gilt als spezifischer Blocker von L-Typ-Ca ${ }^{2+}$-Kanälen. Unter Applikation von Nifedipin konnte eine Reduktion des $\mathrm{I}_{\mathrm{Ca}^{2+}}$ belegt werden. In allen Fällen verblieb aber ein Rest- oder auch Leckstrom $\left(\mathrm{I}_{\mathrm{Ca}^{2+}}^{\mathrm{L}}\right)$. Dies lässt die Überlegung zu, dass neben L-Typ-Ca ${ }^{2+}$-Kanälen wohl auch andere Strukturen einen Fluss von $\mathrm{Ca}^{2+}$ Ionen während des Aktionspotentials zulassen. In Betracht kommen hierfür zum einen weitere (unentdeckte) Subformen von $\mathrm{Ca}^{2+}$-Kanälen, zum anderen aber ebenfalls Kanäle, die neben ihren eigentlichen Ionensorten einen unspezifischen Fluss, im

Sinne eines $\mathrm{I}_{\mathrm{Ca}^{2+}}^{\mathrm{L}}$, ermöglichen. Zur grundsätzlichen Diskussion um die Bedeutung des $\mathrm{I}_{\mathrm{Ca}^{2+}}$ sei an dieser Stelle auf das Kapitel 4.1.3 auf S. 63 verwiesen.

Als mögliche Fehlerquelle dieser Versuchsreihe muss die Blockersubstanz Nifedipin angesehen werden. Aufgrund ihrer Lichtempfindlichkeit wurden alle Versuche abgedunkelt durchgeführt. Trotzdem war eine Aussetzung gegenüber Licht nicht immer zu vermeiden. Ein $\mathrm{I}_{\mathrm{Ca}^{2+}}^{\mathrm{L}}$, wie er beobachtet wurde, könnte deswegen auch Ausdruck einer Substanzschädigung sein. Eine Überprüfung der Ergebnisse mit neueren, lichtunempfindlichen L-Typ- $\mathrm{Ca}^{2+}$-Blockern, wie Nimodipin, ist anzuraten. Diesem schreibt man auch eine größere Potenz bei der Blockierung dieser Kanäle zu, womit eine weitere Fehlerquelle, nämlich die unzureichende Bindung von Nifedipin an die entsprechenden Rezeptoren, ausgeschlossen werden könnte.

\subsubsection{Bedeutung eines $\mathrm{I}_{\mathrm{Ca}^{2+}}$ in olfaktorischen Axonen}

Der zuvor aufgezeigte $\mathrm{I}_{\mathrm{Ca}^{2+}}$ ist an die freie Funktion von $\mathrm{Na}^{+}$-Kanälen gebunden. Der Großteil des $\mathrm{I}_{\mathrm{Ca}^{2+}}$ scheint dabei über L-Typ-Ca ${ }^{2+}$-Kanäle zu fließen. Die Bedeutung des $\mathrm{I}_{\mathrm{Ca}^{2+}}$ unterliegt einer weitgehend nicht geklärten wissenschaftlichen 
Diskussion. Zwar ist bekannt, dass $\mathrm{Ca}^{2+}$-Ionen notwendig sind für die Vesikelausschüttung an Synapsen (Katz und Miledi 1965), doch die Bedeutung des $\mathrm{I}_{\mathrm{Ca}^{2+}}$ am Axon an sich ist weiterhin fraglich. Knöferle et al. konnten zeigen, dass ein $\mathrm{I}_{\mathrm{Ca}^{2+}}$ eine wichtige Rolle nach Schädigungen von Nerven spielt. Durch Einsatz von $\mathrm{Ca}^{2+}$ Kanalblockern konnten sie den Fluss von $\mathrm{Ca}^{2+}$-Ionen und damit den Verlauf posttraumatischer Umbauprozesse im Nerven beeinflussen (Knöferle et al. 2010). Der $\mathrm{I}_{\mathrm{Ca}^{2+}}$ scheint damit im Zusammenhang mit neuroprotektiven Prozessen zu stehen (s. Kap.4.2, S.65). Doch wieso lässt sich ein Kalziumstrom bei einer physiologischen Reizung, wie sie im Rahmen dieser Arbeit mehrfach durchgeführt wurde, darstellen, wo doch keine Schädigung des Gewebes drohte? Es liegt nahe, dass der $\mathrm{I}_{\mathrm{Ca}^{2+}}$ neben der protektiven Aufgabe auch an signalverarbeitenden Prozessen beteiligt ist. Denkbar ist hier eine Fernregulation der Vesikelausschüttung an den Axonterminalen, der Ausbildung eines Aktionspotentials am Axonhügel oder aber eine Beeinflussung der Fortleitung des Aktionspotentials im Axon (s.u.). Bender KJ und Trussell konnten hierzu zeigen, dass ein $\mathrm{I}_{\mathrm{Ca}^{2+}}$ über spannungsabhängige $\mathrm{Ca}^{2+}$-Kanäle am initialen Axonsegment (IAS) Auswirkung auf die Ausbildung und das Timing von komplexen Spikes hat (Bender KJ und Trussell 2009). Der Fluss von $\mathrm{Ca}^{2+}$-Ionen am IAS konnte zuvor schon in anderen Experimenten für verschiedene Neuronklassen verdeutlicht werden (Schiller et al. 1995, Callewaert et al. 1996, Lüscher et al. 1996). Dabei stehen hier vor allem $\mathrm{Ca}^{2+}$-Kanäle vom R- und T-Typ in Verdacht, den dazu benötigten $\mathrm{I}_{\mathrm{Ca}^{2}+}$ zuzulassen und so eine Steuerung der $\mathrm{Na}^{+}$-Kanäle am IAS zu erlauben (Bender KJ und Trussell 2009). Der $\mathrm{I}_{\mathrm{Ca}^{2+}}^{\mathrm{L}}$ unter Nifedipin-Blockade, der in der vorliegenden Arbeit gezeigt werden konnte, könnte also - in Zusammenschau mit den Ergebnissen von Bender KJ und Trussell - über R- und T-Typ-Ca ${ }^{2+}$-Kanäle stattfinden. Ferner könnten die nervalen $\mathrm{I}_{\mathrm{Ca}^{2+}}$ eine Mitbeteiligung an der Aktionspotentialregulation am IAS innehaben. Eine Hypothese, die es, beispielsweise durch Nachweis solcher Kanäle, für ORN von Xenopus-laevis-Larven zu überprüfen gilt. 


\subsection{Dopaminerge Modulation eines $\mathrm{I}_{\mathrm{Ca}^{2+}}$ im olfaktorischen System}

Dopamin reduzierte den $\mathrm{I}_{\mathrm{Ca}^{2+}}$ in Axonen der ORN bei Duftstoffreizung. Mittels $\mathrm{D}_{2} \mathrm{R}$-Antagonisten und $\mathrm{D}_{2} \mathrm{R}$-Agonisten konnte weiterhin belegt werden, dass ein maßgeblicher Effekt Dopamins hierbei über den $\mathrm{D}_{2}$-Rezeptor vermittelt wird.

Schriever konnte bereits mittels Kalzium-Imaging belegen, dass unter Dopamineinfluss das $\mathrm{Ca}^{2+}{ }_{-}$Signal im Soma des ORN bei Duftstoffreizung abnimmt. Auch er identifizierte dabei $\mathrm{D}_{2}$-Rezeptoren als Signalüberträger nach intrazellulär (Schriever 2012) . Man könnte daraus folgern, die hier gezeigten Ergebnisse seien Resultat einer Dopaminwirkung im olfaktorischen Epithel, wo sie das axonale Output herabsetzen. Einzuwenden ist dabei, dass Schriever eine andere Präparation gewählt hat, die eine direkte Wirkung Dopamins am ORN-Zellkörper erlaubt. Dabei wurden Schnitte der Mukosa erstellt. In dieser Arbeit hingegen wurde eine Schädigung der ORN der Mukosa vermieden und eine Freilegung des olfaktorischen Nervs versucht zu erreichen. Somit stellt die hier vorgestellte Versuchsanordnung einen erheblichen Unterschied zu den vorliegenden Ergebnissen dar. Dennoch scheinen sich die gezeigten Wirkungen Dopamins am olfaktorischen Nerven mit denen in der olfaktorischer Mukosa (Schriever 2012) und im olfaktorischen Bulb (Hsia et al. 1999, Ennis et al. 2001) zu decken. Dopamin scheint dabei die zelluläre Antwort auf einen Reiz herabzusetzen oder - im Falle des Bulbus olfactorius - die Weiterleitung des Aktionspotentials auf nachgeschaltete Zellgruppen zu unterdrücken (Davison et al. 2004).

Bezogen auf die vorliegenden Ergebnisse wäre es denkbar, dass der inhibitorische Effekt, der im Axon beobachtet wurde, Ergebnis einer Modulation über Dopaminrezeptoren direkt am Axon ist. Die immunhistochemischen Färbungen unterstrichen dies, indem sie die Existenz dieser Rezeptoren aufzeigten (s. Kap. 3.5, S. 58). Ebenfalls ließ sich die Tyrosinhydroxylase als spezifisches Markerenzym des Dopaminstoffwechsels in olfaktorischen Nerven identifizieren. Auch das verstärkt die Idee eines modulatorischen Effekts am Axon, da hier Dopamin direkt am potenziellen Wirkort produziert werden würde. Ferner ist das Ergebnis der Antikörperuntersuchungen interessant, da aufgezeigt werden konnte, dass die Stützzellen des Nerven (olfactory ensheathing glia) für die Produktion von Dopamin verantwortlich sind, 
da gerade jene über Tyrosinhydroxylase verfügen (s. Kap. 4.5, S. 68). Die physiologische Rolle des freiwerdenden Dopamins ist in der wissenschaftlichen Diskussion umstritten. So ist klar, dass eine Erhöhung der Dopaminkonzentration in verschiedenen Hirnarealen zum einen protektiv als auch negativ für die Entstehung von Erkrankungen sein kann (Starr 1996, Olanow et al. 1998). Zu hohe Dopaminkonzentrationen gelten sogar als toxisch (Bozzi und Borrelli 2002, Bozzi und Borrelli 2006).

Von Interesse sind in diesem Zusammenhang die Vorgänge, die sich auftun, wenn es zu einer Schädigung des Nervens kommt: Koster et al. zeigten diesbezüglich, dass sich die Dichte von $\mathrm{D}_{2}$-Rezeptoren erhöht (Koster et al. 1999). Weiterhin gibt es Untersuchungen, die mittels in-vivo-Imaging verdeutlichten, dass es bei einer Schädigung des Nervus opticus zu einem Anstieg der $\left[\mathrm{Ca}^{2+}\right]_{\mathrm{i}}$ kommt (Knöferle et al. 2010). Selbige Autoren belegen ferner, dass eine Unterdrückung des $\mathrm{I}_{\mathrm{Ca}^{2+}}$ zur Milderung der axonale Degeneration führt. Der Schluss liegt nahe, dass das dopaminerge System über die Beeinflussung des $\mathrm{I}_{\mathrm{Ca}^{2+}}$ Einfluss auf degenerative Prozesse hat, wie sie sich nach traumatischen Ereignisse abspielen. Es könnte somit degenerative Prozesse nach nervalen Schädigungen abbremsen. Über eine gesteigerte Rezeptorexpression und Ausschüttung des Transmittermoleküls Dopamin aus Gliazellen könnte es den schädlichen $\mathrm{I}_{\mathrm{Ca}^{2+}}$ unterdrücken und neuroprotektiv wirken.

Ausblickend kann letztlich nur die weitere Erforschung der intrazellulären Signalskaskaden aufzeigen, inwiefern diese Ergebnisse in gemeinsamen molekularen Pathways enden bzw. zusammenfinden. Aufschlussreiche Ergebnisse könnte zudem eine genauere Untersuchung der Konditionen einer Dopaminfreisetzung erbringen. Insbesondere der exakte Stimulus, der zur Freisetzung von endogenem Dopamin auf axonaler Ebene führt, könnte dabei richtungsweisend sein. Die weitere Interpretation der physiologischen Rolle Dopamins könnte dabei Auswirkungen auf das Verständnis und die Behandlung von Erkrankungen des ZNS haben. Auch ein weitreichender Einfluss auf das klinische Management nervaler Schädigungen ist denkbar. 


\subsection{Dopamin erhöht die Nervenleitgeschwindigkeit}

In dieser Arbeit konnte die Zunahme der Nervenleitgeschwindigkeit unter Dopaminapplikation bei vier Tieren beobachtet werden. Unklar bleibt, welche Aussagekraft die aufgezeigte Tendenz innehat.

Grundsätzlich ist eine kurzzeitige Beeinflussbarkeit der Nervenleitgeschwindigkeit für neuronale Systeme, insbesondere eine Erhöhung, in anderen wissenschaftlichen Arbeiten nur selten beschrieben worden. Ausnahme sind hierbei kurzfristige Beeinflussungen des autonomen Reizleitungssystems des Herzens (Napolitano et al. 1996), das aber histologisch zur Herzmuskulatur gezählt wird und nicht zu den Neuronen. Langfristige Veränderungen der Axonstruktur, wie sie bei Krankheiten und medikamentöser Dauertherapie nachgewiesen wurden, zeigen häufig, dass die Nervenleitgeschwindigkeit abnimmt. Lang et al. konnte zwar auch eine kurzfristigen Einfluss von Serotonin auf unmyelinisierte, periphere Nerven der Ratte nachweisen (Lang et al. 2006), aber auch hier stand wieder eine Verlangsamung der Nervenleitgeschwindigkeit im Vordergrund.

Einschränkend ergaben sich neben Problemen bei der Durchführung der Messungen, die Folge einer doppelten Elektroporation und einer schwierigen Präparation waren, technische Schwierigkeiten. Zum einen erfolgte teilweise eine unphysiologische Reizung durch versuchsbedingte Kurzschlüsse, zum anderen ergab sich häufig ein zu starkes Hintergrundrauschen und überlagernde Schwingungen, die die Auswertung der Messungen erschwerten. Zur genaueren Problemdarstellung der Messmethode und deren mögliche Lösungen sei hier auf Diedrichs verwiesen (Diedrichs 2011).

Insgesamt muss also vorsichtig mit der aufgezeigten Tendenz umgegangen werden, da weder genauere Kenntnis über deren Signifikanz noch über die möglichen molekularen Wirkungswege vorliegt, die einer solchen Erhöhung der Nervenleitgeschwindigkeit zu Grunde liegen könnten. Hier gilt es, statistisch signifikante Messungen zu etablieren, die eine abschließende Beurteilung erlauben. 


\section{4 $\mathrm{D}_{2}$-Rezeptoren liegen im olfaktorischen Nerven vor}

Die durchgeführten immunhistochemischen Experimente legen die Existenz von $\mathrm{D}_{2}$-Rezeptoren auf den Axonen der ORN nahe. Zuvor wurden Nachweise von $\mathrm{D}_{2^{-}}$ Rezeptor-mRNA im olfaktorischen Epithel von Breunig für Xenopus-laevis-Larve erbracht (unveröffentlicht, Institut für Neurophysiologie und zelluläre Biophysik, Universität Göttingen). Verschiedene weitere Studien zeigten die Existenz von $\mathrm{D}_{2^{-}}$ Rezeptoren im olfaktorischen System der Ratte per Radioligandenbindung und InSitu-Hybridisierung auf (Coronas et al. 1997, Koster et al. 1999). $\mathrm{D}_{2}$-Rezeptoren wurden dabei den terminalen Axonendigungen im olfaktorischen Bulb zugeschrieben (Nickell et al. 1991, Koster et al. 1999). Auch in dieser Arbeit konnten $\mathrm{D}_{2}$ Rezeptoren am terminalen Ende der Axone dargestellt werden. Dies steht im Einklang mit oben genannten Studien. Weiterhin wurde aber deutlich, dass der $\mathrm{D}_{2^{-}}$ Rezeptor auch entlang des Nerven lokalisiert zu sein scheint. In Zusammenschau mit den Ergebnissen der dopaminerge Modulation eines $\mathrm{I}_{\mathrm{Ca}^{2+}}$ (s. Kap. 4.2, S. 65) wirkt dies sinnvoll, da Rezeptorlokalisation und Effektorort überlappen.

Als problembehaftet sind die Ergebnisse des Nachweises von $\mathrm{D}_{2}$-Rezeptoren insoweit anzusehen, da die verwendeten Antikörper für den Einsatz bei Xenopus-laevisLarven nicht grundsätzlich vorgesehen sind. Bei gesicherter Antikörperverwendung könnten elektronenmikroskopische Analysen größere Sicherheit über die Lokalisation des Rezeptors liefern.

\subsection{Tyrosinhydroxylase liegt in den Gliazellen des olfaktorischen Nerven vor}

Tyrosinhydroxylase ist ein häufig gebrauchtes Markerenzym des Dopaminstoffwechsels, welches in verschiedensten Fragestellungen bei Xenopus-laevis-Larven (Schütte und Witkovsky 1991, Gonzalez et al. 1993, Ubink et al. 1998) wie auch anderen Arten zum Einsatz kam (Gonzalez und Smeets 1991, Spasojevic et al. 2011, Moss et al. 2011). Im olfaktorischen Nerven der Xenopus-laevis-Larve konnte diese Arbeit die Tyrosinhydroxylase klar den Gliazellen zuordnen. Es gab keine Überlagerungen der Tyrosinhydroxylase-Färbungen, zu der für Neurone spezifischen Tubulin-Färbung 
noch zum Biocytin-Backtrace, welcher ebenfalls neuronale Strukturen markiert.

In der Diskussion über Gliazellen im olfaktorischen Nerven bezeichnet man diese als sogenannte olfactory ensheating glia. Hier konnte belegt werden, dass diese olfactory ensheating glia das Enzym Tyrosinhydroxylase trägt. Die Existenz von Tyrosinhydroxylase in Neuronen konnnte ausgeschlossen werden. Damit wird klar, dass die olfactory ensheating glia eine wesentliche Rolle im Dopaminstoffwechsel des olfaktorischen Nerven spielt. Dabei steht die olfactory ensheating glia schon länger in Verdacht, die Steuerung der Entwicklung von ORN zu lenken und über Wachstumsfaktoren Einfluss zu nehmen (Chuah und West 2002). Es sei an dieser Stelle auf Kapitel 4.2 auf S. 65 verwiesen. Die dort diskutierten Erkenntnisse legen zudem eine neuroprotektive Rolle des peripheren Dopaminsystems nahe. Die beteiligte olfactory ensheating glia könnte in diesem Zusammenhang, für den Schutz der benachbarten Neurone, Tyrosinhydroxylase exprimieren, um - im Falle einer Schädigung - Dopamin als neuroprotektive Substanz zur Verfügung zu stellen. Auch wurde die Bedeutung Dopamins bei einer möglichen Beeinflussung der Aktionspotentialgenerierung diskutiert. Auch wenn die Erkenntnisse hierzu bei weitem nicht abgeschlossen sind, zeigen die hier erkennbaren Zusammenhänge doch, dass die Neuro-Glia-Interaktion weit über das schlichte Bereitstellen eines extrazellulären Mileus hinausgeht. Die olfactory ensheating glia scheint essentiell für neuronales Wachstum, Neuroprotektion bishin zur neuronalen Signalweiterleitung zu sein. Sie ist für den gesamten Lebenszyklus des peripheren olfaktorischen Systems von herausragender Bedeutung. 


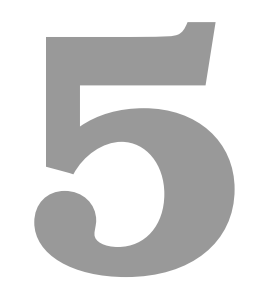

Zusammenfassung

Im Hinblick auf die Zielsetzung dieser Dissertation konnte eine Methode entwickelt werden, die es ermöglicht, einen $\mathrm{I}_{\mathrm{Ca}^{2+}}$ in olfaktorischen Nervenfasern von Xenopuslaevis-Larven zu messen. Damit ist es erstmals gelungen, einen axonalen $\mathrm{I}_{\mathrm{Ca}^{2}+}$ als Folge eines adäquaten Stimulus mittels Kalzium-Imaging zu visualisieren und zu untersuchen. Es konnte weiterhin aufgezeigt werden, dass der dargestellte $\mathrm{I}_{\mathrm{Ca}^{2+}}$ mit spezifischen Kanalblockern, namentlich TTX als $\mathrm{Na}^{+}$-Kanal-Blocker und Nifedipin als L-Typ-Ca ${ }^{2+}$-Kanal-Blocker, beeinflussbar ist. Folglich konnte belegt werden, dass der Fluss von $\mathrm{Ca}^{2+}$-Ionen über die Membran von olfaktorischen Axonen an eine schnelle $\mathrm{Na}^{+}$-Depolarisation gebunden ist. Ein $\mathrm{I}_{\mathrm{Ca}^{2+}}$ ohne Aktionspotential scheint am Axon - im Gegensatz zum Soma - also ausgeschlossen.

Des Weiteren wurde eine inhibitorische Wirkung von Dopamin auf den $\mathrm{I}_{\mathrm{Ca}^{2+}}$ bewiesen und mit spezifischen $\mathrm{D}_{2} \mathrm{R}$-Antagonisten und $\mathrm{D}_{2} \mathrm{R}$-Agonisten gezeigt, dass diese Modulation größtenteils über den $\mathrm{D}_{2}$-Rezeptor vermittelt wird. Dieser Rezeptor ließ sich axonal mittels Immunfluoreszenzfärbung aufzeigen. Durch diese Nachweismethode wurden zudem Gliazellen als Syntheseort des Dopamins mit Hilfe der Tyrosinhydroxylase, ein Markerenzym des Dopaminstoffwechsels, identifiziert. Wei- 
terhin konnte in dieser Arbeit die Erhöhung der Nervenleitgeschwindigkeit unter Dopaminapplikation an allen der vier getesteten Tiere beobachtet werden.

In Zusammenschau mit der aktuellen wissenschaftlichen Diskussion scheint es möglich, dass das periphere olfaktorische dopaminerge System eine wesentliche Rolle im Rahmen der Neuroprotektion innehat. Ein enges Zusammenspiel der olfactory ensheating glia und der Neurone kann diesbezüglich postuliert werden. Eine weiterführende Untersuchung der intrazellulären Signalkaskaden und der Ausschüttungsreize des endogenen Dopamins könnte dabei helfen, die physiologischen Zusammenhänge besser zu verstehen. Dies könnte zur Entschlüsselung der neuroprotektiven Rolle Dopamins und damit wesentlich zum Verständnis der Pathogenese sowie ferner zur Behandlung von Nervenerkrankungen und -traumata beitragen. 


\section{Literaturverzeichnis}

Armstrong DM, Ross CA, Pickel VM, Joh TH und Reis DJ (1982): Distribution of dopamine-, noradrenaline-, and adrenaline-containing cell bodies in the rat medulla oblongata: Demonstrated by the immunocytochemical localization of catecholamine biosynthetic enzymes. J Comp Neurol 212, 2, 173-187

Baker H, Kawano T, Margolis F und Joh T (1983): Transneuronal regulation of tyrosine hydroxylase expression in olfactory bulb of mouse and rat. J Neurosci $\underline{3,1}, 69-78$

Bao G: Detection and functional analysis of Ca2+ microdomains and BK channels in olfactory receptor neurons of larval Xenopus laevis. PhD Thesis Universität Göttingen 2010

Belluscio L, Gold G, Nemes A und Axel R (1998): Mice deficient in G(olf) are anosmic. Neuron 20, 1, 69-81

Bender A, Krishnan K, Morris C, Taylor G, Reeve A, Perry R, Jaros E, Hersheson J, Betts J, Klopstock T, Taylor R und Turnbull D (2006): High levels of mitochondrial DNA deletions in substantia nigra neurons in aging and Parkinson disease. Nat Genet $\underline{38}, 515-7$

Bender KJ und Trussell L (2009): Axon initial segment Ca2+ channels influence action potential generation and timing. Neuron $\underline{61,2}$, 259-271

Berkowicz D und Trombley P (2000): Dopaminergic modulation at the olfactory nerve synapse. Brain Res $855,1,90-9$

Bonnot A, Mentis GZ, Skoch J und O'Donovan MJ (2005): Electroporation Loading of Calcium-Sensitive Dyes Into the CNS. J Neurophysiol 93, 3, 1793-1808 
Boutin C, Diestel S, Desoeuvre A, Tiveron M und Cremer H (2008): Efficient in vivo electroporation of the postnatal rodent forebrain. PLoS One $\underline{3}$, e1883

Bozzi Y und Borrelli E (2002): Dopamine D2 receptor signaling controls neuronal cell death induced by muscarinic and glutamatergic drugs. Mol Cell Neurosci $\underline{19}, 263-271$

Bozzi Y und Borrelli E (2006): Dopamine in neurotoxicity and neuroprotection: what do D2 receptors have to do with it? Trends Neurosci 29, 3, 167-174

Braak H und Braak E (2000): Pathoanatomy of Parkinson's disease. J Neurol 247, II, 3-10

Broillet M und Firestein S (1996): Gaseous second messengers in vertebrate olfaction. J Neurobiol 30, 1, 49-57

Buck L (2000): The molecular architecture of odor and pheromone sensing in mammals. Cell 100, 6, 611-8

Burd G (1991): Development of the olfactory nerve in the African clawed frog, Xenopus laevis: I. Normal development. J Comp Neurol 304, 1, 123-34

Burgess C, Tse G, Gillis L und Peever J (2010): Dopaminergic regulation of sleep and cataplexy in a murine model of narcolepsy. Sleep 33, 10, 1295-304

Callewaert G, Eilers J und Konnerth A (1996): Axonal calcium entry during fast 'sodium' action potentials in rat cerebellar Purkinje neurones. J Physiol 495, 3, 641-647

Cave J und Baker H (2009): Dopamine systems in the forebrain. Adv Exp Med Biol $\underline{651}, 15-35$

Chuah M und West A (2002): Cellular and molecular biology of ensheathing cells. Microsc Res Tech $\underline{58}, 216-27$

Coopersmith R, Weihmuller F, Kirstein C, Marshall J und Leon M (1991): Extracellular dopamine increases in the neonatal olfactory bulb during odor preference training. Brain Res $\underline{564}, 149-153$ 
Coronas V, Srivastava L, Liang J, Jourdan F und Moyse E (1997): Identification and localization of dopamine receptor subtypes in rat olfactory mucosa and bulb: a combined in situ hybridization and ligand binding radioautographic approach. J Chem Neuroanat 12, 4, 243-257

Davison I, Boyd J und Delaney K (2004): Dopamine inhibits mitral/tufted - ¿ granule cell synapses in the frog olfactory bulb. J Neurosci 24, 37, 8057-8067

Débat H, Eloit C, Blon F, Sarazin B, Henry C, Huet J, Trotier D und Pernollet J (2007): Identification of human olfactory cleft mucus proteins using proteomic analysis. J Proteome Res $\underline{5}, 1985-96$

Deitmer J und Schild D: $\mathrm{Ca}(2+)$ und pH. Ionenmessungen in Zellen und Geweben, 1. Auflage, Spektrum Akademischer Verlag, Heidelberg 2000

Dhallan RS, Yau KW, Schrader KA und Reed RR (1990): Primary structure and functional expression of a cyclic nucleotide-activated channel from olfactory neurons. Nature $\underline{347}, 184-187$

Diaconu M: Tasten, Riechen, Schmecken. Eine Asthetik der anästhesierten Sinne, 1. Auflage, Königshausen \& Neumann, Würzburg 2005

Diedrichs R: Experimentelle Analyse der Ca2+-Permeabilität von olfaktorischen Nervenfasern in larvalen Xenopus laevis. Biol. Dipl.-Arb. Universität Göttingen 2011

Doucette J (1984): The glial cells in the nerve fiber layer of the rat olfactory bulb. Anat Rec $\underline{210,2}, 385-91$

Eisthen HL (1997): Evolution of vertebrate olfactory systems. Brain Behav Evol $\underline{50}, 222-33$

Ennis M, Zhou F, Ciombor K, Aroniadou-Anderjaska V, Hayar A, Borrelli E, Zimmer L, Margolis F und Shipley M (2001): Dopamine D2 receptor-mediated presynaptic inhibition of olfactory nerve terminals. J Neurophysiol 86, 6, 29862997 
Falk J, Drinjakovic J, Leung KM, Dwivedy A, Regan AG, Piper M und Holt C (2007): Electroporation of cDNA/Morpholinos to targeted areas of embryonic CNS in Xenopus BMC Dev Biol 7, 107

Farrer M, Gwinn-Hardy K, Muenter M, DeVrieze F, Crook R, Perez-Tur J, Lincoln S, Maraganore D, C A, Newman S, MacElwee K, McCarthy P, Miller C, Waters C und Hardy J (1999): A chromosome 4p haplotype segregating with Parkinson's disease and postural tremor. Hum Mol Genet $\underline{8}, 81-5$

Fearnley J und Lees A (1991): Ageing and Parkinson's disease: substantia nigra regional selectivity. Brain 114, 5, 2283-301

Féron F, Vincent A und Mackay-Sim A (1999): Dopamine promotes differentiation of olfactory neuron in vitro. Brain Res 845,2 , 252-9

Friggi-Grelin F, Coulom H, Meller M, Gomez D, Hirsh J und Birman S (2003): Targeted gene expression in Drosophila dopaminergic cells using regulatory sequences from tyrosine hydroxylase. J Neurobiol 54, 4, 618-627

Fuchs T, Glusman G, Horn-Saban S, Lancet D und Pilpel Y (2001): The human olfactory subgenome: from sequence to structure and evolution. Hum Genet $\underline{108}, 1-13$

Gasser T (2001): Genetics of Parkinson's disease. J Neurol 248, 833-40

Gaudin A und Gascuel J (2005): 3D atlas describing the ontogenic evolution of the primary olfactory projections in the olfactory bulb of Xenopus laevis. J Comp Neurol $\underline{489}$, 403-24

Gee K, Brown K, WNU C, Bishop-Stewart J, Gray D und Johnson I (2000): Chemical and physiological characterization of fluo-4 Ca2+-indicator dyes. Cell Calcium 27, 2, $97-106$

Geschwind J: Repräsentation von Düften, 1. Auflage, Wißner-Verlag, Augsburg 1998

Getchell M und Getchell T (1991): Immunohistochemical localization of components of the immune barrier in the olfactory mucosae of salamanders and rats. Anat Rec 23, 3, 358-74 
Gingrich J und Caron MG (1993): Recent advances in the molecular biology of dopamine receptors. Annu Rev Neurosci 16, 299-321

Gonzalez A und Smeets W (1991): Comparative analysis of dopamine and tyrosine hydroxylase immunoreactivities in the brain of two amphibians, the anuran Rana ridibunda and the urodele Pleurodeles waltlii. J Comp Neurol 303, 3, $457-477$

Gonzalez A, Tuinhof R und Smeets W (1993): Distribution of tyrosine hydroxylase and dopamine immunoreactivities in the brain of the South African clawed frog Xenopus laevis. Anat Embryol 187, 2, 193-201

Griff ER, Greer CA, Margolis F, Ennis M und Shipley MT (2000): Ultrastructural characteristics and conduction velocity of olfactory receptor neuron axons in the olfactory marker protein-null mouse. Brain Res $\underline{866}, 227-36$

Gross G und Kreutzberg G (1978): Rapid axoplasmic transport in the olfactory nerve of the pike: I. Basic transport parameters for proteins and amino acids Brain Res 139, 1, 65-76

Haas K, Jensen K, Sin WC und Foa L (2002): Targeted electroporation in Xenopus tadpoles in vivo - from single cells to the entire brain. Differentiation $\underline{70}, 148-54$

Hajjar E, Perahia D, Débat H, Nespoulous C und Robert C (2006): Odorant binding and conformational dynamics in the odorant-binding protein. J Biol Chem $\underline{281}$, 29929-29937

Hansen A, Reiss J, Gentry C und Burd G (1998): Ultrastructure of the olfactory organ in the clawed frog, Xenopus laevis, during larval development and metamorphosis. J Comp Neurol 398, 2, 273-88

Hassenklöver T, Kurtanska S, Bartoszek I, Junek S, Schild D und Manzini I (2008): Nucleotide-induced Ca2+ signaling in sustentacular supporting cells of the olfactory epithelium. Glia 56, 15, 1614-24

Hassenklöver T, Schwartz P, Schild D und Manzini I (2009): Purinergic signaling regulates cell proliferation of olfactory epithelium progenitors. Stem Cells $\underline{8}$, $2022-31$ 
Hatt H (2004): Molecular and cellular basis of human olfaction. Chem Biodivers $\underline{12}, 1857-69$

Hatt H: Geschmack und Geruch, in: Physiologie des Menschen mit Pathophysiologie, hrg. v. Schmidt R, Lang F und Heckmann M, 31. Auflage, Springer Medizin Verlag, Heidelberg 2010, 387-400

Hegg C und Lucero M (2004): Dopamine reduces odor- and elevated-K(+)-induced calcium responses in mouse olfactory receptor neurons in situ. J Neurophysiol $91,4,1492-9$

Hobson B (1952): Routine pregnancy diagnosis and quantitative estimation of chorionic gonadotropin using female Xenopus laevis. Obstet Gynaecol 599, 352-362

Hobson B (1958): Some observations on the use of female Xenopus laevis for the diagnosis of pregnancy. Am J Obstet Gynecol $\underline{75}$, 825-828

Hsia A, Vincent J und Lledo P (1999): Dopamine depresses synaptic inputs into the olfactory bulb. J Neurophysiol $\underline{82,2}$, 1082-1085

Invitrogen (2012): Strukturformel fluo-4 AM, veröffentlicht auf http://probes.invitrogen.com/media/structure/33304.jpg (Webseite), Invitrogen, Leiden (Niederlande) 2012 (29.03.2012, 19:30 Uhr)

Jacobson L (1813): Anatomisk beskrivelse over et nyt organ I huusdyrenes nase. Vet-Selskapets Skrifter 2, 209-246

Junek S: Investigation of spatio-temporal coding in the olfactory bulb of larval Xenopus laevis using fast confocal imaging. Phd Thesis Universität Göttingen 2008

Kanda S, Tamada Y, Yoshidome A, Hayashi I und Nishiyama T (2004): Overexpression of bHLH genes facilitate neural formation of mouse embryonic stem (ES) cells in vitro. Int J Dev Neurosci 22, 3, 149-156

Katz B und Miledi R (1965): The effect of calcium on acetylcholine release from motor nerve terminals. Proc R Soc Lond B Biol Sci 161, 496-503 
Kludt E: Bilateral processing of thermoreception in the olfactory system of larval Xenopus laevis. Diss. rer. nat. Universität Göttingen 2010

Knöferle J, JC K, Ostendorf T, Michel U, V P, Vutova P, Tönges L, Stadelmann C, Brück W, Bähr M und Lingor P (2010): Mechanisms of acute axonal degeneration in the optic nerve in vivo Proc Natl Acad Sci U S A 107, 13, 6064-6069

Koster N, Norman A, Richtand N, Nickell W, Puche A, Pixley S und Shipley M (1999): Olfactory receptor neurons express D2 dopamine receptors. J Comp Neurol 411, 4, 666-673

Kreitzer AC, Gee KR, Archer EA und Regehr WG (2000): Monitoring presynaptic calcium dynamics in projection fibers by in vivo loading of a novel calcium indicator. Neuron 27, 25-32

Labarca P und Bacigalupo J (1988): Ion channels from chemosensory olfactory neurons. J Bioenerg Biomembr 20, 5, 551-69

Lang P, Moalem-Taylor G, Tracey D, Bostock H und Grafe P (2006): Activitydependent modulation of axonal excitability in unmyelinated peripheral rat nerve fibers by the 5-HT(3) serotonin receptor. J Neurophysiol 96, 6, 2963-71

Lee T und Seeman P (1980): Elevation of brain neuroleptic/dopamine receptors in schizophrenia. Am J Psychiatry 137, 2, 191-7

Lipina T, Niwa M, Jaaro-Peled H, Fletcher P, Seeman P, Sawa A und Roder J (2010): Enhanced dopamine function in DISC1-L100P mutant mice: implications for schizophrenia. Genes Brain Behav 9, 7, 777-89

Lukrez: Von der Natur, übers. und hrsg. von Diels H, mit einer Einführung und Erläuterungen von Schmidt E G, vollst. Auflage, Artemis \& Winkler, München 1991

Lukrez: De rerum natura, hrsg. v. Cicero, erste von Hieronymus erwähnte Originalausgabe, 50 v.Chr.

Lüscher C, Lipp P, Lüscher H und Niggli E (1996): Control of action potential propagation by intracellular $\mathrm{Ca} 2+$ in cultured rat dorsal root ganglion cells. J Physiol 490, 2, 319-324 
Manzini I: Diversity of transduction mechanisms in receptor neurons of the main olfactory epithelium in Xenopus laevis tadpoles. Phd Thesis Universität Göttingen 2002

Manzini I und Schild D: Olfactory Coding in Larvae of the African Clawed Frog Xenopus laevis., in: The Neurobiology of Olfaction, hrg. v. Menini A, 1. Auflage, CRC Press, Boca Raton (USA) 2009, 113-130

Maraganore D, de Andrade M, Lesnick T, Strain K, Farrer M, Rocca W, Pant P, Frazer K, Cox D und Ballinger D (2005): High-resolution whole-genome association study of Parkinson disease. Am J Hum Genet $\underline{77}$, 685-93

Mast TG und Samuelsen CL (2009): Human Pheromone Detection by the Vomeronasal Organ: Unnecessary for Mate Selection? Chem Senses $\underline{34}, 529-531$

Mezler M, Konzelmann S, Freitag J, Rössler P und Breer (1999): Expression of olfactory receptors during development in Xenopus laevis. J Exp Biol 202, 4, $365-76$

Monaca C (2010): Pathophysiology of restless legs syndrome. Presse Med 39, 5, $587-91$

Morales B und Bacigalupo J (1996): Chemical reception in vertebrate olfaction: evidence for multiple transduction pathways. Biol Res 29, 3, 333-41

Moss J, Ungless M und Bolam J (2011): Dopaminergic axons in different divisions of the adult rat striatal complex do not express vesicular glutamate transporters. Eur J Neurosci 33, 7, 1205-1211

Müller F und O'Rahilly R (2004): Olfactory structures in staged human embryos. Cells Tissues Organs $178 \underline{178}, 93-116$

Nagayama S, Zeng S, Xiong W, Fletcher ML, Masurkar AV, Davis DJ, Pieribone VA und Chen WR (2007): In vivo simultaneous tracing and $\mathrm{Ca}(2+)$ imaging of local neuronal circuits. Neuron $\underline{53}, 789-803$

Napolitano C, Raatikainen M, Martens J und Dennis D (1996): Effects of intravenous anesthetics on atrial wavelength and atrioventricular nodal conduction in 
guinea pig heart. Potential antidysrhythmic properties and clinical implications. Anesthesiology 85, 2, 393-402

Nickell W, Norman A, Wyatt L und Shipley M (1991): Olfactory bulb DA receptors may be located on terminals of the olfactory nerve. Neuroreport $\underline{2,1}, 9-12$

Nietzsche F: Götzen-Dämmerung oder wie man mit dem Hammer philosophiert, 1. Auflage, Verlag von C. G. Naumann, Leipzig 1889

Nietzsche F: Götzen-Dämmerung, in: Der Fall Wagner, Götzen-Dämmerung, Der Antichrist/Ecce homo, Dionysos-Dithyramben/Nietzsche contra Wagner, Kritische Studienausgabe Bd. 6, hrg. v. Colli G und Montinari M, 2. Auflage, Verlag de Gruyter, Berlin/New York 1988, 55-162

Nieuwkoop PD und Faber J: Normal Table of Xenopus laevis (Daudin)., 1. Auflage, Garland Publishing Inc, New York. 1994

Olanow C, Jenner P und Brooks D (1998): Dopamine agonist and Neuroprotection in Parkinson's disease. Ann Neurol 44, 167-174

Ottoson D (1960): Comparison of slow potentials evoked in the frog's nasal mucosa and olfactory bulb by natural stimulation. Acta Physiol Scand 47, 149-159

Pace U, Hanski E, Salomon Y und Lancet D (1985): Odorant-sensitive adenylate cyclase may mediate olfactory reception. Nature $\underline{316}, 255-8$

Pickel VM, Beckley SC, Joh TH und Reis DJ (1981): Ultrastructural immunocytochemical localization of tyrosine hydroxylase in the neostriatum. Brain Res 225, 2, 373 - 385 ISSN 0006-8993

Platon: Timaeus und Kritias, übers. v. Wagner F W, 1. Auflage, Georg Philipp Aderholz 1841

Platon: Timaios, Originalfragmente, 360 v.Chr.

Plumb D: Veterinary Drug Handbook, 5. Auflage, PharmaVet Publishing, White Bear Lake (USA) 2005 853-855

Rawson N und Yee K (2006): Transduction and coding. Adv Otorhinolaryngol $\underline{63}$, $23-43$ 
Ronnett G und Moon C (2002): G proteins and olfactory signal transduction. Annu Rev Physiol $\underline{64}, 189-222$

Salazar I und Quinteiro P (2009): The risk of extrapolation in neuroanatomy: the case of the Mammalian vomeronasal system. Front Neuroanat $\underline{3}, 22$

Schild D (1985): A computer-controlled device for the application of odours to aquatic animals. J Electrophysiol Techn $\underline{12}, 71-79$

Schild D und Restrepo D (1998): Transduction mechanisms in vertebrate olfactory receptor cells. Physiol Rev 78, 2, 429-66

Schiller J, Helmchen F und Sakmann B (1995): Spatial profile of dendritic calcium transients evoked by action potentials in rat neocortical pyramidal neurones. $\mathrm{J}$ Physiol 487, 3, 583-600

Schopenhauer A: Die Welt als Wille und Vorstellung, Bd.1, 1. Auflage, F. A. Brockhaus, Leipzig 1819

Schopenhauer A: Die Welt als Wille und Vorstellung, Bd. 1, Hübscher A (Hrsg.), 3. Auflage, F.A. Brockhaus, Wiesbaden 1972

Schriever V: Physiologische und morphologische Charakterisierung des dopaminergen Systems in der olfaktorischen Peripherie von Xenopus laevis-Larven Med. Diss. Universität Göttingen 2012 (in Vorbereitung ${ }^{1}$ )

Schütte M und Witkovsky P (1991): Dopaminergic interplexiform cells and centrifugal fibres in the Xenopus retina. J Neurocytol 20, 3, 195-207

Sharo D, Glusman G, Pilpel Y, Khen M, Gruetzner F, Haaf T und Lancet D (1999): Primate evolution of an olfactory receptor cluster: diversification by gene conversion and recent emergence of pseudogenes. Genomics $\underline{61}, 24-36$

Snyder S (2006): Dopamine receptor excess and mouse madness. Neuron 49, 4, $484-5$

\footnotetext{
${ }^{1}$ mit freundlicher Genehmigung des Verfassers
} 
Spasojevic N, Gavrilovic L und Dronjak S (2011): Regulation of catecholaminesynthesising enzymes and beta-adrenoceptors gene expression in ventricles of stressed rats. Physiol Res 60, 1, 171-6

Starr M (1996): The role of dopamine in epilepsy. Synapse 22, 159-94

Süskind P: Das Parfum: Die Geschichte eines Mörders, 1. Auflage, Diogenes Verlag, Zürich 1985

Szeemann H, Busek E, Stieger C, Qendro G, Ditchev I, Muka E, Pandilovski M, Rusu S und Essl K: Blood \& Honey: Future's in the Balkans. (Ausstellungskatalog), 2. Auflage, Ed. Sammlung Essl Privatstiftung, Klosterneuburg 2004

Teruel M und Meyer T (1997): Electroporation-induced formation of individual calcium entry sites in the cell body and processes of adherent cells. Biophys J $\underline{73,4}, 1785-1796$

Trenkwalder C, Walters A und Hening W (1996): Periodic limb movements and restless legs syndrome. Neurol Clin $\underline{14,3}$, 629-50

Ubink R, Tuinhof R und Roubos EW (1998): Identification of suprachiasmatic melanotrope-inhibiting neurons in Xenopus laevis: a confocal laser-scanning microscopy study. J Comp Neurol 397, 1, 60-68

Weiss G: Die Struktur des Geruchsorgans und des Telencephalons beim südafrikanischen Krallenfrosch Xenopus laevis (Daudin) und ihre Veränderungen während der Metamorphose. Diss. rer. nat. Universität Regensburg 1986

Witt M und Hummel T (2006): Vomeronasal Versus Olfactory Epithelium: Is There a Cellular Basis for Human Vomeronasal Perception? Int Rev Cytol 248, 209259

Witt M, Georgiewa B, Knecht M und Hummel T (2002): On the chemosensory nature of the vomeronasal epithelium in adult humans. Histochem Cell Biol 117, 493-509 
Wong S, Trinh K, Hacker B, Chan G, Lowe G, Gaggar A, Xia Z, Gold G und Storm D (2000): Disruption of the type III adenylyl cyclase gene leads to peripheral and behavioral anosmia in transgenic mice. Neuron 27, 3, 487-97

Zeiss-Broschüre: Das konfokale Laser Mikroskop, 1. Auflage, Carl Zeiss MicroImaging AG, Jena 2003 


\section{Danksagung}

Im Rahmen dieser Dissertation erhielt ich von vielen Menschen Hilfe, Unterstützung wie auch Zuspruch. Diesen Menschen möchte ich gern meinen Dank aussprechen.

Danksagen möchte ich zuerst Herrn Prof. Dr. Dr. Schild, der mir diese Arbeit ermöglicht und mit seinen kritischen Nachfragen zur Weiterentwicklung maßgeblich beigetragen hat.

Auch möchte ich Dr. Esther Breunig für die Hilfe bei der Einarbeitung in das wissenschaftliche Arbeiten und für die Unterstützung während der Versuchsphase danken. Mein Dank gilt auch Dr. Eugen Kludt, der mir geduldig bei vielen technischen Fragen weitergeholfen hat. Hervorragend wurde ich von Robin Diedrichs und Mihai Alvera in das LIM-Setup eingearbeitet. Dankend möchte ich ebenfalls Dr. Sebastian Gliem erwähnen, der mich mit seinen kritischen Anmerkungen zur schriftlichen Arbeit vorangetrieben hat.

Eine kollegiale und produktive Atmosphäre im Labor wurde geschaffen von Ivan Manzini, Dr. Thomas Hassenklöver, Gudrun Federkeil und Josko Guduz. Zu jeder Zeit war man hier offen für meine Fragen. 


\section{Lebenslauf}

Am 2. Februar 1986 wurde ich als Sohn der Sozialpädagogin Birgit Baßfeld, geb. Mehl, und des Ingenieurs Claus Baßfeld in Bad Kissingen geboren.

Nach Absolvierung der Grundschule in Niedenstein folgte der Besuch des gymnasialen Zweigs der Georg-August-Zinn Schule in Gudensberg, welche ich bis zur zehnten Klasse besuchte. Anschließend schloss ich an der Ursulinenschule in Fritzlar mit der Allgemeinen Hochschulreife meinen schulischen Werdegang erfolgreich ab.

Den sich anschließenden Zivildienst leistete ich beim Deutschen Roten Kreuz in Fritzlar ab. Im Rahmen des Dienstes wurde ich zum Rettungshelfer geschult. Diese Qualifizierung vervollständigte ich nach Dienstende zum Rettungssanitäter.

Mein Studium begann ich an der Göttinger Georg-August-Universität zunächst in der Fachrichtung Physik im Oktober 2006. Nach einem Semester wechselte ich zum Studiengang Humanmedizin. Hier absolvierte ich im Frühjahr 2009 das erste Staatsexamen und begann ein Jahr später mit meinen Forschungen in der Abteilung Neurophysiologie und Zelluläre Biophysik (Prof. Dr. Dr. D. Schild). Im Oktober 2013 hoffe ich, mein Studium mit dem zweiten Staatsexamen abzuschließen, um dann meine ärztliche Weiterbildung beginnen zu können. 